\title{
Identity, Interrupted
}

\author{
Thesis by: \\ Philam Nguyen \\ ₹ \\ Thesis Supervisor: \\ Professor Michael Jemtrud
}

A thesis submitted to the Faculty of Graduate Studies and Research in partial fulfilment of the requirements for the degree of

Professional Masters of Architecture

School of Architecture

Carleton University

Ottawa, Ontario

Sept 07, 2004

(C) copyright 2004

Philam Nguyen 


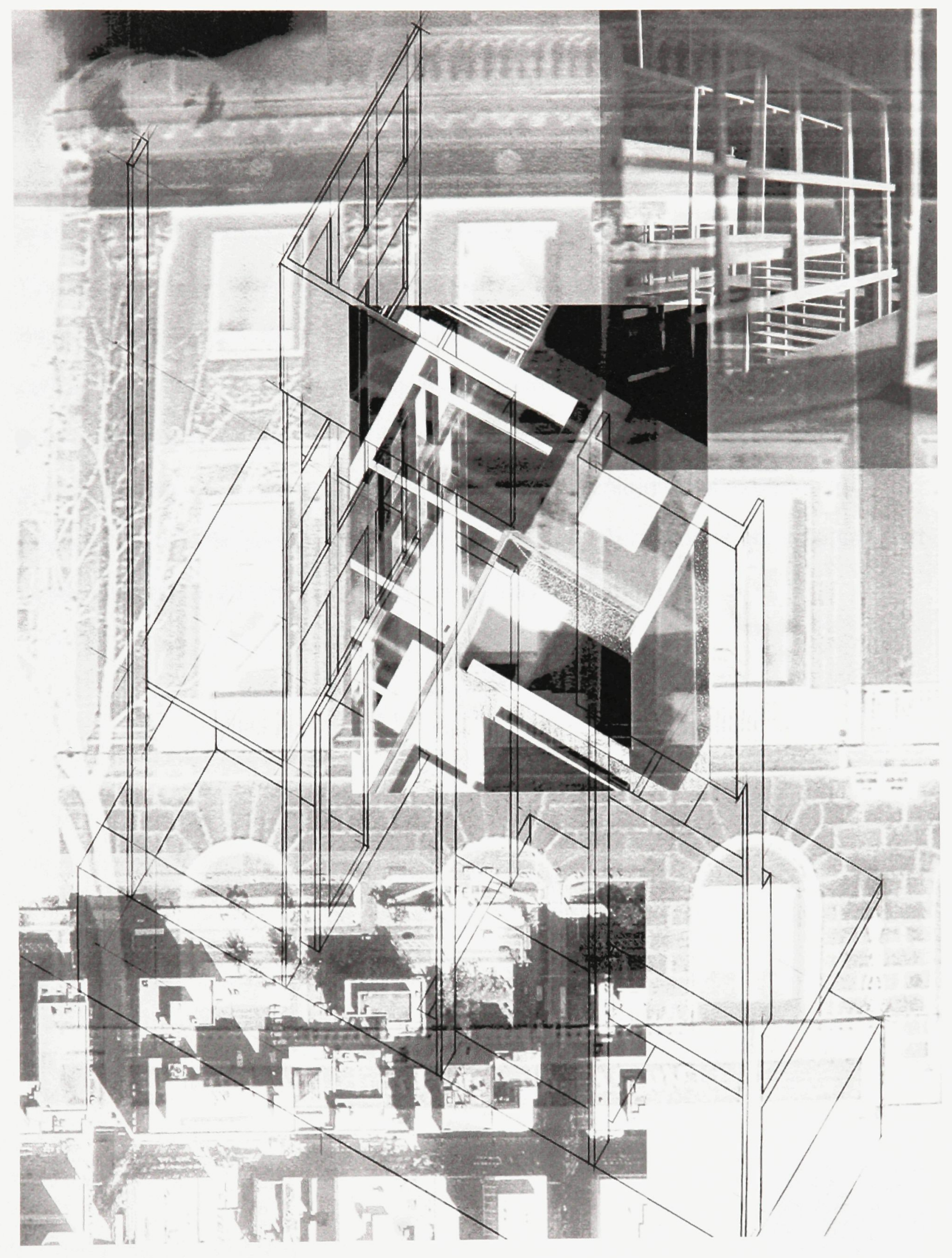




\section{Abstract}

This thesis situates itself between discursive realms and physical sites. It does not propose to be a connective element as much as it frames, and is framed by, discussions that necessarily overlap and, move in, over and around one another. The fluctuation of this discussion on identity touches on various notions that inform one another - notions that contribute to an overall way of thinking about identity that is not prescriptive yet still evocative of our contemporary cultural condition. Through the design proposal of the Portrait Gallery of Canada and the research on the nature of perception and its implications on one's understanding of identity, this thesis argues that architecture's experiential capacity to provide spaces of intersubjectivity and interaction is an essential part in the cultivation and the discussion of identity in Canada.

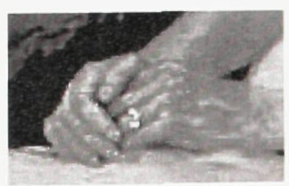


Table of Contents

Title

Page Number

$\begin{array}{ll}\text { Introduction } & 1\end{array}$

$\begin{array}{ll}\text { Recognition, Translated } & 5\end{array}$

$\begin{array}{ll}\text { Cultivating Paradoxes } & 13\end{array}$

$\begin{array}{ll}\text { Site, Specified } & 19\end{array}$

$\begin{array}{ll}\text { Programmatic Stages } & 27\end{array}$

$\begin{array}{ll}\text { Intertwining Worlds } & 42\end{array}$

Moment of Weakness $\quad 47$

In-Formed Vision $\quad 54$

$\begin{array}{ll}\text { Identity, Interrupted } & 62\end{array}$

Appendix A: Process Work 66

$\begin{array}{ll}\text { Appendix B: Urban Studies } & 71\end{array}$

Appendix C: Chancery Building Plans 73

Appendix D: 1:30 Sectional Model 75

$\begin{array}{ll}\text { Works Cited } & 76\end{array}$

$\begin{array}{ll}\text { Selected Bibliography } & 78\end{array}$ 


\section{List of Illustrations}

Title/Description

Page Number

1 Silhouette of John Casper Lavater, 1792. From J.C.

Lavater, Essays on Physiognomy, London.

2 Sidney Carter, Pauline (Archer) Vanier, ca. 1920,

National Archives of Canada.

3 Dora de Pédery-Hunt, Celia Franca, 1974, National Archives of Canada.

4 Diego Velazquez, Las Meninas, 1665, Museo Nacional del Prado, Madrid.

5 Francis Bacon, Three Studies of Isabel Rawsthorne, 1967, Staatliche Museen Preussischer Kulturbesitz, Berlin.

6 Francis Bacon, Self-Portrait, 1971, Musée National d'Art Moderne, Centre Geeorge Pompidou, Paris.

7 Joan Miro, Self-Portrait, 1937-38, Museum of Modern Art, New York.

8 Detail of collage, image by author.

9 Detail of collage, image by author.

10 Detail of collage, image by author.

11 Detail of collage, image by author.

12 Detail of collage, image by author.

13 East elevation of Chancery Building (former United States Embassy), image by author.

14 West elevation of Chancery Building, photograph taken by author.

15 Site plan of surrounding area, image by author. 
16 The small plaza on Wellington Street, photograph taken by author.

17 Location of building on site, image by author.

18 View of Sparks Street Pedestrian Mall, photograph taken by author.

19 View of Sparks Street Pedestrian Mall, photograph taken by author.

20 Aerial view, image by author.

21 Street view, mage by author.

22 View from Sparks, image by author.

23 Paul Cézanne, Self-Portrait, 1878-80, Phillips Collection, Washington D.C.

24 Conceptual model exploring ambiguity between solid/ void, inside/outside, image by author.

25 Alternate view of conceptual model exploring ambiguity between solid/void, inside/outside, image by author.

26 Marcel Duchamp, Boîte-en-Valise, 1941, Deluxe edition of 20 Boxes enclosed in leather valises, numbered I/XX $-X X / X X$.

27 Marcel Duchamp, Sixteen Miles of String, 1942, Installation for First Papers of Surrealism, exhibition, New York City.

28 View of interior of the Sir John Soane Museum in London

29 Interior view gallery space, image by author.

30 Basement plan of gallery, image by author.

31 Basement plan, image by author.

32 Ground floor plan, image by author.

33 Second floor plan, image by author. 
34 Longitudal section through gallery and daycare, image by author.

35 Longitudal section through gallery and daycare overlaid with vignette views of interior of gallery, image by author.

36 Longitudal section through gallery and daycare overlaid with vignette views of interior of gallery, image by author.

37 Longitudal section through gallery and daycare overlaid with vignette views of interior of gallery, image by author.

38 Michelangelo Caravaggio, Narcissus, 1596-97, Pallazo Barbarini, Rome.

39 Detail of second floor plan, in between existing building and addition, image by author.

40 Interior view of gallery and daycare, image by author.

41 Jean-Auguste-Dominique Ingres, Napoleon I on His Imperial Throne, 1806, Musée de l'Armée, Paris.

42 Parliament Buildings, photograph taken by author.

43 Chancery Building, photograph taken by author.

44 Reception room of Chancery Building, photograph taken by author.

45 Doorway to Ambassador's office, photograph taken by author.

46 Sectional view of interior gallery space within the existing building, image by author.

47 El Lissitzky, Design for the first Exhibition Room, International Art Exhibition, 1926, Niedersächsische Landesgalerie, Hanover.

49 El Lissitzky, Self-Portrait, 1924, location unknown. 
50 View of conceptual model, image by author.

51 Hans Holbein, The Ambassadors, 1533, National Gallery, 54 London.

52 Detail of anamorphic skull.

53 Marcel Duchamp, Tu'm, 1918, Yale University Art Gallery, 55 New Haven.

54 Sequence of interior gallery spaces, image by author. 
List of Appendices

Title

Page

Number

A Process Work

A.1 Book Panels 66

A.2 Conceptual Model 67

A.3 Axonometric Drawings and Collages 68

B Site Massing

Models

C Chancery

Building Floor

Plans

D 1:30 Sectional Model 


\section{Introduction}

This thesis began as an exploration into the relationships between architecture and the representation and declarations of national identity, specifically, Canadian identity. The initial inspiration to pursue this thesis is rooted in questions concerning a notion of identity that cannot be evoked by the terms commonly used in one discussion or another, but rather, in an understanding of identity that is in constant fluctuation and development. The term monumentality, as I use it in this thesis, is based on a notion of identity that is expresses through symbolic representation. While monumental artifacts play a part in constructing a sense of community and collective memory, Henri Lefebvre argues that monumental approaches often work under the guise of such intentions.

Monumentality always embodies and imposes a clearly intelligible message. Monumental buildings mask the will to power and the arbitrariness of power beneath signs and surfaces which claim to express collective will and collective thought. ${ }^{1}$

In offering each citizen of society one unified image of their membership, monumental representations often result in homogenous expressions of a single identity.

In contrast to the notion of identity represented through a monumental will, exists the discussion concerning the Other. On this side of the discussion, notions of marginalization inform an understanding of identity that is diffracted and acknowledges the multitude of voices now present in our contemporary cultural condition. While this marginal understanding of identity makes room for 
counter-narratives to be acknowledged, the problem is that they are contingent on established notions of identity and remain within binary relationships.

Architecture's role in constructing and representing identities is not situated on either side, exclusively, but in a place that acknowledges its monumental will while still being evocative a condition of culture that is open to various points of view and origins. In order to transcend conventional terms of knowledge that are associated with discussions of identity, this thesis instead adopts a rhetorical framework primarily informed by an ontological notion expressed through an interlacing of entities of separate origins. The concept of Being Singular Plural, by Jean-Luc Nancy, defines a notion of existence as a coexistence of distinct strands.

From one singular to another, there is contiguity but not continuity. There is proximity, but only to the extent that extreme closeness emphasizes the distancing it opens up. All of being is in touch with all being, but the law of touching is separation; moreover, it is the heterogeneity of surfaces that touch each other. ${ }^{2}$

By exploring various discussions of identity on multiple levels- levels that are separate but tangential and inherently connected, an alternate understanding of identity can be formed that does not necessarily rely on unified or prescriptive notions. While, the philosophical notion of being singular plural is reflective of a contemporary condition without unified system or structure, the imagery it conjures of a fluid and shifting space of co-inhabitation also informs architectural interventions and propositions. In this thesis, the way the rhetorical notion of interlacing is used is twofold. With the hope to gain an understanding of identity of various perspectives, interlacing is used to structure the investigation of 
certain theoretical discussions related to identity. This approach may not grant an overall understanding of the subject, but will instead inform an understanding that is fragmented but nonetheless dense. Discussions of identity in portraiture painting juxtaposed against a discussion of psychoanalytic notions of identity formation in infants are seen as separate strands of a knot that necessarily touch at certain points.

In the design proposition for the Portrait Gallery of Canada, the notion of interlacing is used as a way of envisioning a space that is evocative of the shared condition of Being explicated by Nancy. With specific emphasis on the urban intervention and scale of the project, this notion informs architectural strategies that address the communicative and interactive condition of co-inhabitation. Within these discussions, the term interlacing or intertwining, although adopted from philosophical ideas, is used as a way of describing an architectural space that facilitates and nurtures the reciprocity and shared aspects of life.

Weak philosophy and specifically, Weak Architecture, by Ignasi de SolaMorales is used as a foundation-less approach at assessing a current cultural condition that is without universality. As a way of looking at given situations, an approach of weakness, re-interprets conventional terms and conditions, such as monumentality, so that they can be given an altered significance - significance based on the fragmented specificity of time and space. In this thesis, such an attitude is used to assess both theoretical notions and design requirements.

Although the investigation into architectural representations of Canadian identity is not as explicit as intended initially, the questions and urges to pursue 
such a discussion are still inherent in the discussions within this thesis. As a way of getting out of a conventional way of thinking about identity, to interrupt it momentarily, so to speak, the theoretical ideas touched upon in this thesis along with the design proposition is offered here to inform a way of thinking about architecture and identity in a way that is reflective of the on-going processes of development inherent in these discussions.

\section{Notes}

${ }^{1}$ Henri Lefebvre, The Production of Space, Donald Nicholson-Smith, trans., (Oxford: Blackwell, 1992) 220.

2 Jean-Luc Nancy, "Of Being Singular Plural," eds. Werner Hamacher and David Wellbery, Being Singular Plural, (Stanford: Stanford U.P., 2000) 5. 


\section{Recognition, Translated}

An artist's conception, a sitter's faith, a likeness captured, a viewer's recognition. The genre of portraiture is situated in a unique place in artistic classifications. Not tied to a stylistic movement or medium, the art of portraiture cuts across historical boundaries and stylistic tendencies. Not surprisingly, the first image is said to have been a portrait. The history of portraiture is directly related to perpetual questions concerning the self, the representation of the self and what this representation says to others. It is these questions that therefore allows portraiture's origins to be traced to the beginning of existence. Joanna Woodall's intoroduction in the book, Portraiture: Facing the Subject, forms the foundational basis of the genre's history. ${ }^{1}$

Traditional portraiture was an art form very much tied to the declaration of status and power based on a subject's stance, position within the canvas and the representational devices used in capturing that subject's likeness. It is for reasons such as these that it is regarded as an art form created for the aristocratic and the privileged. ${ }^{2}$ However, a closer look at the essential

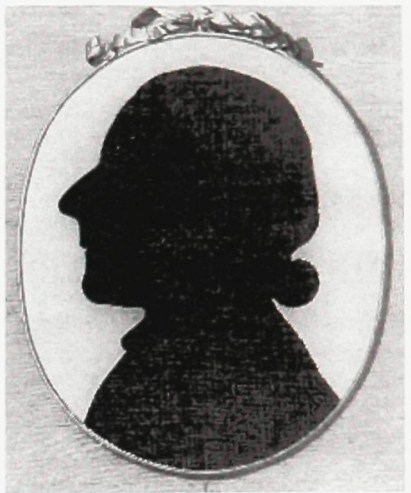

Figure 1 Profile shadow tracing of John Casper Lavater from Essays on Physiognomy (London, 1792). qualities inherent in portraiture may reveal a weakness of thought behind its exterior declarations of strength.

\footnotetext{
1 Joanna Woodall, Portraiture: Facing the Subject, (New York: Manchester UP, 1997), 1-28.

2 Woodall writes about seventeenth-century Dutch portraiture and its ties to concepts of nobility in the essay, Sovereign Bodies, 75-100.
} 
Despite the commonplace understanding that the art of portraiture is not evocative of a contemporary art practice that values abstract qualities over mimetic representation, portraiture is still an elusive and popular art form. Evidence of its popularity can be seen in the attendance of portrait galleries where people still seek out paintings, photographs and sculptures of both prominent and not-so-prominent figures. Therefore, there is a need to go back and reflect on the qualities of the art form that make it still so seductive for many. Joanna Woodall, in the introduction to a collection of essays entitled, Portraiture:

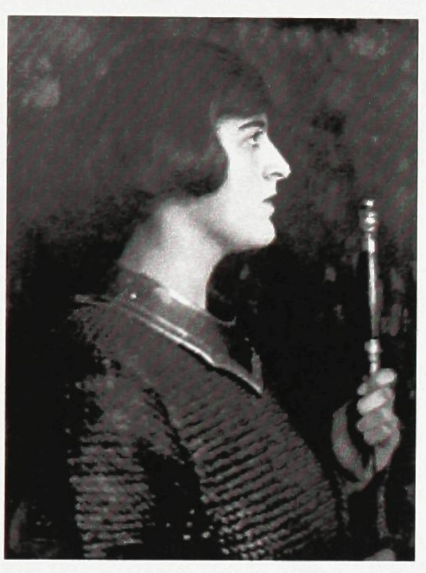

Figure 2 Sidney Carter, Pauline (Archer) Vanier, ca. 1920, National Archives of Canada Collection
Facing the Subject, traces the genres physiognomic roots and discusses antiquated notions of portraiture as the paradigm of representation. Woodall writes,

For Aristotle, portraiture epitomized representation in its literal and definitive sense of making present again: re-presentation. According to him, our pleasure in seeing a portrait consists primarily in recognition, which is the process of identifying a likeness with what it is perceived to be like, of substituting something present for something absent. For him, a proper illusion of the bodily self necessarily entailed a sense of the presence of the person depicted. ${ }^{3}$

In this sense, it is quite easy to accept that portraiture's power is found in the moment of recognition of a likeness or of a presence. If, however, this notion is contemplated for a moment and looked at from a slightly different angle, it can be argued that the recognition essential in portraiture is not necessarily recognition of a physical likeness but a likeness attributed with the closing of a

\footnotetext{
${ }^{3}$ Woodall, 8.
} 
spatial gap between distant things. This understanding of the nature of portraiture transcends traditional notions that a portrait must represent the sitter's entire physical likeness in order to elicit a moment of recognition from the viewer.

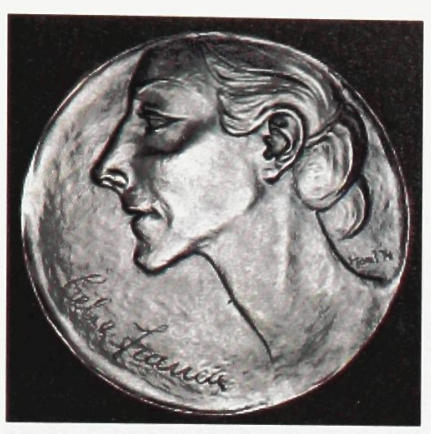

Figure 3 Dora de Pédery-Hunt, Celia Franca, 1974, National Archives of Canada Collection
Portraiture's ability to give presence to something that is absent - by uniting a memory or idea with its physical manifestation - is an essential quality that all portraits possess whether they use mimetic modes of representation or more abstract methods. This "weaker"4 understanding of portraiture is especially significant today. Contemporary artists strive to break conventional boundaries of classification, modes of representation and perception and find it difficult to incorporate naturalistic portraiture into their repertoire. Furthermore, the ubiquity of images as a result of technological advances enables physical likeness to be captured in an instant and makes it increasingly difficult to penetrate past a traditional portrait's static face (or façade). Therefore, identifying an essential quality inherent in portraiture in its ability to make a viewer overcome a separation through a recognition of likeness allows for a broader and looser interpretation of the "un-inventive" and "static" genre. If, for Aristotle, the joy found in portraiture was in its ability to close the spatial gap between something absent and something present, today, the power of recognition is experienced through a portrait that does not rely solely on mimetic references and, in fact, allows for contemplation and interpretation to occur within the space of the gap - in oscillation between absence and presence.

\footnotetext{
${ }^{4}$ The philosophical concept of weak philosophy or, specifically weak thought, as coined by Gianni Vattimo, describes a de-centered contemporary approach that recognizes the error in attitudes that adhere to universal "truths" and "objectivity".
} 
In other words, the moment of recognition does not come from looking at a portrait that shows us everything we know about the person/thing depicted, but instead comes from an artist's ability to show us something (not everything) we do not know of that person/thing depicted - a "something" that is unkown, yet,

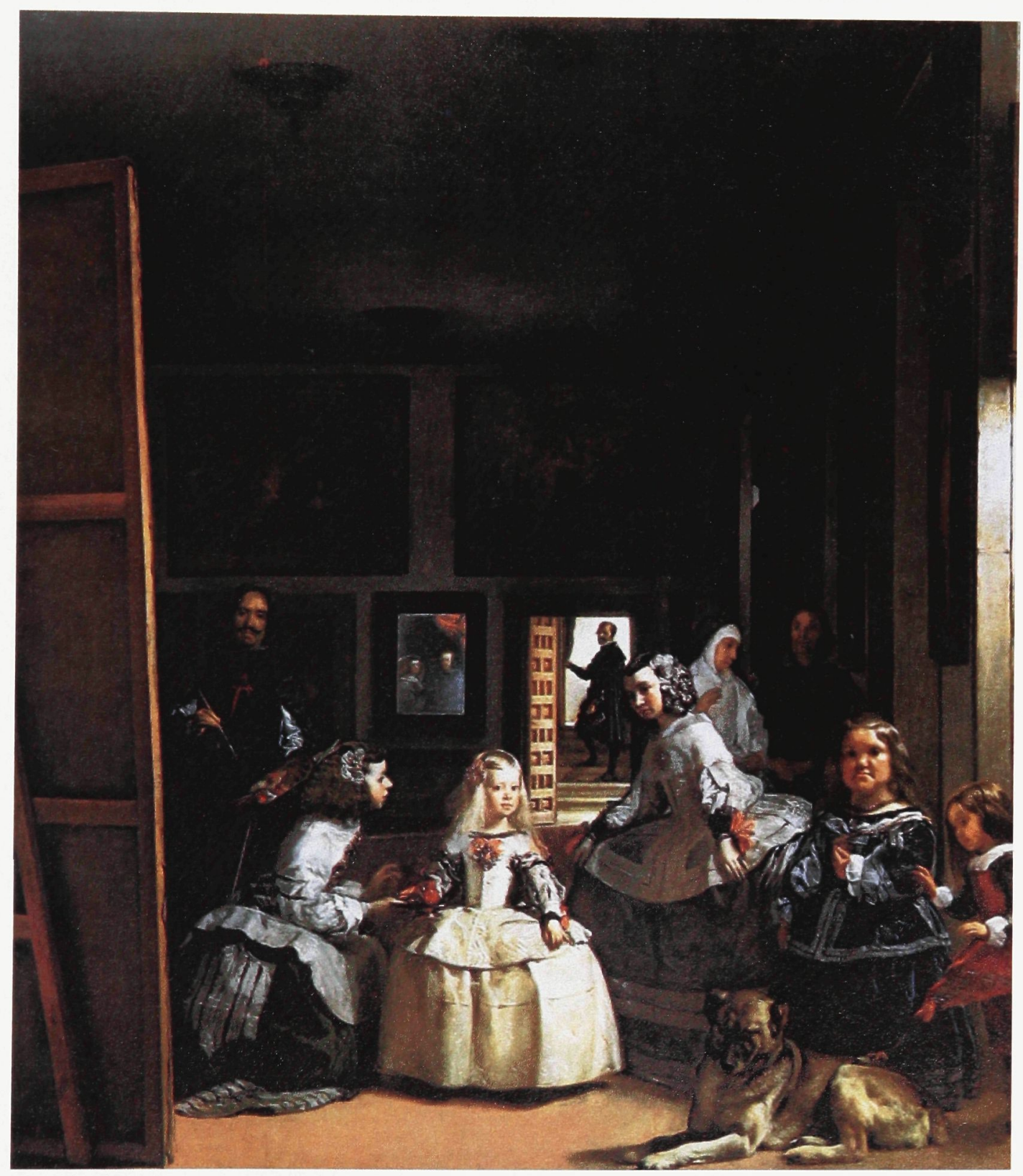

Figure 4 Diego Velazquez, Las Meninas, 1665, Museo Nacional del Prado, Madrid.

Velazquez broke with tradition and convention in this portrayal of the Spanish Royal family. 
still recognisable as an attribute belonging to the subject captured. A degree of recognition is still acknowledged, but it does not exclusively occur through the representation of physical traits; it is also acknowledged through the recognition of the ontological status of the work, that is, the gap itself.

Another quality inherent in the creation of a portrait is the notion of transaction. In the life of any artwork there exists an exchange between the artist and the viewer. In the life of a portrait, however, there exists a triadic relationship between the artist, sitter and viewer. ${ }^{5}$ An understanding of the exchanges evident in portraiture signified by a concept of a knot formed by an "interlacing of strands" is especially significant and may shed light on contemporary notions of identity. Even in the most "life-like" or "true to life" depiction that an artist may produce of a subject, a portrait is never merely an act of transcription, since inherent in the creative process is the translation and thus transference of the artist's own subjectivities and interpretation of the sitter onto the canvas. ${ }^{6}$ The subject lends his/her own subjectivity to the portrait, which therein informs the artist, as part of the creative transaction. Similarly, each viewer lends his/her own subjectivity to the interpretation of the artwork. The transactions inherent in works such as Las Meninas [Figure 4], as discussed by Michel Foucault ${ }^{7}$, cannot be simply symbolized by a meeting of subject and object because it is not clear where the

${ }^{5}$ David Lomas argues that a transaction also occurs within the artist's own inner psyche in the cases of self-portraits, $\mathrm{p} 167$.

${ }^{6}$ Alberto Pérez-Gómez and Louise Pelletier make the distinction between transcription and translation in the book, Architectural Representation and the Perspective Hinge, p 4-8.

${ }^{7}$ Michel Foucault discusses the reciprocity of vision in the composition and viewing of Las Meninas in the first chapter of The Order of Things, (New York, Random House, 1970) 3-16. 
subjectivities of artist, sitter and viewer begin and end. In this sense, a portrait is the manifestation and re-presentation of an interstitial space of reciprocal affect and intersubjectivity - the acknowledgement of a space of co-existence between and through various points of view. The transactions inherent in portraiture are always becoming; they are fluid and ambiguous in nature and can be understood as an interlacing of elements that are in constant negotiation with one another. The elements that are part of this transaction are not limited to artist, sitter and viewer; they are but three threads of many in the intertwined knot that also include threads such as literature on portraiture and architecture for portraiture, which are now all constitutive of its identity.

The insight that an essential quality of portraiture is found in its conveyance of a likeness that evokes/invokes a viewer to close the gap between an idea or memory of someone or something and its actual presence, along with, the acceptance that portraiture embodies a process of transaction understood as a union of interlacing elements sets up slippery grounds for the

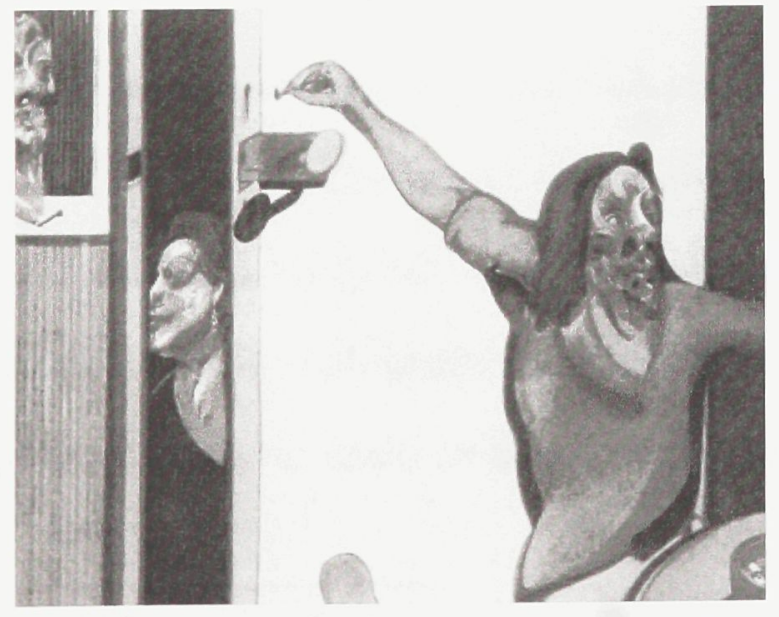

Figure 5 Francis Bacon, Three Studies of Isabel Rawsthorne, 1967, Staatliche Museen Preussischer Kulturbesitz, Berlin.

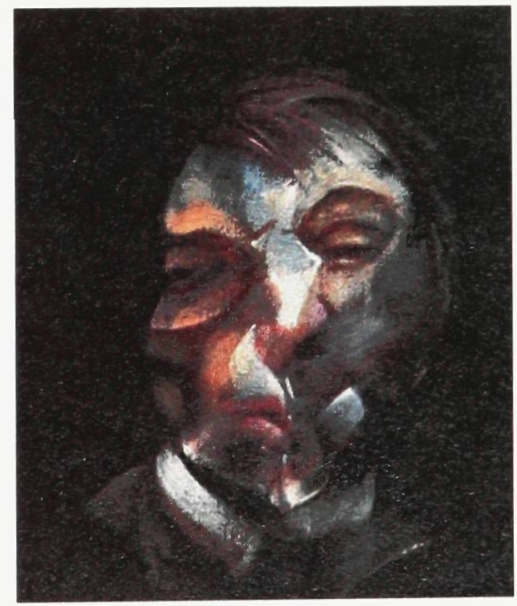

Figure 6 Francis Bacon, SelfPortrait, 1971, Musée National d'Art Moderne, Centre Geeorge Pompidou, Paris. 
genre's classification. This ambiguity of definition, though, allows portraiture to be defined by its essential qualities while not being limited by them; it allows portraiture to be both re-defined and embodied by re-presentational modes outside of art's conventional framework. While this altered way of looking, specifically, at the genre of portraiture allows for an understanding that transcends boundaries of classification, this understanding of portraiture can, on another level, significantly inform other discursive practices and elucidate notions of identity. Portraiture's continual and transcendental existence in the art world is due to the changing ideas behind a portrait's very creation - ideas preoccupied with shifting notions of self and identity. Contemporary artist, Frances Bacon uses the genre of portraiture to embody a multi-layered understanding of the self. Ernst van Alphen examines this quality in Bacon's painting, Three Studies of Isabel Rawsthorne [Figure 5]. Alphen states,

[It] is not only a portrait, it is also a work about the portrait. Isabel Rawsthorne is portrayed on different ontological levels. We see her in the primal space of the painting, but also as the subject of a portrait nailed to the wall. In this painting the distinction, or tension, between inside (subjectivity) and outside (representation) is first of all thematised literally. ${ }^{8}$

It is thus in and through portraiture where the transactions that make up a subject's identity are made manifest. As contemporary notions of identity reflect an understanding that is unbounded, fluid and ever-changing, the art of portraiture too, re-interprets conventional modes of representation and perception in order to capture a subject's essence or identity. This representation

\footnotetext{
${ }^{8}$ Ernst van Alphen, "The Portrait's Dispersal”, Portraiture: Facing the Subject, ed. Joanna Woodall (New York: Manchester UP, 1997) 247.
} 
is not limited to physical or symbolic likeness but is instead a re-presentation that is evocative of an intertwining of a subject's qualities that are in-process. Just as a human face, in a moment, cannot express the multitude of a person's lived experiences, the contemporary portrait transcends conventional dualistic notions in order to elicit moments of recognition that co-exist in and/or beyond the realm of representation. This understanding is not just embodied in the artistic practice of portraiture but because it is informed by a contemporary way of thinking, it is evocative of a contemporary cultural condition and can thus be translated to a way of thinking about other discursive and experiential realms that, in turn, re-inform concepts of portraiture. A cross-pollination occurs across these discussions; the investigation of identity in portraiture is an investigation of identity on various levels. 


\section{Cultivating Paradoxes}

When speaking of national identity, the usual tropes and stereotypes undoubtedly reoccur. Images such as mosaic, melting pot, fabric and village are one-dimensional and, not surprisingly, do not

embody a multiplicity and heterogeneity of diverse communities such as those inherent in Canada.

Canada is a nation that is essentially imageless, that is, it is inherently "un-nationalistic" in conventional political terms. This does not mean that Canada is without an identity but rather that its identity (in terms of the way it "looks" and "is") cannot be represented with a homogenous image and, as such, any understanding of Canada's identity cannot rely on the tropes and platitudes that are commonly used to describe cultural conditions.

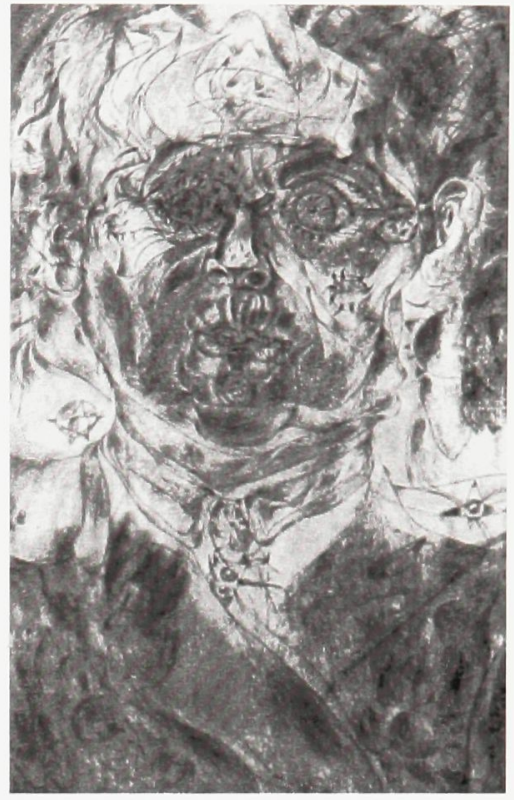

Figure 7 Joan Miro, SelfPortrait, 1937-38, Museum of Modern Art, New York. Just as contemporary portraitists, such as Bacon, embody an understanding of identity that is not tied to a conception that is fixed or static, an understanding of nation that embraces its identity as an on-going process of becoming can signify the various layers of existence that form a nation instead of just representing the idea of nation with an image. Adopting an understanding of the concept of Being Singular Plural, as conceived by philosopher Jean-Luc Nancy, will shed light on this issue and allow for an understanding outside of conventional classifications and dialectical modes of thinking.

Nancy's conception of Being Singular Plural relays an idea that puts the 
emphasis of the ontological state of Being on its shared quality - existence is meaningful because it is a common experience. Being is essentially singularly plural:

It is the originary plurality of origins and the creation of the world in each singularity, creation continued in the discontinuity of its discrete occurrences. From now on, we, we others are charged with this truth - it is more ours than ever - the truth of this paradoxical "first person plural" which makes sense of the world as the spacing and intertwining of so many worlds (earths, skies, histories) that there is a taking place of meaning, or the crossingthrough of presence. "We" says (and "we say") the unique event whose uniqueness and unity consist in multiplicity. ${ }^{9}$

In this sense, the act of uttering "we" connotes a meaning that is shared but does not limit the "we" to having a homogenous quality, necessarily. The understanding that any perceived unity consists of diverse "origins", and the difference between these origins is the quality that makes these divergent parts similar is fundamental to an alternative understanding of a community that is comprised of multiple "worlds". The difference between diverse origins is defined in the "space and intertwining" of these worlds and it is here where this conception of being singular plural can start to take on an architectural significance. Nancy's discussion is often described and articulated in spatial and embodied terms, never in a static image. Understanding this notion of unity is forever paradoxical and is inherently spatial. As such, seemingly impossible images are conjured

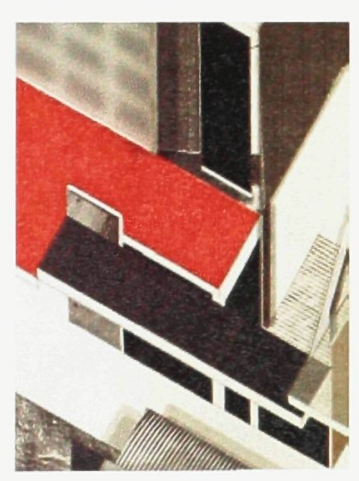

Figure 8

9 Jean-Luc Nancy, "Of Being Singular Plural," eds. Werner Hamacher and David Wellbery, Being Singular Plural, (Stanford: Stanford U.P., 2000) 5. 
that are simultaneously multi-dimensional, particular and always fluid. The interstitial spaces that connect and define differences, and therefore similarities, of diverse origins convey an imagery that implies constant movement and fluidity.

Everything, then, passes between us. This "between," as its name implies, has neither a consistency nor continuity of its own. It does not lead from one to another; it constitutes no connective tissue, no cement, no bridge. Perhaps it is not even fair to speak of a "connection" to its subject; it is neither connected nor unconnected; it falls short of both; even better, it is that which is at the heart of a connection, the interlacing of strands whose extremities remain separate even at the very center of the knot. ${ }^{10}$

This notion is especially significant because it embodies an ontological understanding that is quite different from certain accepted ideas. The space of the "between" is a space that exists outside of a dialectical mode of thinking and therefore cannot be understood as neither being "here" nor "there" or on one "side" or another but instead is understood as a paradoxical, transformative medium that defines no system or structure and is always in a state of flux. The idea of "interlacing" is especially significant and evocative of Canada's cultural condition where a unity of people of

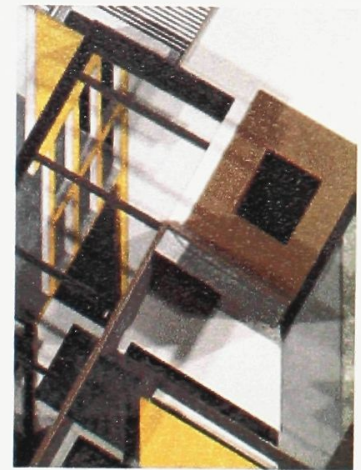

Figure 9

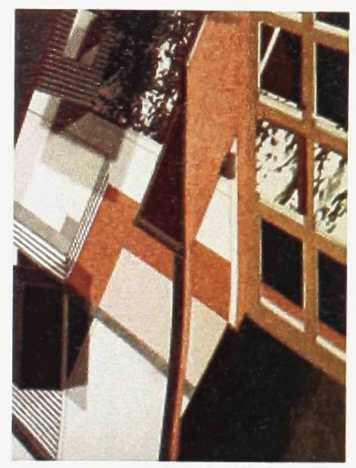

Figure 10

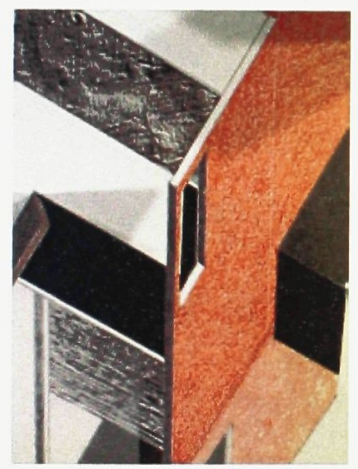

Figure 11

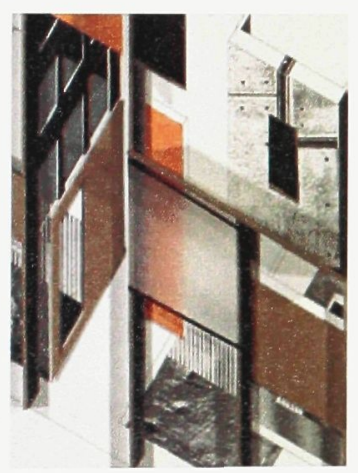

Figure 12

${ }^{10}$ Nancy, 5. 
diverse backgrounds is celebrated for their differences, and whose diversities are encouraged to be maintained. That said, the importance in this discussion, however, is not so much the acknowledgement of differences, since differences are always apparent, differences are - but the desire for sameness, despite differences, like the search for recognition in a portrait, is the condition that starts to inform a way of being.

The theoretical concept of being singular plural informs an understanding of a community of diversity in that it offers an alternative way of thinking about how such a community is - how it lives. And although it offers provocative imagery and visualizations, an architectural practice that borrows such a concept must be weary not to take its visual devices literally, for such a strategy would contradict its very insights. As such it should be regarded as a productive rhetorical framework. The important insight to take away from this theoretical concept is that the idea of a unity of "diverse origins" can only be articulated spatially. The use of spatial explication is not just a way of describing or talking about this notion of existence but this notion is given life through the movement and circulation in space. It is manifested in the disjunction and contrasts of proximities that ultimately produces a whole - a whole that is defined by its shared experiential quality. If the emphasis here was not on a sharing of experience, the theoretical concept of being singular plural could be articulated through the experience of a painting or of a movie (it will be later discussed how the arts are significant to this discussion) but its inherent shared quality can only be produced in and through an architectural experience. An understanding of oneself is gained only in the understanding and communication with an other, with others - "other" not being an abstracted notion of the Other which Nancy 
argues is a conception produced by fear and desire, but that the meaning of being is constituted in a space that nurtures a co-existence of oneself with others, oneself with another, so that an understanding of oneself is arrived at through others and that reciprocally, another's understanding is arrived at through oneself. With this gained insight, the quest to define any sort of stable identity or to arrive at any definitive goal is to miss the point, and is essentially fruitless since a relationship of communication requires a constant negotiation and is forever changing. It is in this shared experience where the emphasis of Being is found in the co- of co-essence, as Nancy puts it, that makes this concept significant on multiple levels - applicable to national, urban and architectural conditions.

Nancy regards the arts with special significance and identifies the arts as essentially being singular plural.

What counts in art, what makes art art (and what makes humans the artists of the world, that is, those who expose the world for the world), is neither the "beautiful" nor the "sublime"; it is neither "purposiveness without a purpose" nor the "judgment of taste; it is neither "sensible manifestation" nor the "putting into work of truth." Undoubtedly, it is all that, but in another way: it is access to the scattered origin. This is what "the imitation of nature" has always meant. Art always has to do with cosmogony, but it exposes cosmogony for what it is: necessarily plural, diffracted, discreet, a touch of colour or tone, an agile turn of phrase or folded mass, a radiance, a scent, a song, or a suspended movement, exactly because it is the birth of a world (and not the construction of a system). A world is always as many worlds as it takes to make a world. ${ }^{11}$

\footnotetext{
${ }^{11}$ Nancy, 14.
} 
Regarding art as an "access to the scattered origin" speaks of art's capacity to embody something other than the represented image. As another point of access, though, the art and experience of architecture can go one step further to offer and embody a "birth of a world" that does not only visualize a particular cultural condition but that can also physically offer a spatial condition that requires social participation and facilitates a space of negotiation, reversibility, inter-action and trans-action. Architecture has the capacity to enact - to essentially put into practice a way of thinking that is not purely representational but that is also evocative of being singular plural - a way of being and thinking that speaks of Canada's contemporary condition. The way architecture does so is through its contribution (it affects as it is affected) on multiple levels, from the macro to the micro - on the humble level of everyday experiences, on the level of the city and on the level of cultural discourse. Therefore, the way that these symbiotic relationships are enacted can be seen through the examination of the transactions that are involved in the process of architectural design. 


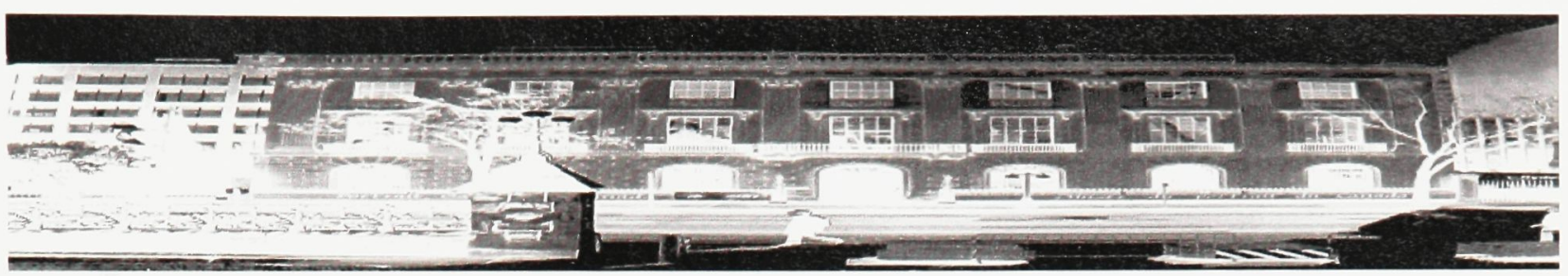

There are many different ways of entering a discussion on identity.

The discourse on the subject in this epistemologically-realized culture is overwhelmingly vast. Discussions of abstract notions, such as nation and identity, only perpetuate stereotypes and often errantly lead the discussion astray. Therefore, adopting an approach that looks to the specific to inform the general and likewise, the general to inform the specific, facilitates a layered understanding that cannot be gained by a strategy of identifying causes and effects. This thesis frames (and is framed by) a discussion of identity through architecture and more specifically through its own design proposal for the Portrait Gallery of Canada.

The building itself will now become an ambassador, joining the Parliament Buildings in symbolizing the people and the life of the nation. The requirement both to restore and adapt a treasured architectural space and to expand and enhance it with a fresh, contemporary addition provides a rare opportunity to allow building fabric to express symbolically the broad chronological sweep of the Portrait Gallery's mandate which explores not only the past but also the vibrant present and the potential of the future. ${ }^{12}$

\footnotetext{
12 National Archives of Canada with Public Works and Government Services Canada, Portrait Gallery of Canada Project Mandate, hereafter cited as PGCPM, (Ottawa: National Archives, 2003) 10.
} 
Quite the task at hand; the Portrait Gallery of Canada's project mandate describes its vision and makes clear how it believes architecture can manifest this vision. The new gallery has not begun construction and is scheduled to be open in 2006 but has already amassed quite an undertaking. With nearly 20,000 works of art (paintings and works of art on paper), 4 million photographs and 10,000 medallic and philatelic works of portraiture in the archives, the very task of sorting through such an immense collection seems insurmountable on its own. However, the logistical endeavor of categorizing and selecting the works to be exhibited in the museum pales in comparison to the role given to architecture. Any architectural endeavor is wrought with issues but the project for the proposed Portrait Gallery of Canada, hereafter cited as PGC, has many different facets of intrigue written into its text even before it has begun construction. Located directly across the street form the Parliament Buildings, Canada's most prominent symbol of its identity and democracy, the newly conceived gallery is

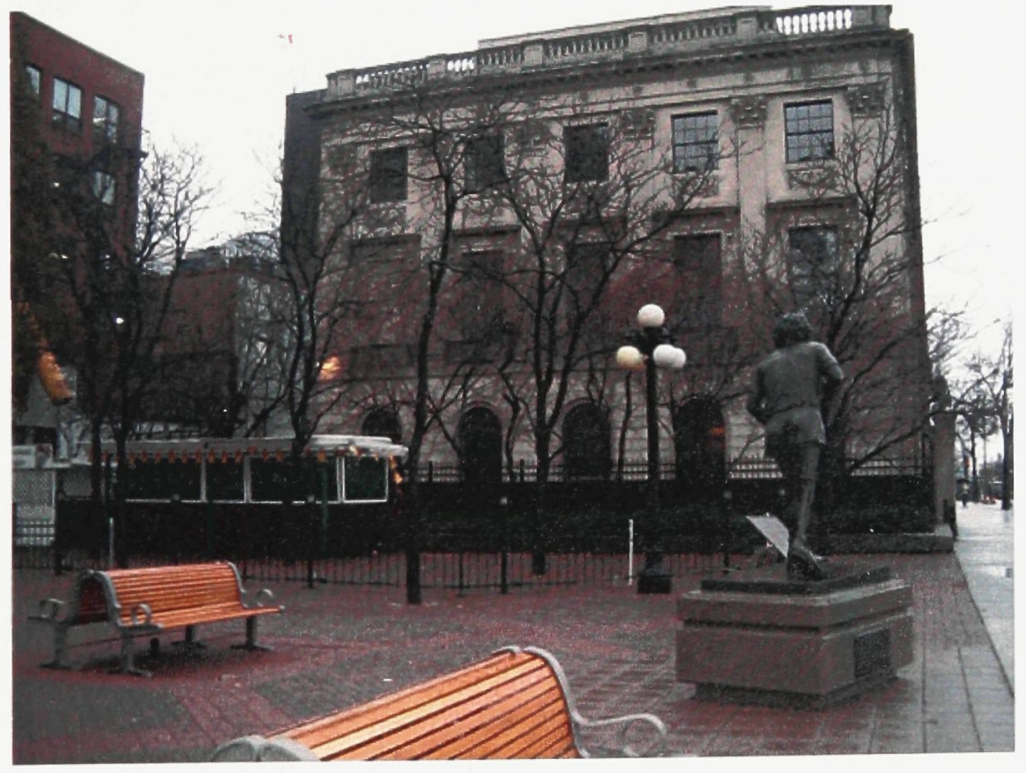

Figure 13 East elevation of Chancery Building (former United States Embassy)

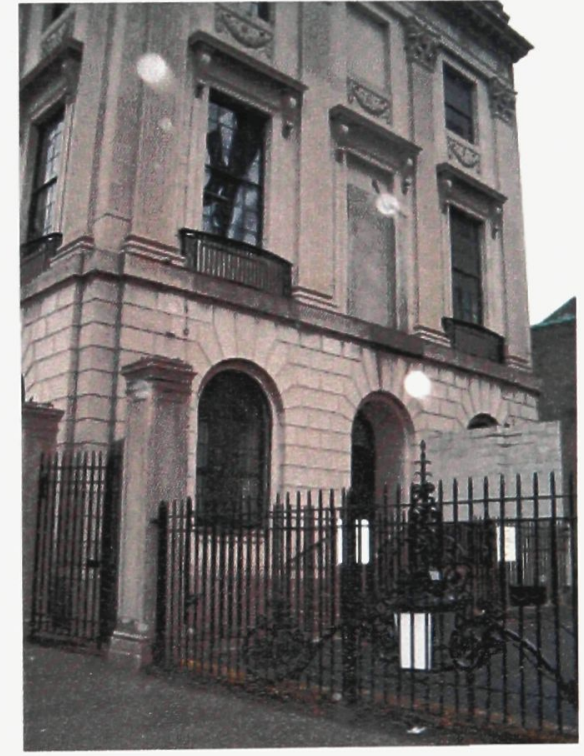

Figure 14 West elevation 
to re-inhabit the building of the former United States embassy. This piece of irony is an underlying friction that gives this project unique precedence. The U.S. Embassy held the privileged position in the parliamentary precinct since the 1930's but in 1997 expanded and relocated to an equally prestigious (and controversial) site on Sussex Drive - adjacent to the National Gallery of Canada and hovering over Ottawa's Byward Market. Therefore, upon the re-location of the U.S. Embassy, it was announced that the evacuated building would subsequently be expanded to become home to the PGC. This decision was quite fitting; how better to re-claim the site and building as Canadian than to make it a gallery to "showcase the faces of Canadians from all walks of life who have shaped and continue to shape the history and culture of our nation."13

The surrounding area in which the site of the PGC is located is one that sees a cross-pollination of users and audiences and therefore is significant on various levels. It is an area infused with government agencies, business headquarters, local retail and tourist activity. The site of the building itself [Figure 15], situated on the stretch of Wellington Street called Confederation Boulevard, is flanked by two "un-inhabited" lots. On the corner of the block, to the east of the existing building, there is a small public space [2] that sits in parallel alignment with the Peace Tower. To the south, this open space is edged with buildings of various programs. The programs on the ground floor include a tourist Information Centre [5] run by the National Capital Commission and small restaurants. Another open lot, this one devoted to parking, flanks the building on the west [3]. The glazed façade of the Library of Parliament [4] takes advantage

${ }^{13}$ PGCPM, 3. 
of the lot's current vacancy and looks onto Parliament Hill. An important feature of this area is Sparks Street [6], located to the south of the site. A street devoted to pedestrians, the Sparks Street Mall is lined with small buildings with retail on the ground floor and is a popular venue for both locals and tourists. The PGC mandate designates the addition to the former U.S. embassy to be built in the empty lot, to its west, thus forming a continuous façade onto Wellington Street.

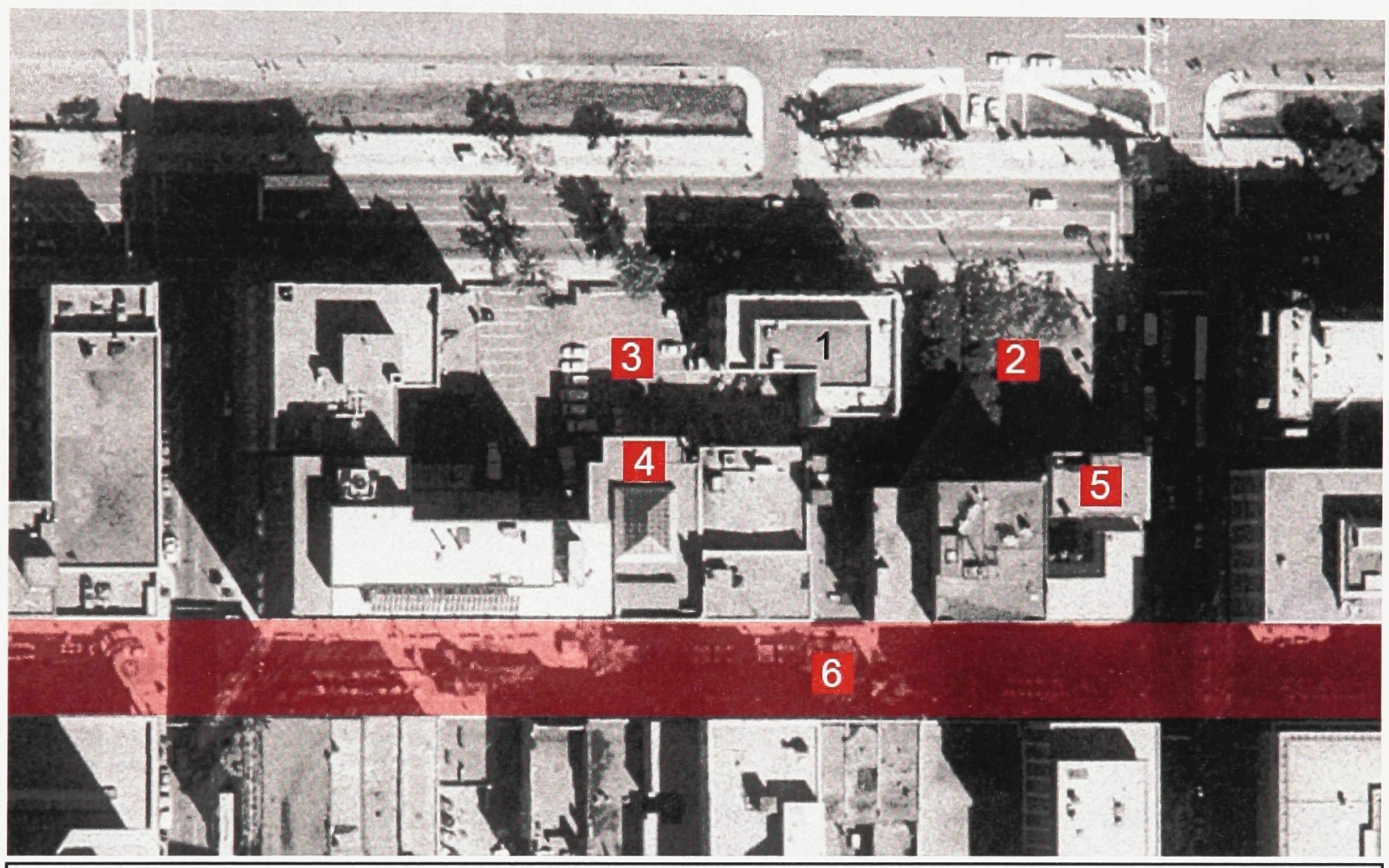

Figure 15 Site plan of surrounding area

1. Chancery Building (Former United States Embassy)

2. East lot - Public Plaza

3. West lot - Parking Lot

4. Library of Parliament

5. Tourist Information Centre

6. Sparks Street Pedestrian Mall 


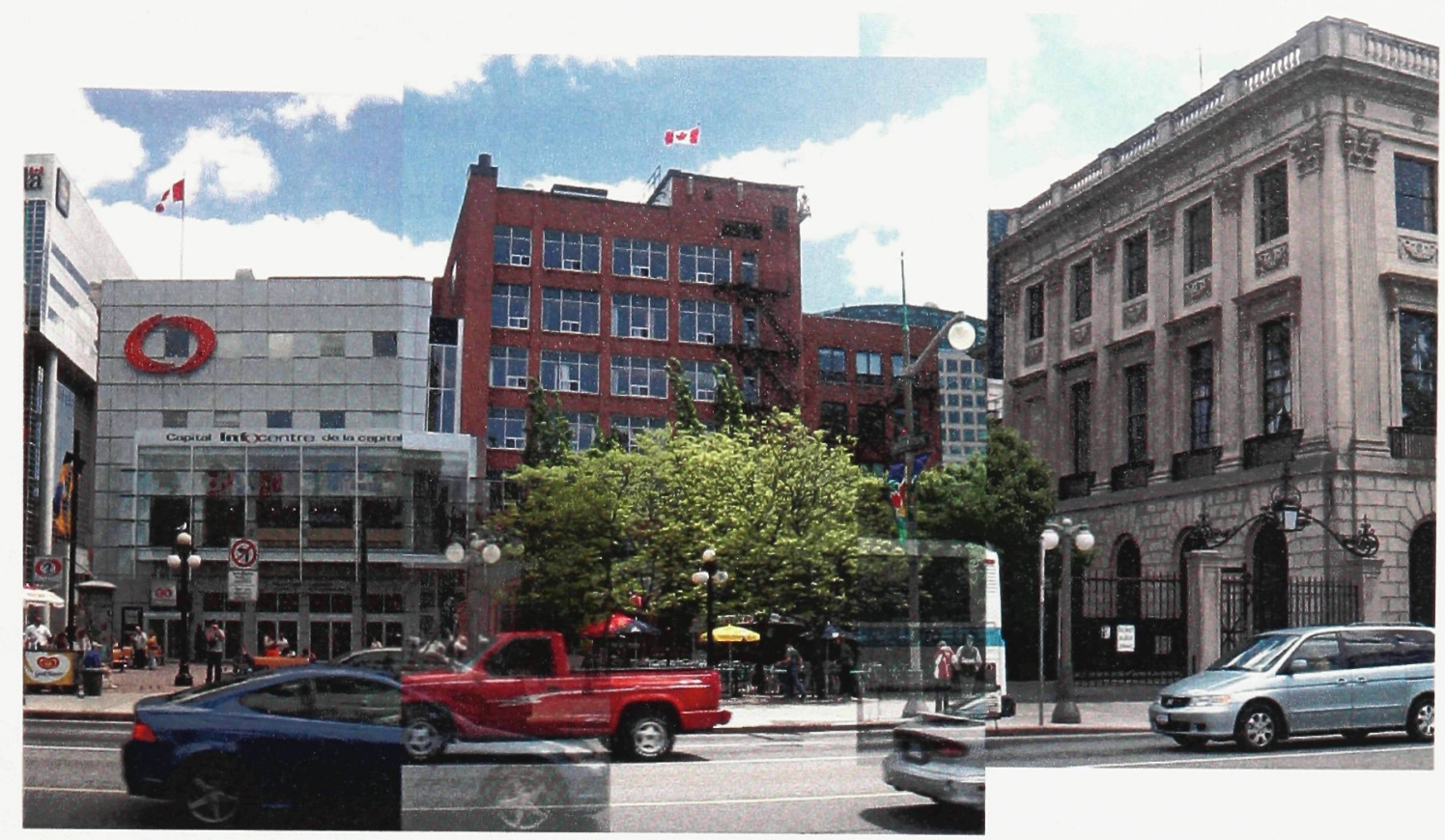

Figure 16 The small plaza on Wellington Street is owned by the NCC and was briefly part of plans to widen Metcalfe Street.

This point in the discussion marks a moment of diversion. In parallel to the discussion of the design requirements and proposals for the Portrait Gallery of Canada, this thesis proposes its own design for a portrait gallery for this site. These divergent proposals are not in opposition to one another necessarily but instead run in parallel structure to one another. This thesis' proposal, hereafter referred to as $p g$, is informed by and takes it impetus from the "real" design requirements mandated by the PGC but is intertwined with other threads as well - threads of theory, threads of discourse - with the hope that this thesis elicits moments of intersection formed by the crossing of various strands in a tangled knot.

The various implications of the site amount to multiple considerations that the design of the $p g$ will have to contemplate, with the approach that looks to the site to inform and shape the building as much as the building will, in turn, shape 
the site. [Refer to Appendix B for urban studies.] The small public plaza adjacent to the former U.S. embassy has in the recent past been the site of a contentious debate [Figure 16]. With their mandate to promote "pride" and "unity", the National Capital Commission (NCC) proposed a plan to widen Metcalfe Street in order to create a ceremonial boulevard to Parliament Hill. As part of their grand vision for the downtown core of Ottawa, whole city blocks would be bulldozed in an effort to "beautify" the capital's identity. Although this plan was dropped in 1999 as a result of public protest and resistance, the proposal seems quite excessive and aggressive in nature - reflective of the ambivalent nature of "constructing" identity. Instead of adhering to the designated site to the west of the existing building, the pg occupies the site to its east. The site, however, is not totally "occupied" in a traditional infill approach. The addition situates itself anamorphically to the existing building and therefore does not obstruct access to the entrances of the Information Centre or retail that resides on the ground floor. Additionally, the intertwining of public passage with programmed space on the ground plane of the addition allows for an intermingling of activity that

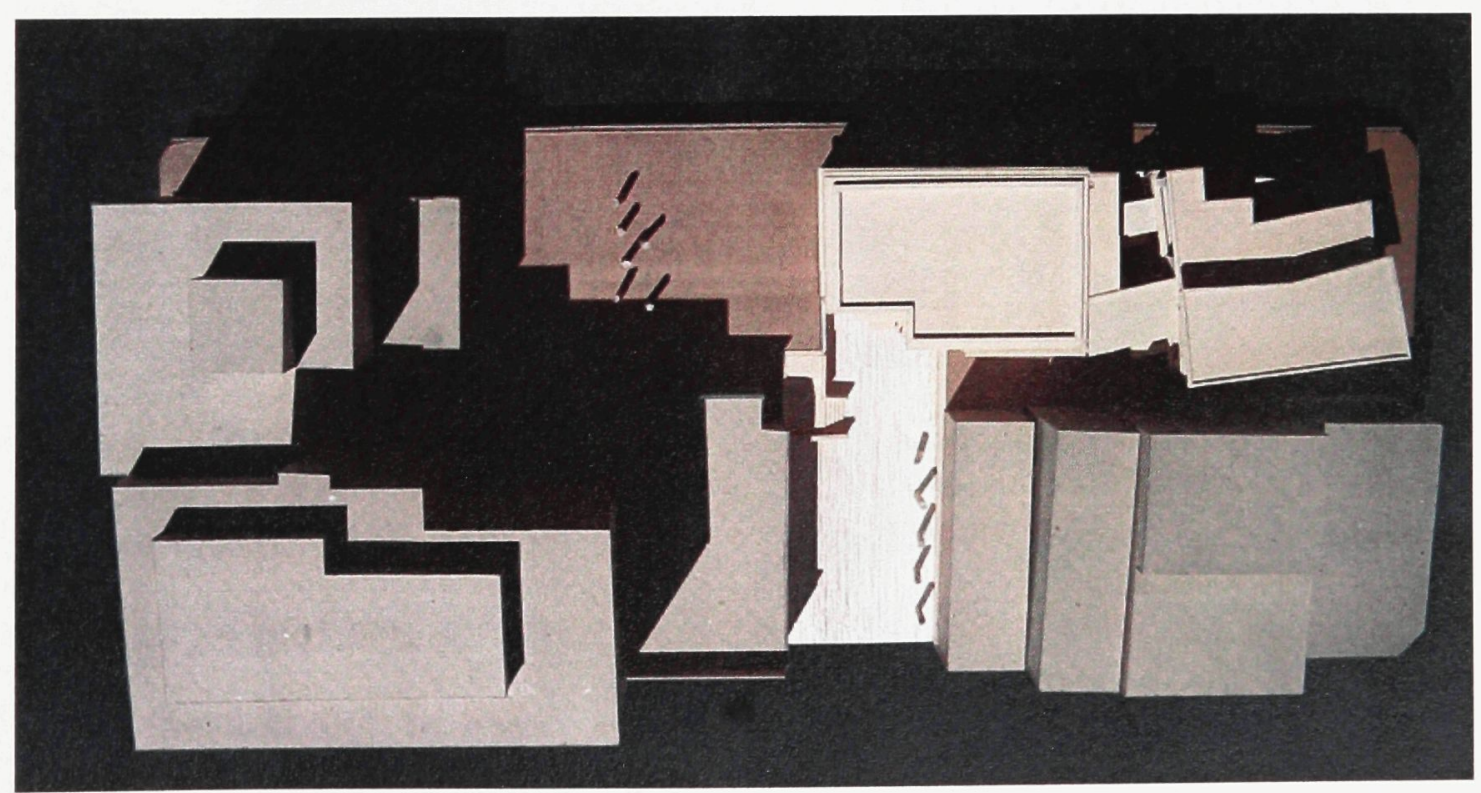

Figure 17 Location of building on site. 
does not currently exist and is evocative of a boundary condition that is thick and inhabitable. The occupation of this site frees up the west lot and does not obstruct the glass façade belonging to the Library of Parliament. A further attempt to create crossings and intersections on this scale is through the forging of a pedestrian connection from Sparks Street to Wellington Street. Sparks Street Mall is a corridor that runs east-west the length of 5 blocks and in recent years, its businesses have experienced a decline in activity. Creating a passage that cuts through the empty lot will facilitate a cross circulation of activity that will benefit both the gallery and Sparks Street vendors.

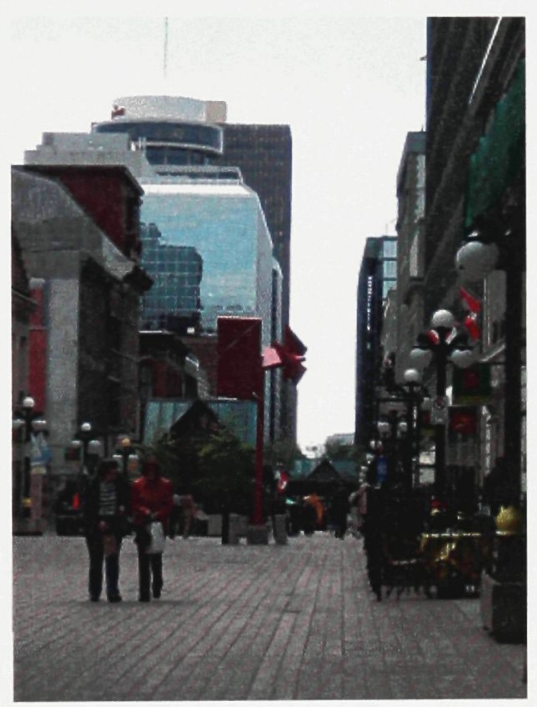

Figure 18 View of Sparks Street Pedestrian Mall

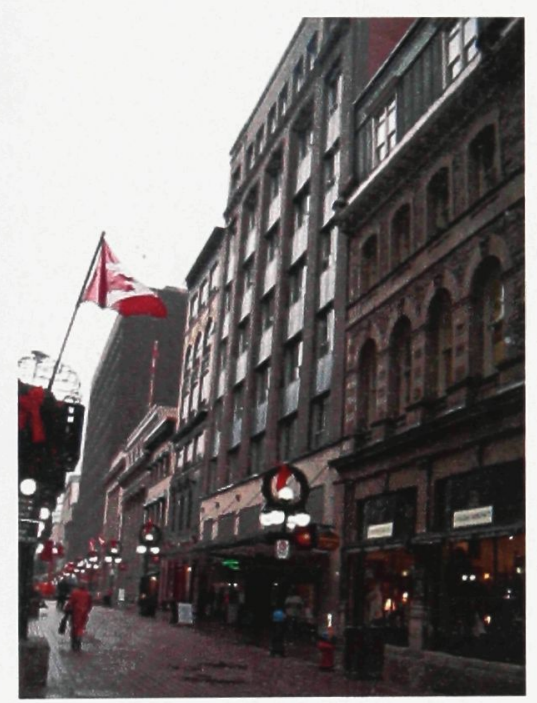

Figure 19 View of Sparks Street Pedestrian Mall

In terms of its mark on the city, the gallery's approach is informed by the site and, in turn, affects and re-shapes its surroundings. Partly, as a quiet protest against master plans, the addition's orientation on the site does not correspond to the city's grid and does not perfectly align itself with any grand processionals and is the first sign of a way of thinking that is written underneath the text of the project. 


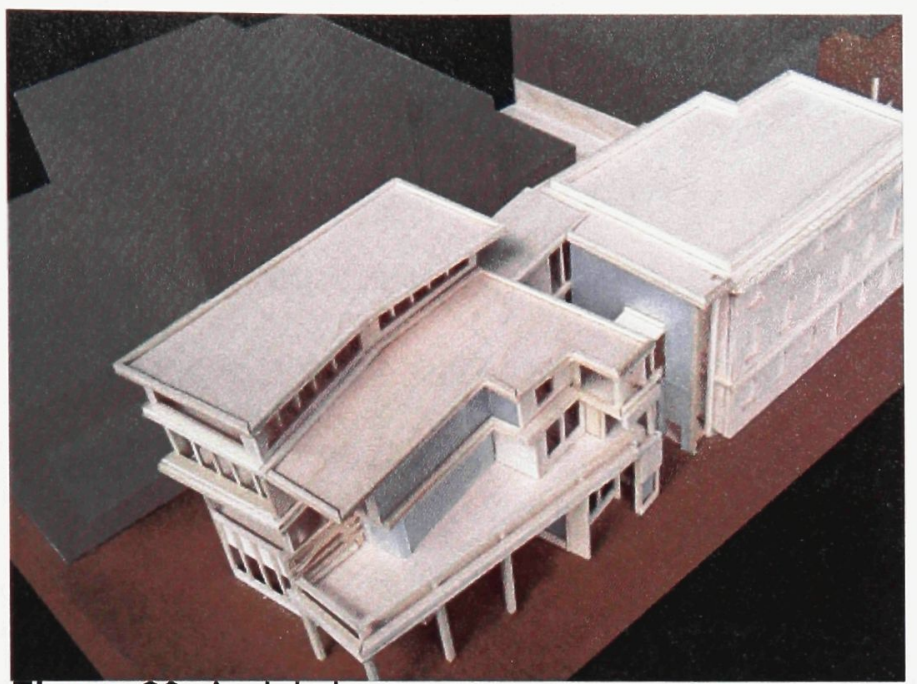

Figure 20 Aerial view

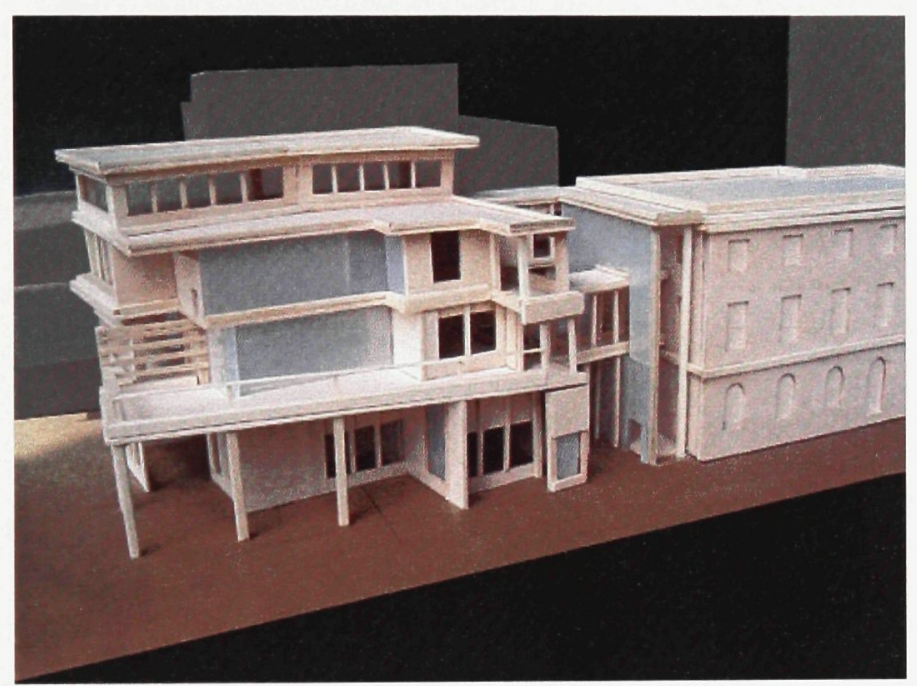

Figure 21 Street view

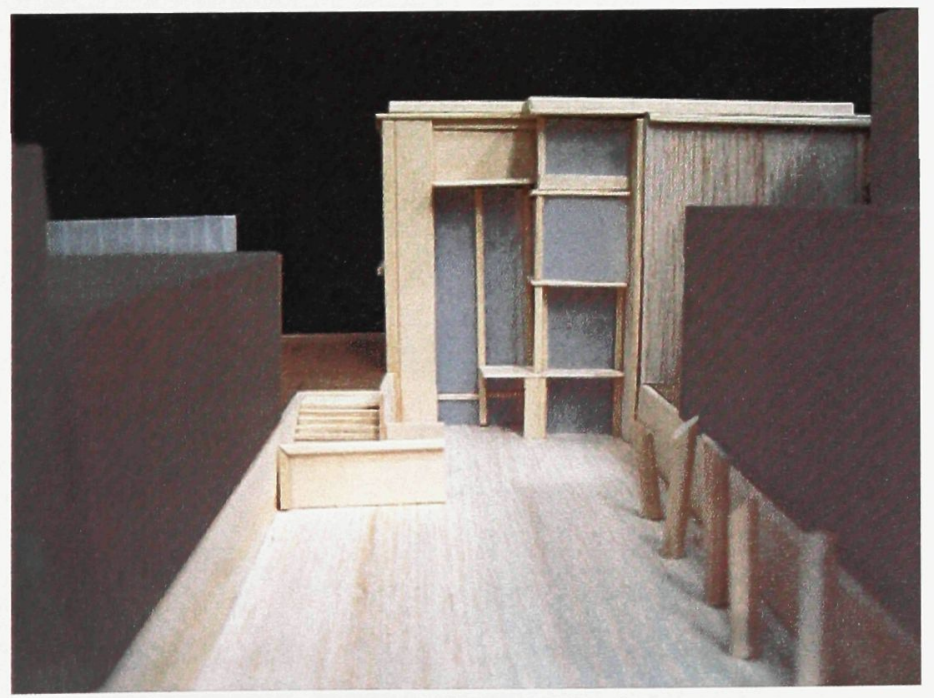

Figure 22 View from Sparks Street 


\section{Programmatic Stages}

In the introduction to Maurice Merleau-Ponty's compilation of works titled,

Sense and Non-Sense, Hubert and Patricia Dreyfus describe the philosophical tenets of phenomenology as being the examination of the "source and status of order in the perceptual world." ${ }^{14}$ Elaborating that,

Phenomenology is not simply

the study of how objects appear to common sense but is a description of the way objects arise. This shakes our perceptual faith in the independent solidity of objects - or rather, it calls our attention to the fact that it is indeed a faith. ${ }^{15}$

According to Merleau-Ponty, moments when the veil of the lived world is lifted occur in and through the experience of works of art. "When we confront a genuine novel, poem, painting, or film, we know that a contact has been established with something, that something has been gained for

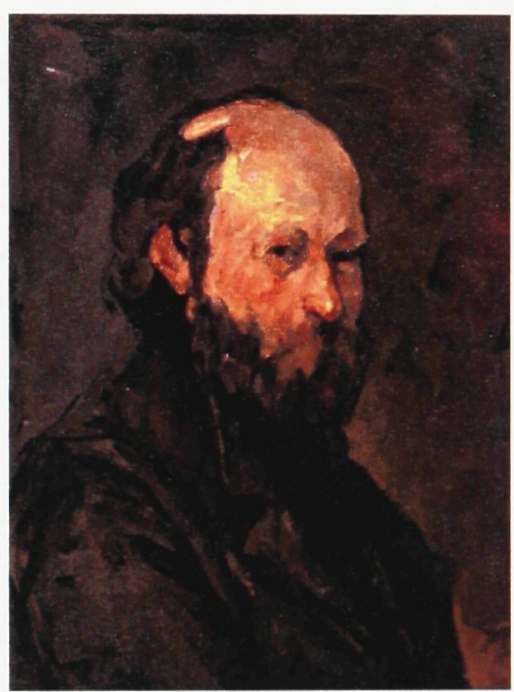

Figure 23 Paul Cézanne, Self-Portrait, 1878-80, Phillips Collection, Washington D.C.

men; and the work of art begins to transmit an uninterrupted message."16 Like Nancy's descriptions of art as a birth of a world, Merleau-Ponty recognized that the act of painting could elicit such moments of realization. In "Cézanne's Doubt", the author writes how artist Paul Cézanne did not wish to represent the

\footnotetext{
${ }^{14}$ Hubert and Patricia Allen Dreyfus, trans., "Introduction", Sense and Non-Sense, (Evanston: Northwestern UP, 1964) $x$.

${ }^{15}$ Dreyfus, xiii.

${ }^{16}$ Maurice Merleau-Ponty, "Sense and Non-Sense", Sense and Non-Sense, Hubert and Patricia Allen Dreyfus, trans., (Evanston: Northwester UP, 1964) 3.
} 
world as it was "seen" but instead "by breaking the skin of things" showed "how the things become things, how the world becomes world." 17 For Merleau-Ponty, the true joy in the art of painting lay in the way it could peel back the physical world's epidermis, going beyond the realm of mere representation.

Because the great examples of art seem to exist in a world of their own, arguably unaffected by economic and other external factors, many often herald the artistic process as the last vestige of "pure" creation. Architecture is not art. There is, within architecture, the privilege of existing within the intertwining of multiple worlds and, like art, architecture has the ability to facilitate the birth of new ones. However, works of architecture are honoured with the responsibility of providing certain "functions" that have to be addressed on the surface of things and, therefore, cannot exist purely as expression. This is precisely what phenomenology makes clear. There are many different qualities and layers that make up our everyday experiences and the

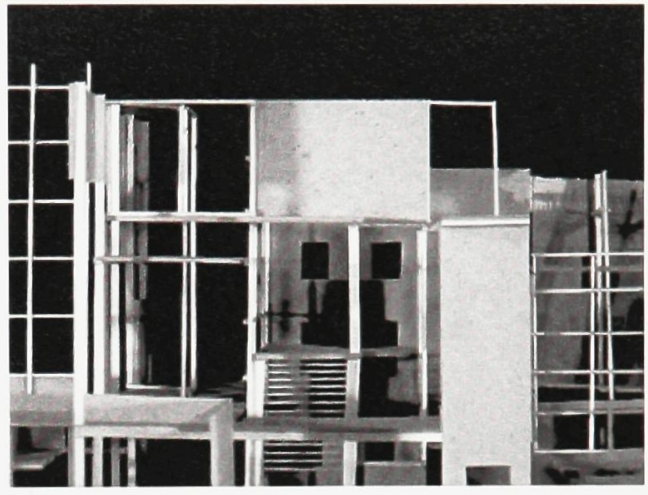

Fig. 24 Conceptual model exploring ambiguity between solid/void, inside/ outside.

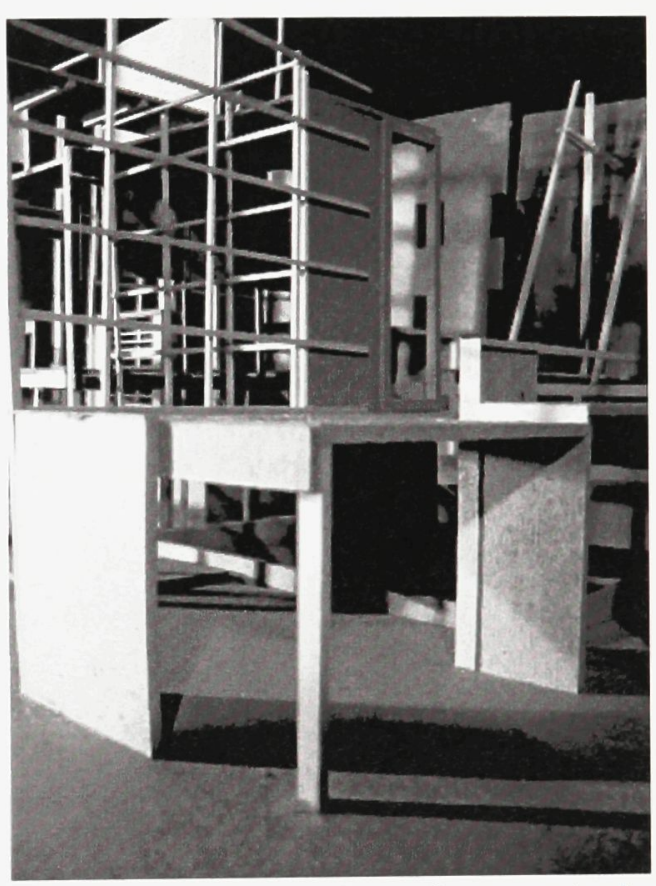

Fig. 25 Alternate view of conceptual model.

\footnotetext{
17 Maurice Merleau-Ponty, "Eye and Mind", The Primacy of Perception, James Edie, ed.,
}

(Evanston, Northwestern UP, 1964) 181. 
fact that architecture has various responsibilities suggests that it can function as art and shelter and safety and sanctuary at the same time. In this sense, architecture has the capacity to offer functions that are not only utilitarian but "functions", in perhaps its weak understanding, that address needs that are also social in nature and that elicit the cultivation of experience and spirit in the way that is embodied in art. Therefore, a discussion of the way architecture functions necessarily includes a discussion of architectural program and its contribution to various users.

Architecture does not have the luxury of choosing its audience, therefore its program plays an integral part in how it functions on the various layers of experience - because, surely, a house behaves differently than a cathedral. On one level, the gallery's prestigious location and program is of significance to users who do not necessarily live in the city. As it is located across from the most-visited landmarks in Canada, the gallery will welcome hundreds of thousands of visitors each year. For these visitors, the gallery exists as a memory associated with a specific time and place. On another level, the gallery's location also plays a significant role in the lives of people who live and work in the city and who experience the gallery on a daily basis. Although, it is important to consider that there exists various users or audiences, the approach in addressing the needs of these users can only be provisionally differentiated. The intention is not to address the specific needs of one particular group independent of another. Instead, an approach that allows the different programmatic needs to inform each other may facilitate spaces of co-inhabitation and mutual participation - a space where art and architecture co-exist in its literal programmatic capacity and in the intentions inherent in their execution. 
A discussion of museum programming requires a brief acknowledgement of the discourse surrounding museum practices. This area of study has become of particular interest in art historical fields as seen through the examination and theorization of the way the "Institution" of the museum shapes perspectives despite its claims of neutrality. Donald Preziosi, in the essay, Brain of the Earth's Body, argues that the "museum comes to be an optical instrument for the refracting of society and its history or histories into biography and narrative, into the prologue to our presentness." ${ }^{18}$ This notion suggests that the museum acts as a device that essentially alters and affects the way in which history is viewed, thus shaping perceptions of the present. Others argue that the institution of the museum is a necessary evil and that its existence provides a framework for the

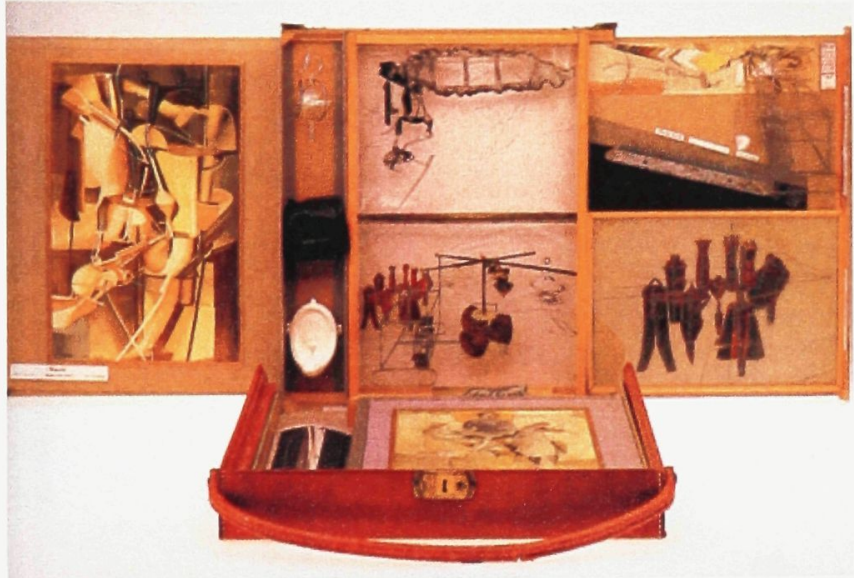

Figure 26 Marcel Duchamp, Boîte-en-Valise, 1941, Deluxe edition of 20 Boxes enclosed in leather valises, numbered I/XX - XX/XX.

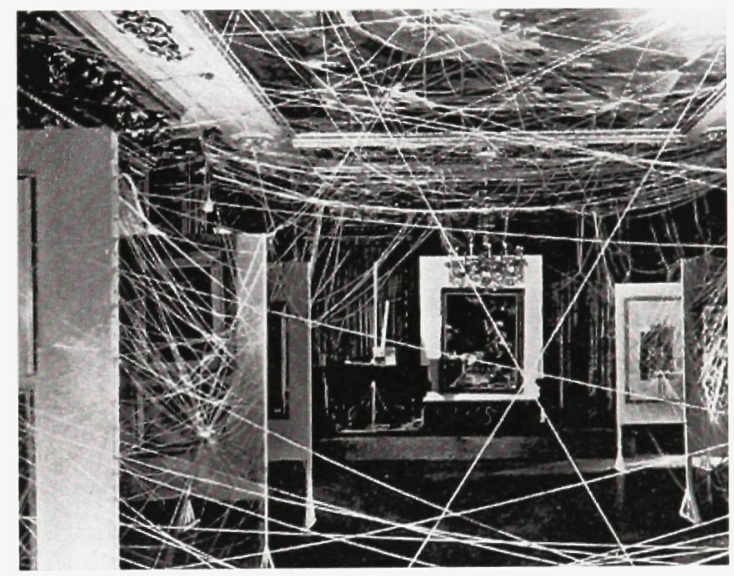

Figure 27 Marcel Duchamp, Sixteen Miles of String, 1942, Installation for First Papers of Surrealism, exhibition, New York City.

${ }_{18}$ Donald Preziosi, "Brain of the Earth's Body," The Rhetoric of the Frame, ed. Paul Duro (New York: Cambridge UP, 1996) 105.

${ }^{19}$ For a selection of essays on the topic, refer to Donald Preziosi, "The Other: Art History and/as Museology", The Art of Art History: A Critical Anthology, ed. Donald Preziosi (New York: Oxford 
perpetuation of critical dialogue. ${ }^{19}$ Evidence that this issue has reached its critical mass is seen through the number of artists who have made it subject of their artworks. For example, artist Marcel Duchamp has demonstrated the love-hate relationship between artist and institution through in situ works that have often rendered his gallery exhibits un-viewable..$^{20}$ [Figures 26,27] Fellow artist, Daniel Buren comments on the role of the art museum through his critical views of its functions. He argues,

[T] he Museum acts as a refuge, no work can "exist". The Museum is an asylum. The work set in it is sheltered from the weather and all sorts of dangers, and most of all protected from any kind of questioning. The museum selects, collects and protects. ${ }^{21}$

Opinions of artists are always insightful and lend a critical edge to an argument but its translation to an architectural approach needs to be carefully contemplated. Such strategies that belong to the artist can begin to inform an architectural practice that questions and re-interprets the "functions" of a museum.

\footnotetext{
${ }^{20}$ In 1938, Duchamp suspended 1200 coal bags from the ceiling of an enxibition room. The apparent "heaviness" of the bags precariously loomed over the heads of unsuspecting gallery visitors.

${ }^{21}$ Daniel Buren, "Function of the Museum", Museums By Artists, eds. AA Bronson and Peggy Gale, (Toronto: Art Metropole, 1983) 59.
} 
In the project mandate the PGC outlines a list of requirements that are to be fulfilled by the design proposal. The gallery and its new addition is to house the following key features ${ }^{22}$ :

- Three floors of gallery space for contemporary, historic and new media exhibits

- A children's gallery

- Multi-media lecture room

- Café and small gallery boutique

The request for these elements to be part of the new gallery is common enough. Today, visitors come to expect these from their experience of any museum, at minimum. However, a closer look at these programmatic requirements may offer a way addressing the needs fulfilled by these elements in a different way.

The request for the gallery to provide space for the exhibition of "contemporary, historic and new media" artworks implies that the organization of the gallery should be determined by such classifications, although it does not explicitly state it. The fact that most museums organize their artifacts chronologically, stylistically or by place of origin is enough reason to interpret this request in this way. This method of organization represents both a linear understanding of time and a presumed neutrality of space, that assesses each artwork on the basis

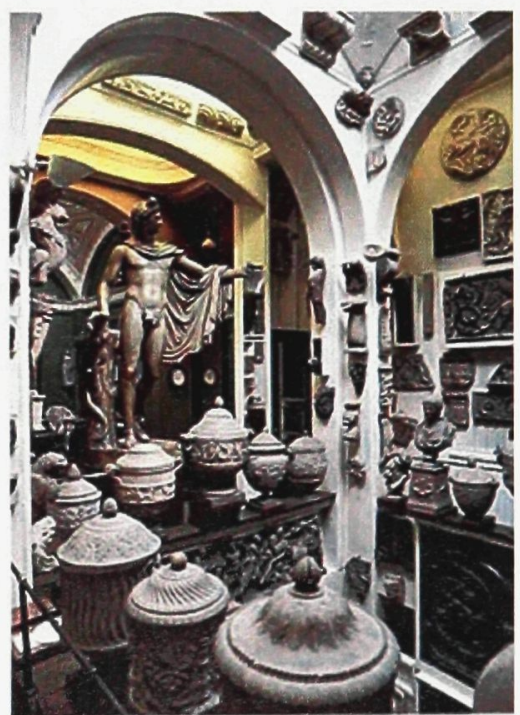

Figure 28 View of interior of the Sir John Soane Museum in London.

22 PGCPM, 4. 
of its date of creation or other associations that may be regarded as essential to the understanding of each work. The design of gallery spaces in museums facilitate this understanding by compartmentalizing art through the organization of rooms and sections dedicated to particular categories defined by art history text books. This approach does not allow an understanding that these methods of classification may actually be quite loose and coincidental and that artworks are not created in vacuums but many different factors and influences take part in their creation. Instead of organizing an exhibition space that makes distinctions in portraiture genres, an exhibition that offers distinctions in the viewing of the artworks, themselves, provides an alternative gallery experience. Diverse spatial conditions that facilitate moments of cross-pollination, through the viewing of a

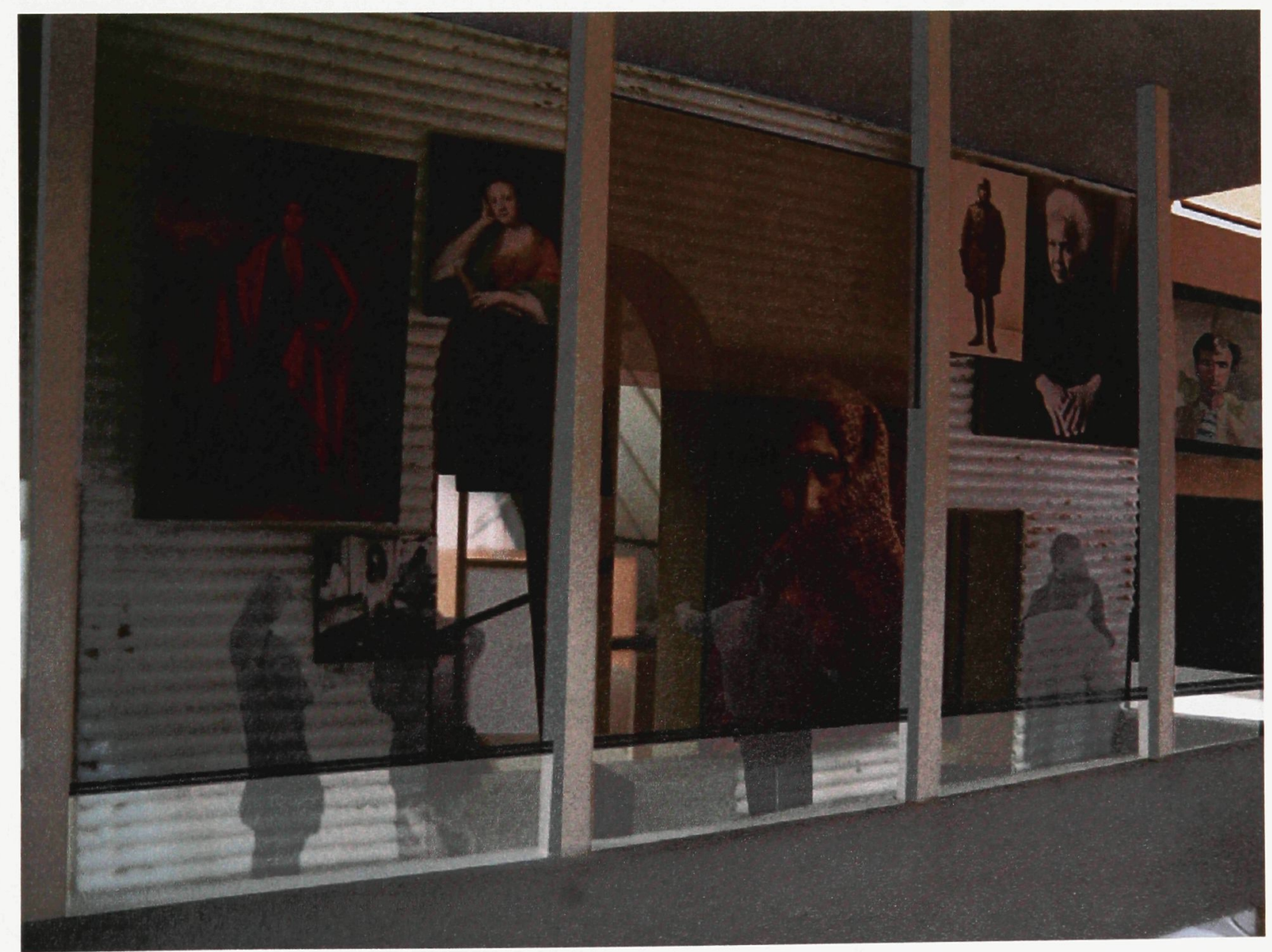

Figure 29 Interior view gallery space. 
portrait, or groups of portraits, in juxtaposition to other portraits allow viewers to form their own associative connections. Also, the space of circulation is also the space of viewing and the space of exhibition. Anomalous examples of museums such as Sir John Soane's Museum in London, England, and Frank Lloyd Wright's Guggenheim Museum in New York City, do not make explicit the distinctions between titles of classification and programmatic functions, and, therefore, galleries such as these should be taken as inspiration.

In order for the gallery to be a vital and contributing part of the city and the site in which it presides, the gallery itself will not house a café or boutique. The gallery boutique is an element found in most conventional galleries and is testament to a consumer driven culture. Also, as a way of marketing an image, a museum may use its insignia on products, taking on the role as arbiter of taste and style, as seen in the Museum of Modern Art and its lucrative MOMA brand. ${ }^{23}$ Instead, the gallery will rely on the stores and restaurants in the surrounding area, particularly Sparks Street, to serve the visitors to the gallery. Since such establishments currently exist on the site, the gallery's positioning leaves access to these businesses, allowing them to benefit from the gallery's attendance. Similarly, the ambiguity between "public" space and "gallery" space creates a dynamic atmosphere gained from the inter-mingling of gallery visitors with people who live and work in the area. This ambiguity facilitates a shared space of recognition and communication. Due to its situation on the edge of a concentrated business and governmental district and the lack of a density of

${ }^{23}$ Karl E. Meyer discusses the MOMA's economic strategies in the book The Art Museum: Power, Money, Ethics, (New York: William Morrow, 1979). 
residences, most of the activity in the area takes place during work hours. As a way of infusing a diversity of activity that occur at different times, the "multi-media lecture room" is situated on the ground floor with public access so that it can also act as a small theatre space. With its own entrance, the theatre space can be used in the evenings as a way of opening the gallery up to other users and functions, thus participating in the cultivation of urban collective memory.

As a way of being critical, the gallery translates the programmatic elements required by the project's mandate by adopting an approach that considers the mutual affect that occurs between the dialogues of museum practices, site, city and the architecture of the gallery. In the PGC mandate, the last programmatic feature asks for the inclusion of a children's gallery. It is in the translation of this programmatic element where intertwining notions of identity, art and viewing are most prominently manifested and infused in and through the design of the gallery. 


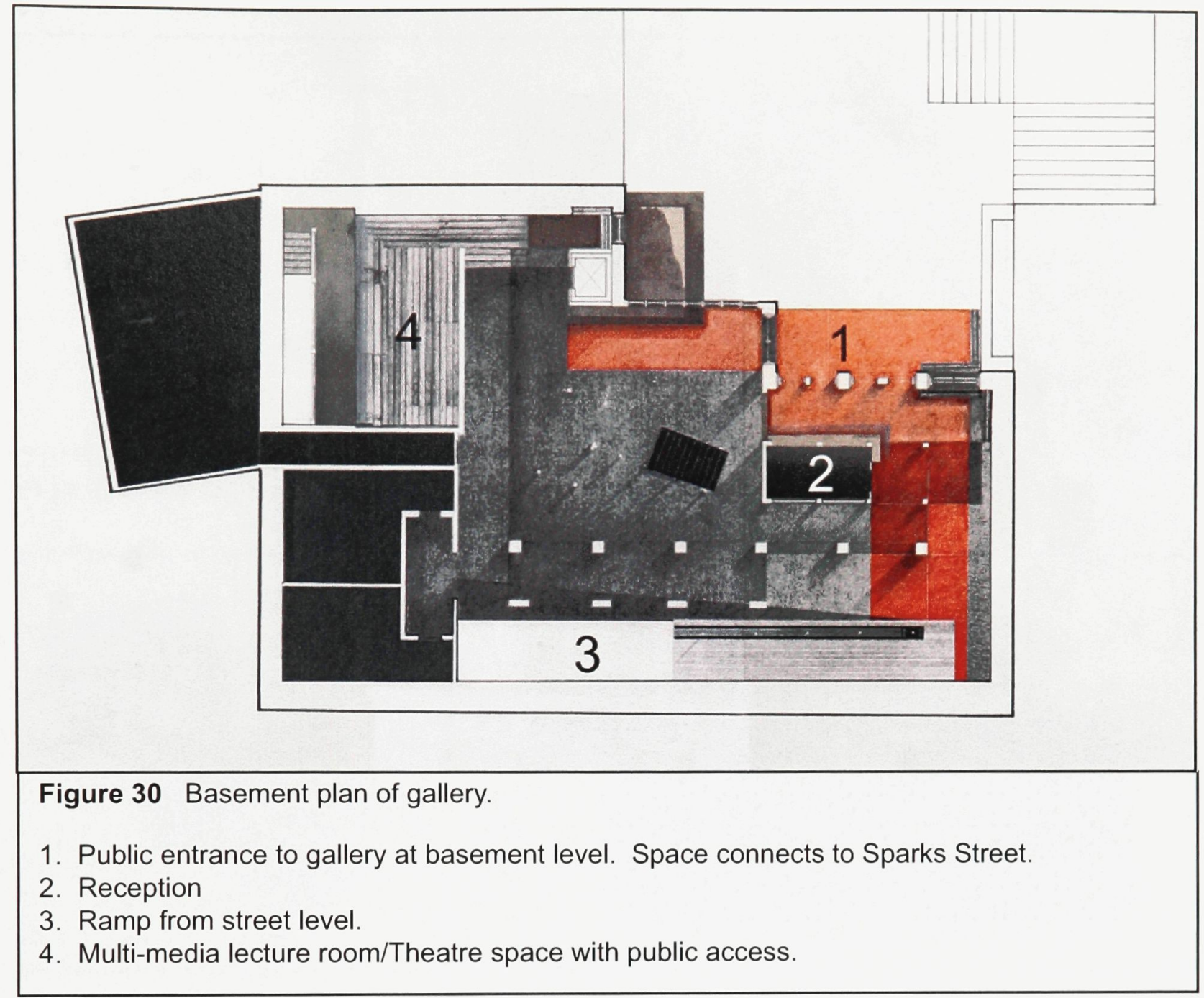




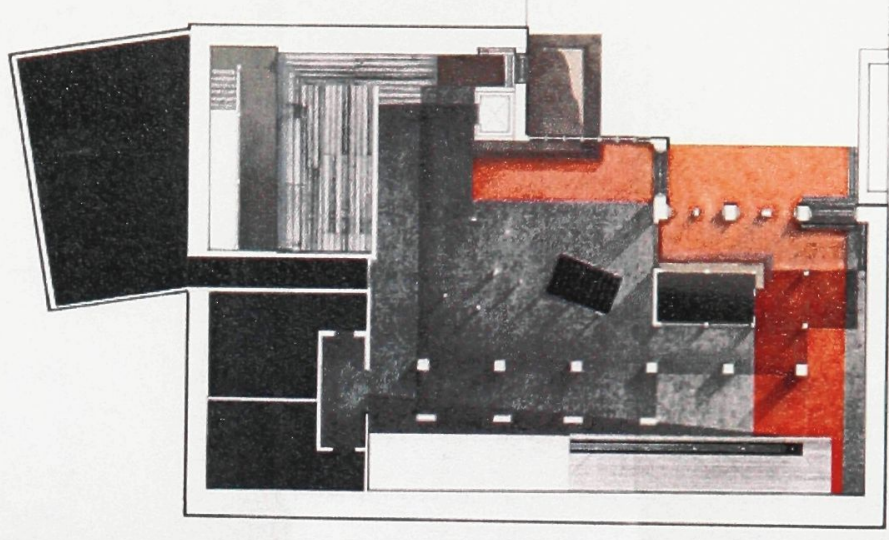

Figure 31 Basement plan. Gallery in plans are rendered in colour, daycare drawn in ink.

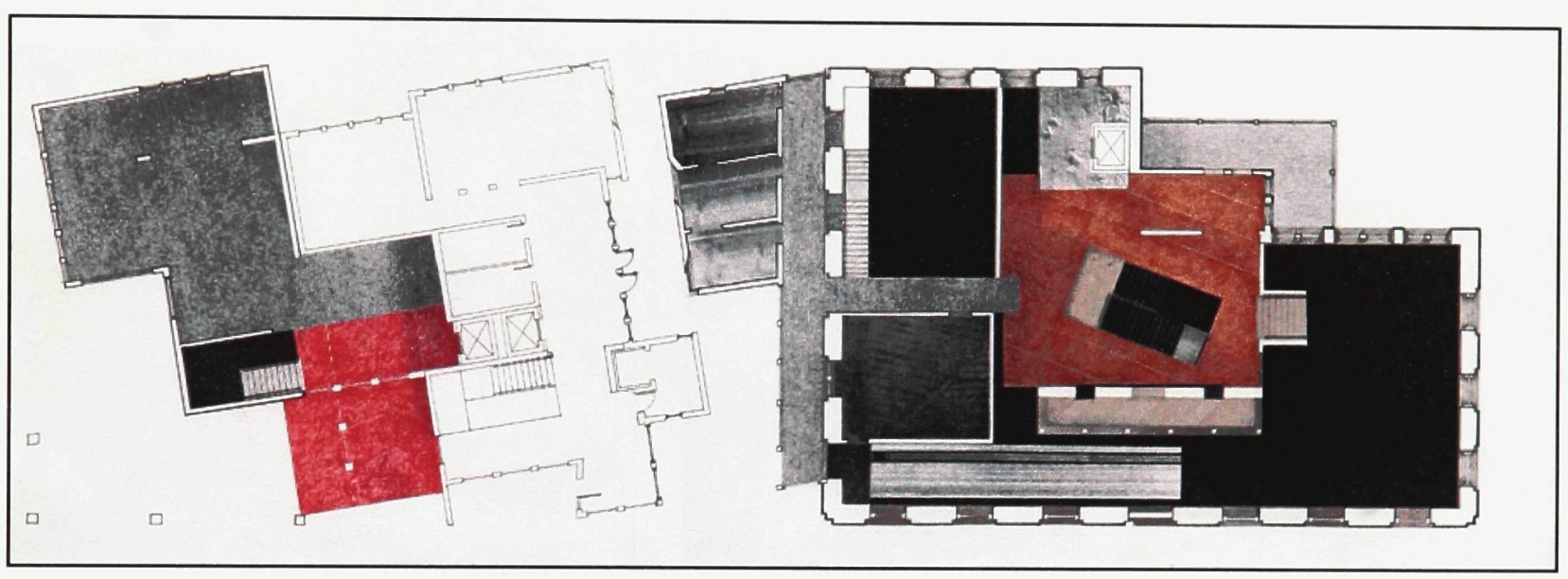

Figure 32 Ground floor plan

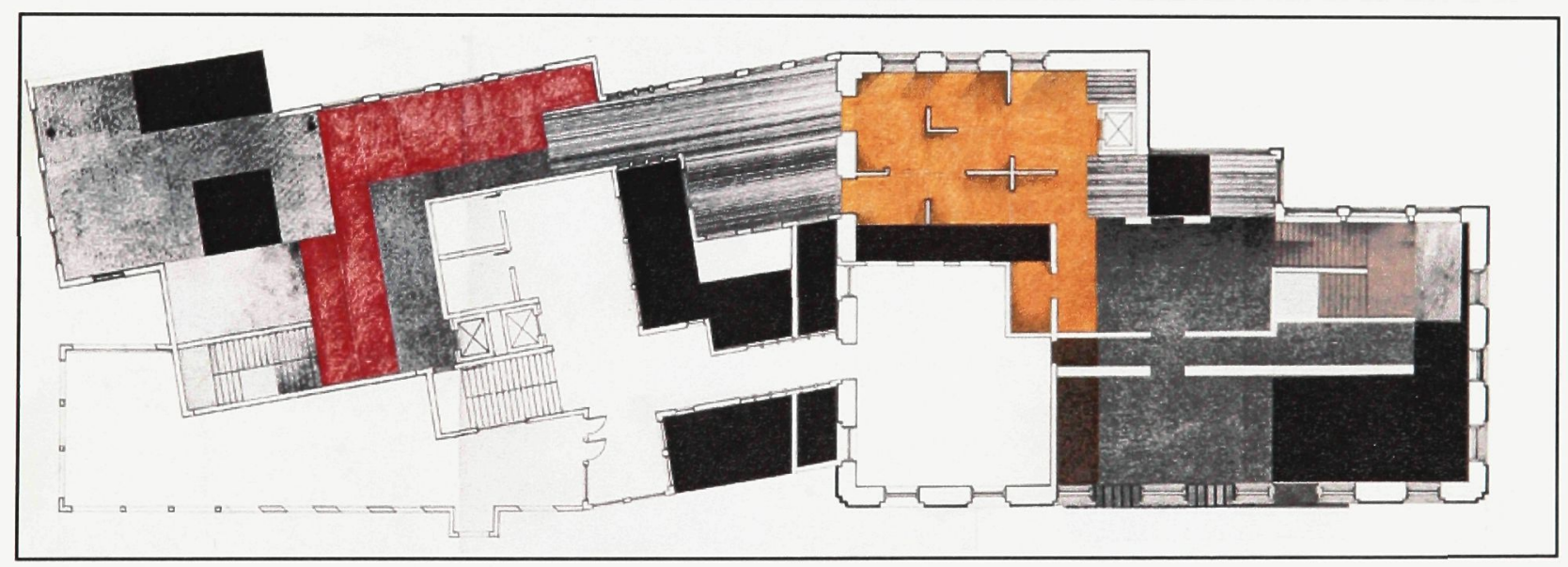

Figure 33 Second floor plan 


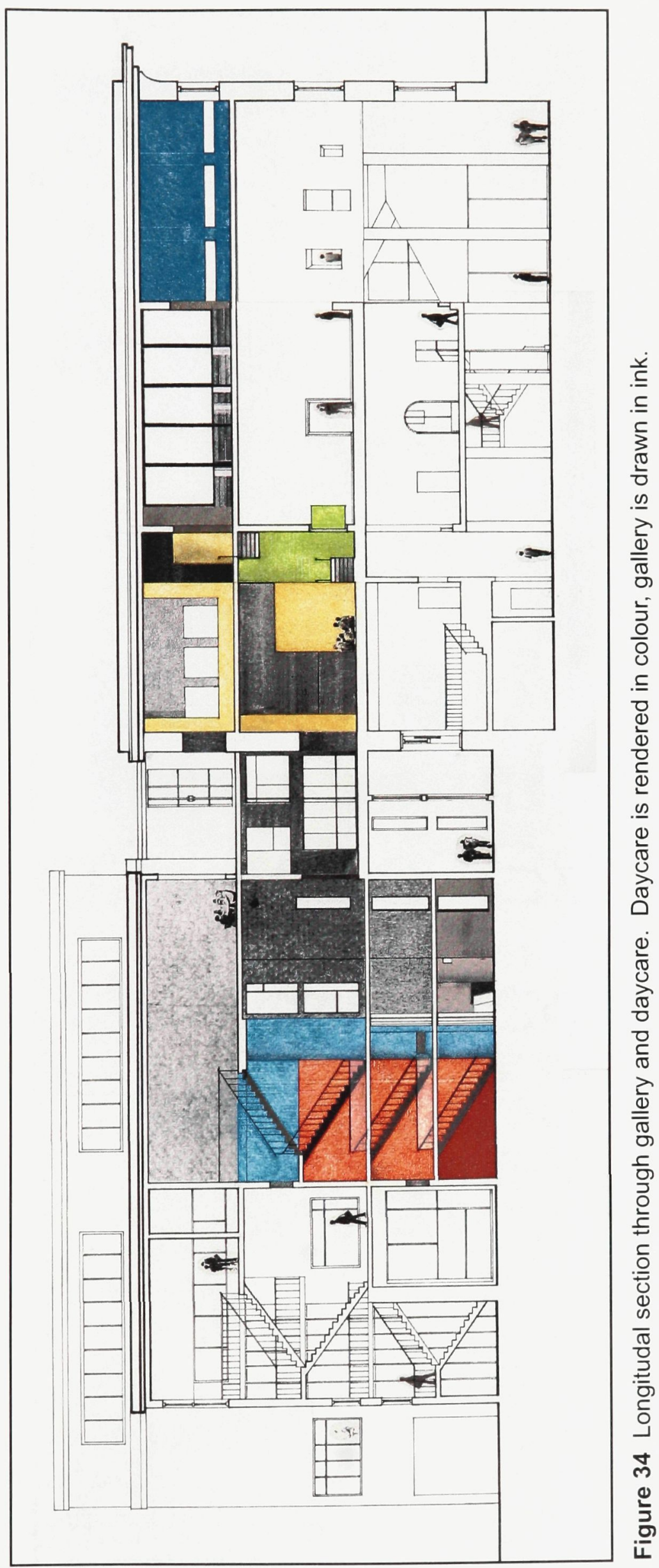




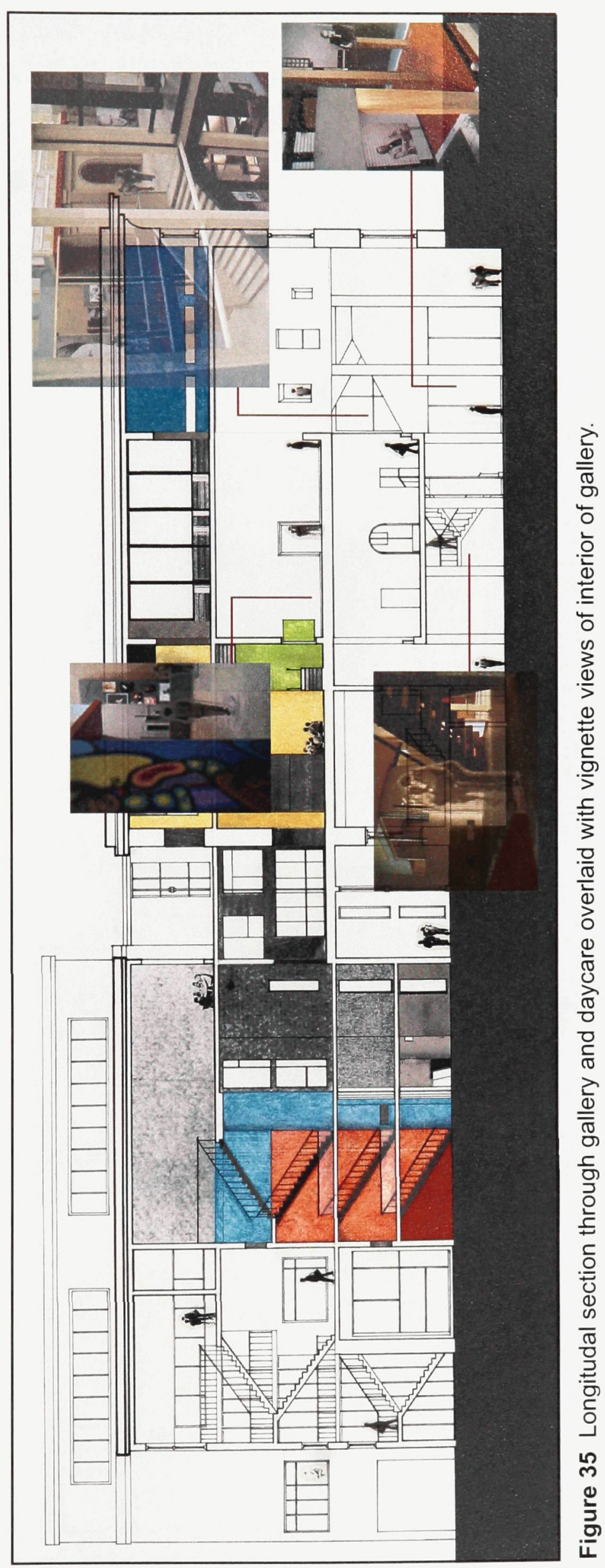




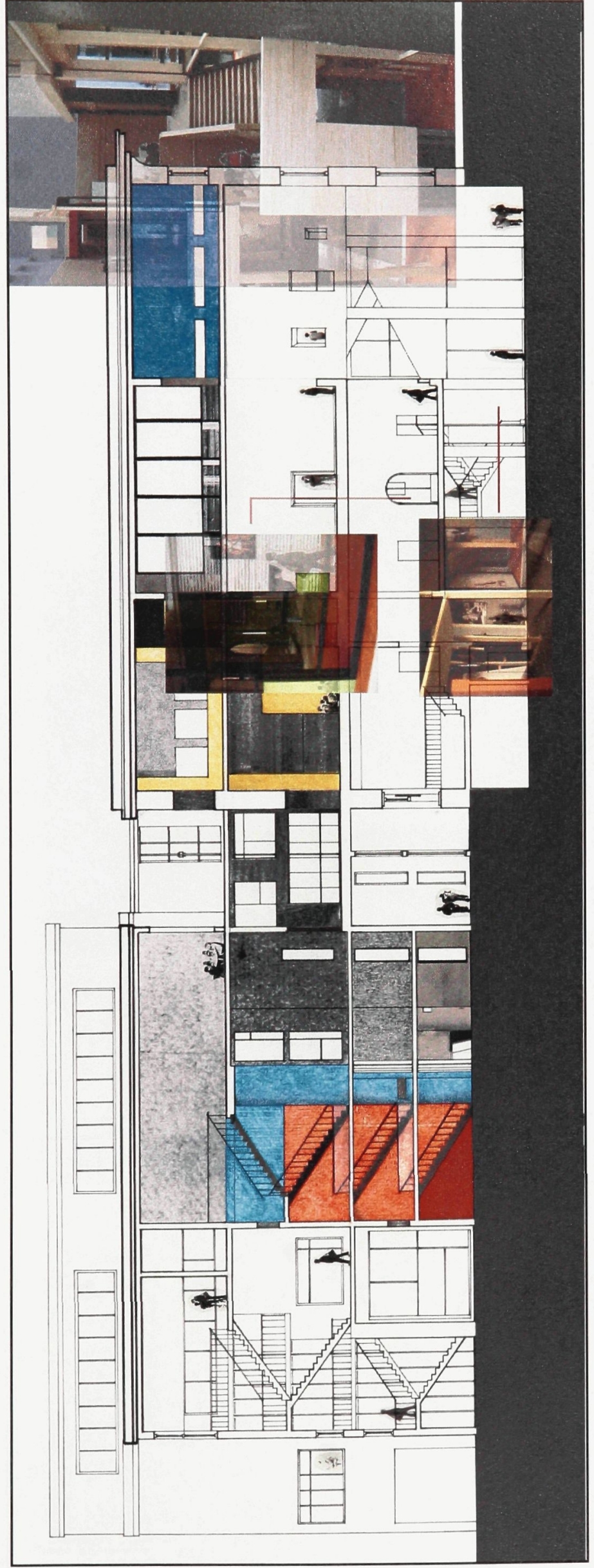

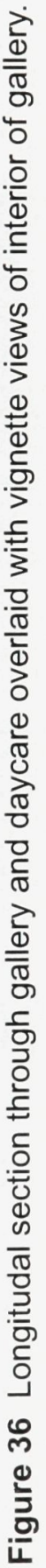




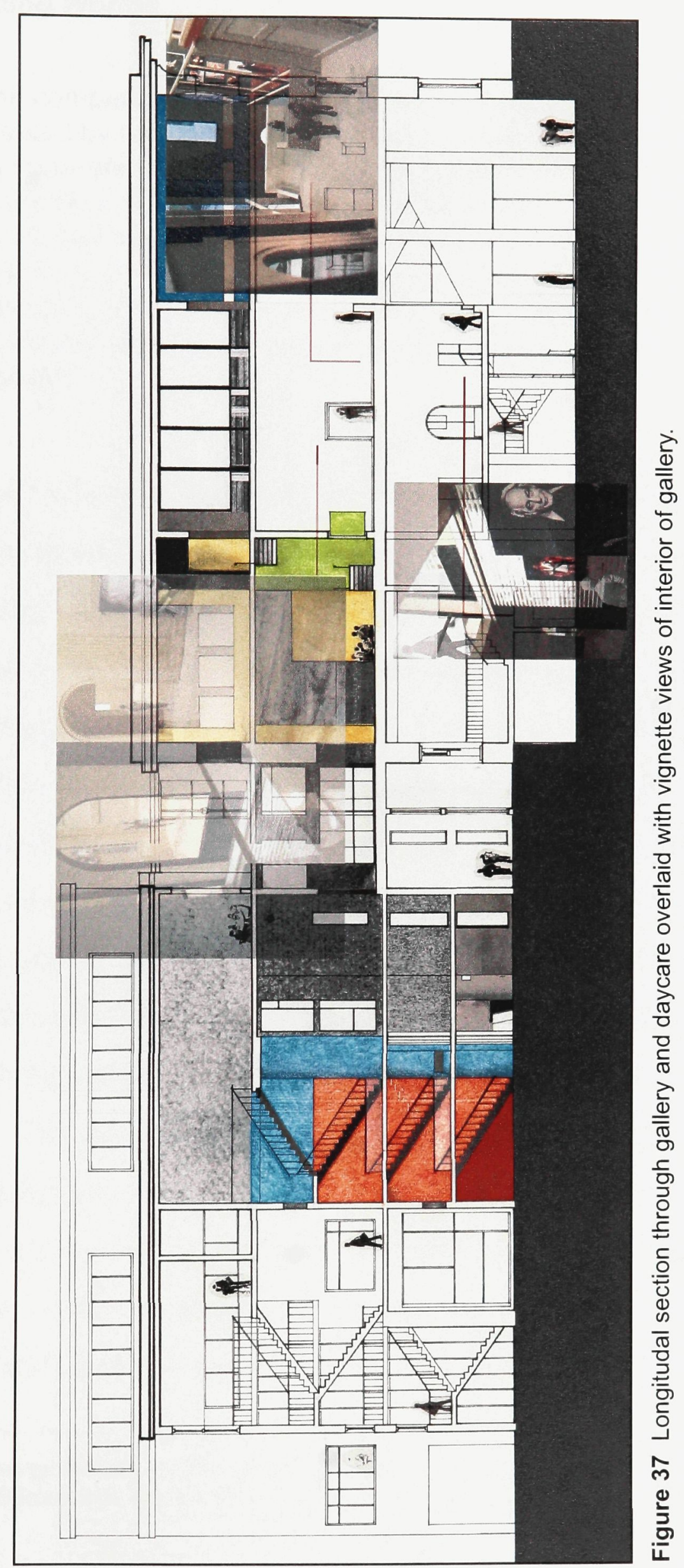




\section{Intertwining Worlds}

The comparison between the forms of play discovered and created by men, and the uninhibited movement of play exhibited by superabundant life, can teach us that precisely what is at issue in the play of art is not some substitute dream-world in which we can forget ourselves. On the contrary, the play of art is a mirror that through the centuries constantly arises anew, and in which we catch sight of ourselves in a way that is often unexpected or unfamiliar: what we are, what we might be, and what we are about. $^{24}$

The inclusion of a children's gallery into the museum's program can be seen as a conscious aim to consider the child's perspective in the act of viewing and learning about art. With the intention of providing a dynamic and educational environment, the elements incorporated in the viewing and spatial conditions in a children's gallery are often much more aware of scale, tactility and interactive participation. Instead of adopting a didactic approach, a children's gallery is often the space within a museum that nurtures the improvisational and communicative qualities inherent in the act of play. By considering the qualities inherent in a children's gallery, the design takes impetus from these characteristics as a way of thinking about the relationships and spatial conditions in the design of the entire gallery. At this point, this design project introduces a second program into its proposal. The gallery does not have a space solely dedicated to children but the overall design incorporates the inclusion of a daycare. Regarded as a separate program, the daycare is essentially intertwined into the museum program.

This thesis, therefore, adopts an approach that regards the threshold between museum and daycare as a transparent mirror that not only allows privilege views

\footnotetext{
${ }^{24}$ Hans-George Gadamer, "The Art of Play," The Relevance of the Beautiful and Other Essays, Robert Bernasconi, ed., Nicholas Walker, trans. (Cambridge: Cambridge UP, 1977) 130.
} 
into another way of being but that also reflects a greater understanding of the self.

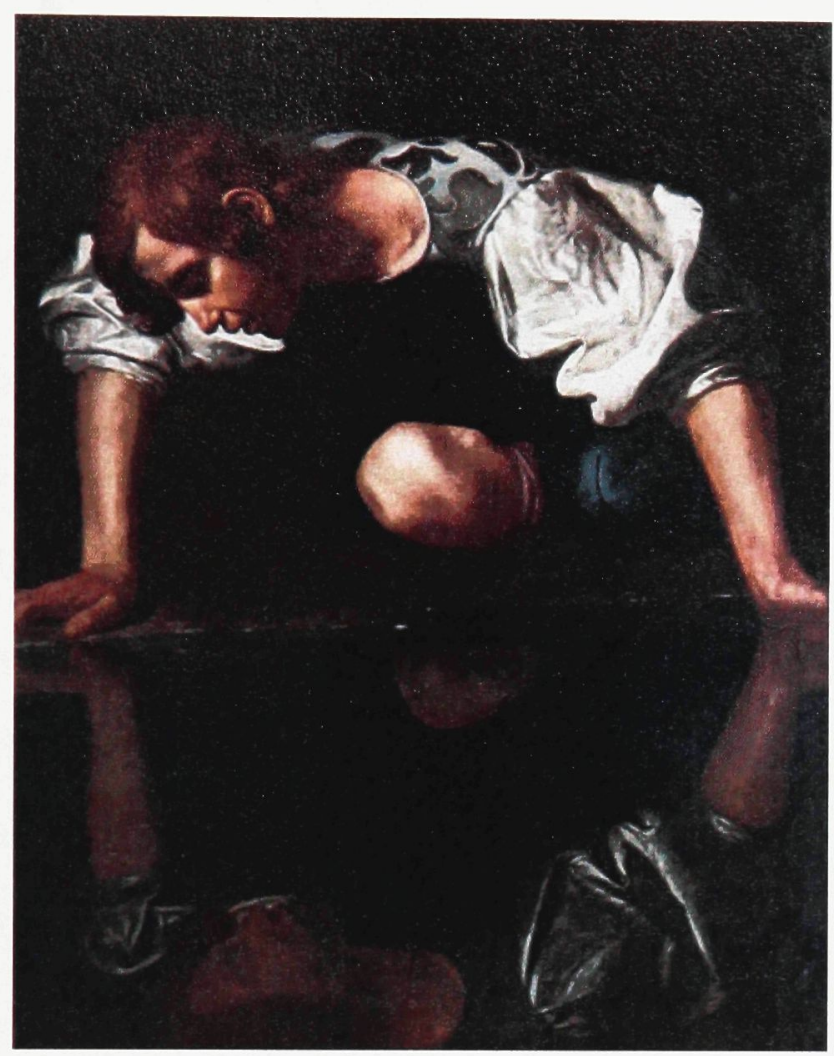

Figure 38 Michelangelo Caravaggio, Narcissus, 159697, Pallazo Barbarini, Rome.

The mythological legend surrounding the character Narcissus, who coincidentally is considered by some to be the first subject captured in a portrait, tells the story of a young man who is transfixed by his own reflection in a pool of water. According to Merleau-Ponty, inherent in all vision is the element of narcissism. ${ }^{25}$ Although the conventional understanding of narcissism is associated with negative traits such as an exaggerated sense of self-importance and self-absorption, author David Levin argues that Merleau-Ponty's translation of the condition allows for an alternative understanding of why it is important to

\footnotetext{
${ }^{25}$ Maurice Merleau-Ponty, The Visible and the Invisible, (Evanston: Northwestern UP, 1968) 139.
} 
first be narcissistic in order to see outside of oneself. He states,

Narcissism for [Merleau-Ponty], is a seduction of the ego, drawing it out of itself into a process of education: it is an alienation that can be reappropriated. Because the other is the medium through which this takes place, the being that is achieved constitutes an identity informed by a differentiated recognition of the other as both same and different: sharing a universal flesh, yet also irreducibly and absolutely different. ${ }^{26}$

Therefore, instead of regarding the pool of water as the element that locks Narcissus into a state of self-absorption, the pool of water is actually the medium that can elicit a moment of greater self understanding, if Narcissus was able to see its potential to do so. The boundaries between the spaces of the museum and the daycare, analogous to the pool of water, can be seen as a condition that is at times transparent, at times opaque and at other times both. The views to and from are not easily granted, however. Apertures and vantage points do not necessarily line up between the two programs. Drawn in by a sense of curiosity or inquisitiveness, a conscience effort or participation is required from both "sides" of the threshold in order to gain a peek. As an act of role reversal, much of the transparency is

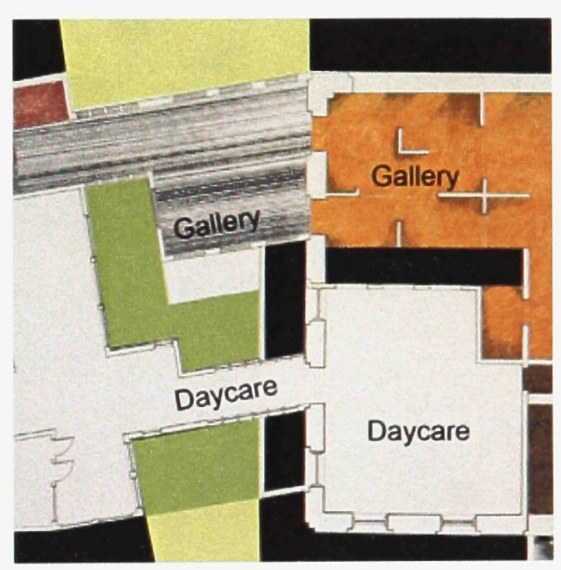

Figure 39 Detail of second floor plan, in between existing controlled by the daycare. Many times it is up to the children and users of the daycare to slide partitions and uncover openings to change the opaqueness of a boundary. Additionally, at times the proportions

\footnotetext{
${ }^{26}$ Levin, David Michael., "Visions of Narcissism: Intersubjectivity and the Reversals of Reflection," Merleau-Ponty Vivant, ed., M.C. Dillon, (Albany: State University of New York Press, 1991) 62.
} 
of the apertures are scaled to a children's vantage, thus requiring an adult gallery visitor to conform to a child's stature. Although the separation between programs is important, due to security and safety reasons, there are moments where programs cross over one another and share a common space. In the space between the existing building and the addition, bridges for the circulation of gallery visitors and bridges for the daycare act as connections between the old and new buildings. The ground floor of the same space is a public passage and therefore this interstitial space is one that physically acknowledges the coexistence of programs.

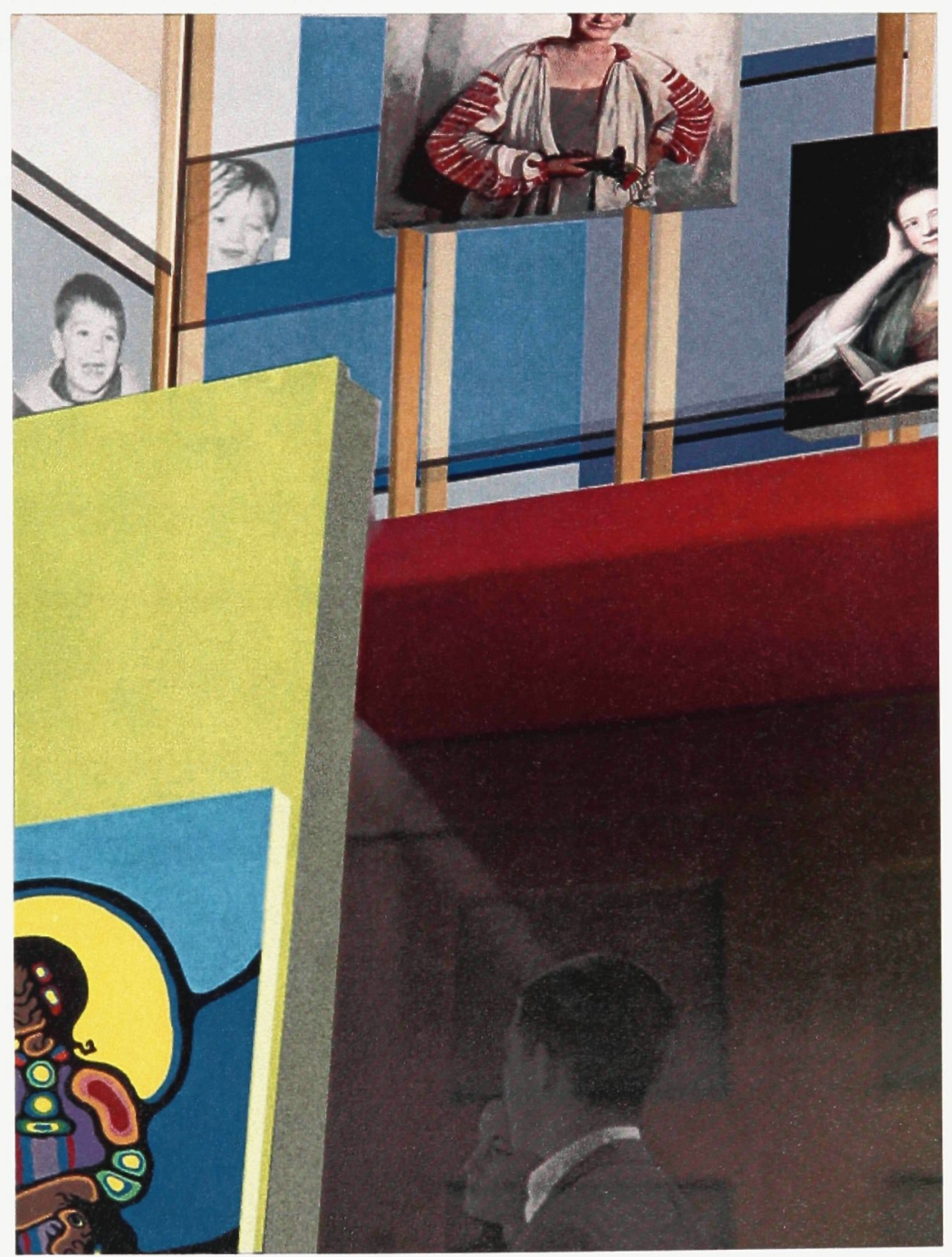

Figure $\mathbf{4 0}$ Interior view of gallery and daycare 
To continue the discussion on the association of the concept of narcissism with the inclusion of the daycare, there is a quality of narcissism as defined by psychoanalysis that is inherent in children, that, in turn, is tied to contemporary notions of identity.

What [is] called primary narcissism refers to the condition of the infant prior to the emergence of a stable ego- structure; it was thought to be - and was seen as - an autoerotic state of symbiotic, relatively undifferentiated awareness in which the differences between self and world, self and other, subject and object were not yet stabilized in a dialectic of oppositions. Because of this alleged primal fusion, this ontological state of "confusion", the dimensions of the infant's being were thought to be virtually coextensive with the dimensions of the world. ${ }^{27}$

This state of narcissism experienced in infants is remarkably similar to an understanding of identity embodied in contemporary discourses and represented in contemporary portraits. In this initial stage of development, a child is unable to distinguish his/her own identity from others and therefore a child's identity is in-process and dependent on multiple factors. Paradoxically, a mature intersubjective understanding of one's identity is actually gained through a child's "immature" understanding of the self. The notion that the aspect of play embodied in children is also inherent in the creative process of making and viewing art, as theorized by Gadamer, specifies that in its most essential capacity art facilitates moments of greater awareness - much like a child's ability to remind us to appreciate the simplicity of things.

${ }^{27}$ Levin, 50. 


\section{Moment of Weakness}

Architecture isn't exactly silent; it is more like a conversation in lowered voices. Ideas are present, but the true effort lies in making then invisible. ${ }^{28}$

Aside from examples that resort to a practice of literal representation that result in the perpetuation of classifications and types, it is often difficult to identify how architecture affects and is affected by theoretical or philosophical ideas. However, Catalan architect/theorist, Ignasi de Sola-Morales has contributed a way of thinking that takes its impetus from philosophical insights but that is also explicitly rooted in the practice of architecture. Identifying the philosophical concept of weakness as reflective of the contemporary architectural condition, Sola-Morales' theory of weak architecture is not a response to a seemingly impending crisis but is instead a contemplation of what architecture's role may be in such a contemporary landscape.

As is implied in the title of the essay, an understanding of weak architecture requires a craning of the neck and the turning of a phrase. The practice of being weak lies in the subtle re-appropriation and the "folding back" of definitions and conventional modes of understanding. Sola-Morales takes inspiration from the Deleuzian concept of pli or fold in order to re-evaluate and repossess ownership of discarded terms such as "decoration" and "monumentality". The notion of the fold is provocative as a contemporary vision of reality since it does not represent a model with two polar conditions but is instead made of one

${ }^{28}$ Ignasi de Sola-Morlaes, "An Eclectic Panorama," Contemporary Spanish Architecture (New York: Rizzoli, 1986) 34. 
continuous surface. In his twisting of the understanding of "decoration", SolaMorales takes a critical approach in order to draw out the concept's essential quality.

[W] hat I have called weak architecture is always decorative. Let no one be shocked: decoration is a parole maudite, a dirty word in the modern tradition, yet there is nonetheless a clear need to go back and reflect on the significance of the term and on the fundamental meaning of the notion of decorum that underlies that of decoration...Decoration, then, or the decorative condition of contemporary art and architecture, not in the sense of vulgarity, of triviality, of the repetition of established stereotypes, but as a discreet folding back to a perhaps secondary function, a pulling back to a function that projects beyond the hypothetical ground of things. ${ }^{29}$

Therefore, a practice of architecture that adopts an understanding of the decorative, in its "weak" definition, is one that is not rooted in the superficial but instead embodies decoration's ancillary function - essentially a practice that does not presume to be of central importance or that embodies universal values. By enacting a process of "folding back", a practice of weak architecture offers insights that are neither nostalgic nor presume to be revolutionary in nature.

Sola-Morales' notion of monumentality is especially intriguing and significant to the discussion of identity. Weak architecture finds significance in the quality of monumentality that is rooted in the collective and of recollection and not in traditional notions of monumentality that imply ideas of permanence, grandeur, and opaqueness. In this altered understanding, monumentality is

${ }^{29}$ Ignasi de Sola-Morales, "Weak Architecture", Differences: Topographies of Contemporary Architecture, Sarah Whiting, ed., Graham Thompson, trans., (Cambridge, MA: MIT Press, 1997) 70. 
manifested not in its physical presence, as much as it is embodied in its affect on multiple layers of experience in space and time. Central to the weak insight is an understanding of space that is inseparable from a fragmented notion of time. This notion of temporality does not present itself as a continuum, but rather, is experienced in discreet moments. Therefore a notion of monumentality that is experienced in a single moment can be likened to, as Sola-Morales eloquently puts it, "the tremulous clangor of the bell that reverberates after it has ceased to ring; as that which is constituted as pure residuum, as recollection." ${ }^{30}$ Like Nancy, the emphasis here is also placed on the shared aspect of existence and the architectural relevance stems from architecture's capacity to provide space and time for this experience. An architecture that

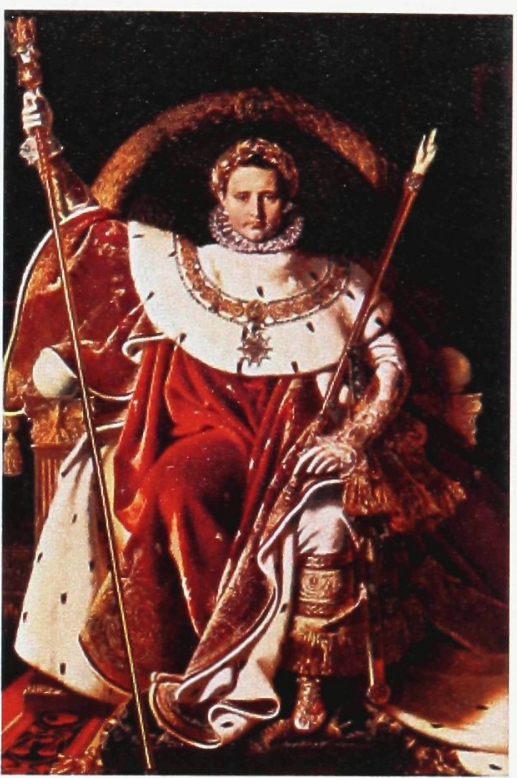

Figure 41 Jean-AugusteDominique Ingres, Napoleon 1 on His Imperial Throne, 1806, Musée de l'Armée, Paris. represents a collectivity solely through signs and symbols fails to offer any sort of significance that goes beyond the represented image - they lose their power once it is discovered that it is all they embody. But an architecture that sensitively situates itself within a physical and discursive site and creates the context for dialogue to occur has the potential to be part of the collective social psyche. An architecture of weak monumentality does not strive to represent its significance but embodies significance through its contribution to lived experience. An architectural practice that hopes to embody an aspect of a Canadian identity and that exists within the collective consciousness embraces its weakness and is

\footnotetext{
${ }^{30}$ Sola-Morales, 72.
} 


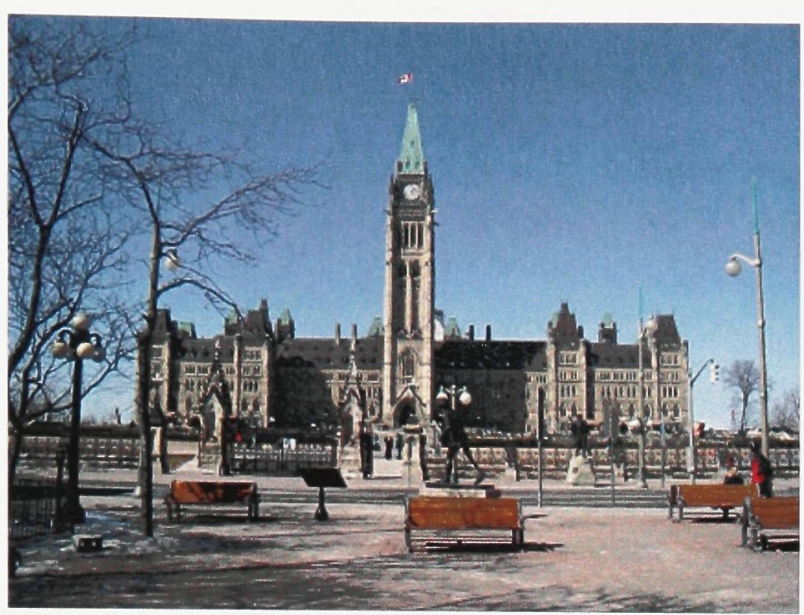

Figure 42 Parliament Building

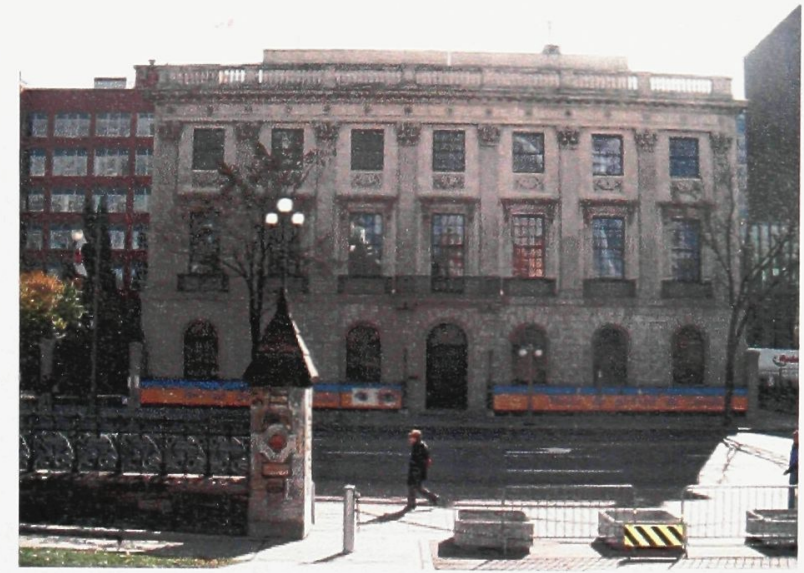

Figure 43 Chancery Building

inherently monumental. Therefore, a strategy such as this can begin to inform an attitude towards the old, and in particular, a design approach for the integration of an addition to the former U.S. embassy.

Constructed in 1931-32, the Chancery building, as it is formerly called, is a testament to the Beaux-Arts architectural style typical in the United States during that time.$^{31}$ [Refer to Appendix B for building plans.] The PGC project mandate requires that the former U.S embassy be restored and for either renovations or enhancements to respect its "heritage status". In the effort to "preserve"32 the building in its original state, any addition to the existing is not to make any indelible marks that would harm the integrity of its heritage. An approach towards the "old" such as this is representative of a way of thinking that is still

\footnotetext{
${ }^{31}$ Information of the Chancery building provided in section 2.1.5, entitled History of the Site in the PGCPM.

32 The "preservation" and "conservation" of historical artifacts is highly a contentious discussion and theoretical issues often represent opposing perspectives. Refer to Nicholas Stanley Price et al, eds., Historical and Philosophical Issues in the Conservation of Cultural Heritage (Los Angeles: The Getty Conservation Institute, 1996).
} 


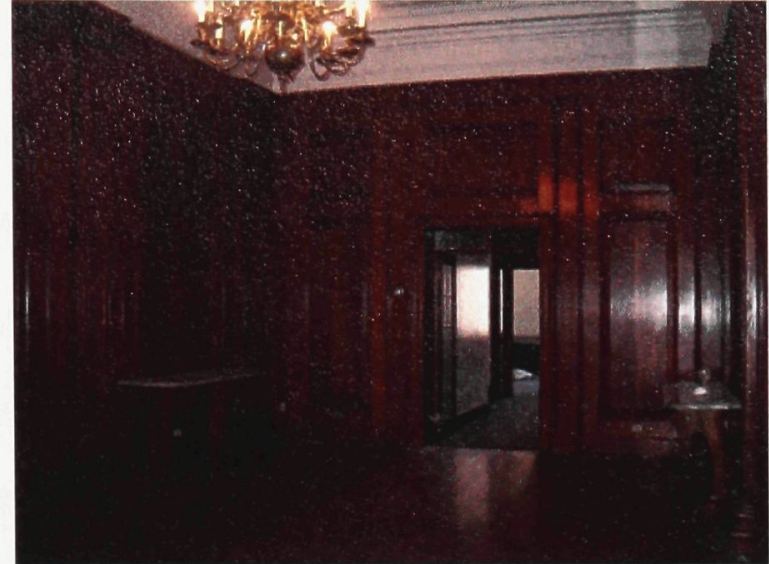

Figure 44 Reception room of Chancery Building

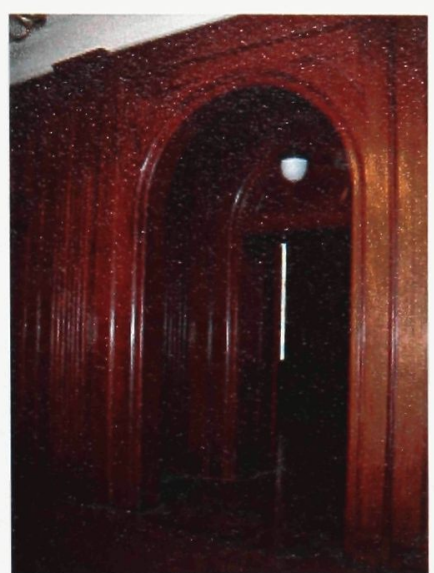

Figure 45 Doorway to Ambassador's office

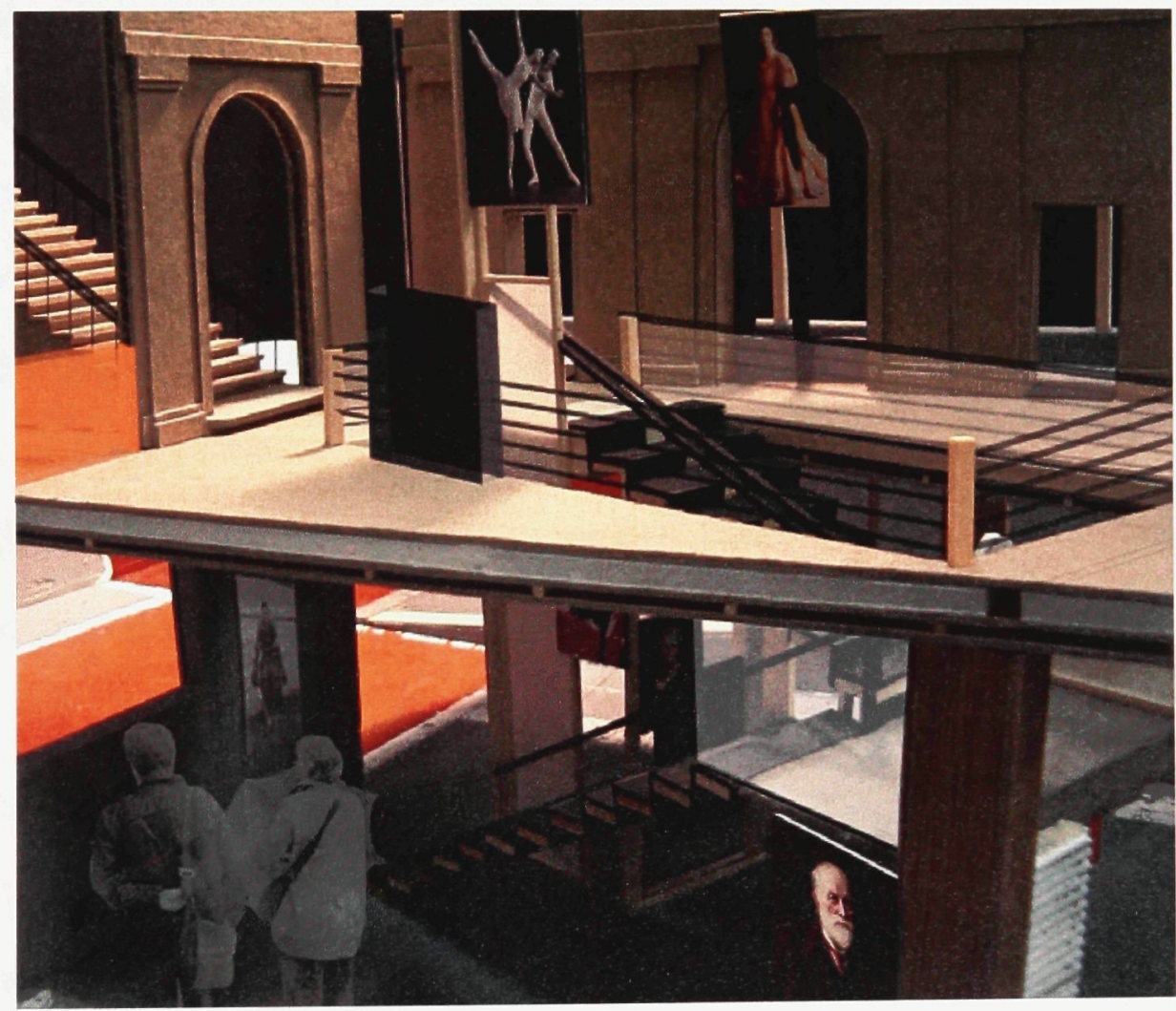

Figure 46 Sectional view of interior gallery space within the exisitng building. 
tied to a notion of monumentality that can only be expressed by the permanence of physical presence and literal substance. Just as traditional portraits rely on mimetic representation to express a subject's authority and immortality, the architecture of monumentality relies on signs and symbols to convey meaning and importance. However, an attitude of weakness recognizes the power of monumentality to be in its ability to leave a trace. Because the aspect of recognition is integral to an experience of shared recollection, leaving physical traces of the existing building can elicit such experiences. The intertwining of old and new spaces, highlight the unique qualities of each - an awareness that could not be gained otherwise. To avoid a proposition of a portrait gallery that relies solely on an existing condition to structure the way visitors move through and inhabit space, the design needs to critically respect the building's existing condition, without being limited by it. Its old tenants have moved out, the building has a new purpose. Therefore, in order to infuse a building with a new life, it must be re-imagined based on the understanding of space and time that is not stable and that cannot be captured in the "preservation" of edifices. By making a monumental impression through an approach such as this, a work of architecture leaves a trace through the recollection of a shared experience.

For Vattimo, the "end of history" signifies an end to a linear understanding of time that is characterised by the progression of events within a singular "metanarrative" ${ }^{33}$. The understanding that comes from the acknowledgment

\footnotetext{
${ }^{33}$ Jean-François Lyotard discusses the universal nature and implicaions of grand narratives on the legitimacy of the production of knowledges in the essay, "The Postmodern Condition: A Report on Knowledge," trans. Geoff Bennington, (Minneapolis: Minnesota U.P., 1984).
} 
that there exists multiple, intertwining histories and points of view implies that neither a universal nor a shared notion of "truth" can exist. Instead of viewing such an understanding as nihilistic, in a debilitating sense, a weakness of thought embraces this contemporary condition as it embraces "monumentality". The inherent attitude that accompanies weak thought does not either dismiss or look to replace the linear understanding of history for a new structure, but employs a weakness of thought to the understanding that history can be interpreted as a palimpsest that reveals layered traces of specific moments in time and space.

Weak thought, in general, and the ideas implicit in weak architecture as specified by Sola-Morales are useful in informing an architectural practice today - a practice seeped in, and dependent on the fast moving currents of multiple worlds. In a contemporary landscape that is quick to discard, privileges the so-called "new" and is still unsure of what to make of tradition and history, an approach of weakness provides not a protocol for working but instead offers an un-foundational attitude that influences the multiple aspects of life. Purposively abstract, weakness suggests that every creation of a new work of architecture does not need to make a bold statement to be heard and concurrently, that looking at a given situation in a particular way can often yield an innovative alternative. 


\section{In-formed Vision}

Although the space of intersubjectivity is encountered through the recognition of a shared existence - a social space in which one's identity is shaped in others and returned, the nature of viewing art and portraiture, in particular, is most commonly addressed to the individual viewer. The traditional way in which a work is displayed and the way one approaches and views a work of art may actually speak more of its false neutral silence than of its ability to demystify the perceptual world. In most cases, art is viewed frontally, on the invisible vertical plane directly in front of our vision. Although this condition of viewing art is taken for granted, a portrait's vertical orientation is rooted in the will to express authority and power. The traditional portrait was of a given dimension and usually oriented vertically with the subject as its central focus. The positioning of the subject on the canvas was a way in which the artist (or perhaps the sitter) expressed a privileged status. For example, portraits that depicted the subject's full body implied that the subject was of a distinguished status. Women were rarely depicted this way. Artist, Marlene Dumas plays on these exact modes of representation of authority to critically call attention to the often-overlooked implications of power in portraiture. In the work, "The Particularity of Nakedness", the artist depicts a male nude in a horizontal position and thus making the direct correlation between the vertical format and the overt masculine expression of power. By essentially objectifying the male subject, Dumas' art plays with viewing conditions through the reversal of orientation and the exploitation of the human body's inherent horizontality. As coined by Yve-Alain Bois and Rosalind Krauss, horizontality refers to the state of mind associated with the act of going from a vertical posture to one that is horizontal. 
Inherent in this act is the recognition of one's "baseness", that is, the human primal tendency to occupy the horizontal plane. An approach of horizontality, essentially, acknowledges the existence of the body in the act of viewing art. The architecture of conventional art galleries, though, set up viewing conditions that promote an "out-of-body" experience. According to Yve-Alain Bois, "Vertical, man has no other biological sense than to stare at the sun and thus burn his eyes or to contemplate his feet in the mud: his present architecture, by means of which his horizontal gaze traverses a vertical visual field, is a travesty." ${ }^{34}$ The spacing and isolation of individual works of art encourages moments of un-interrupted meditation and contemplation. This inherently vertical and frontal experience contradicts the carnal aspect embodied in the creation and expression of art. In order to

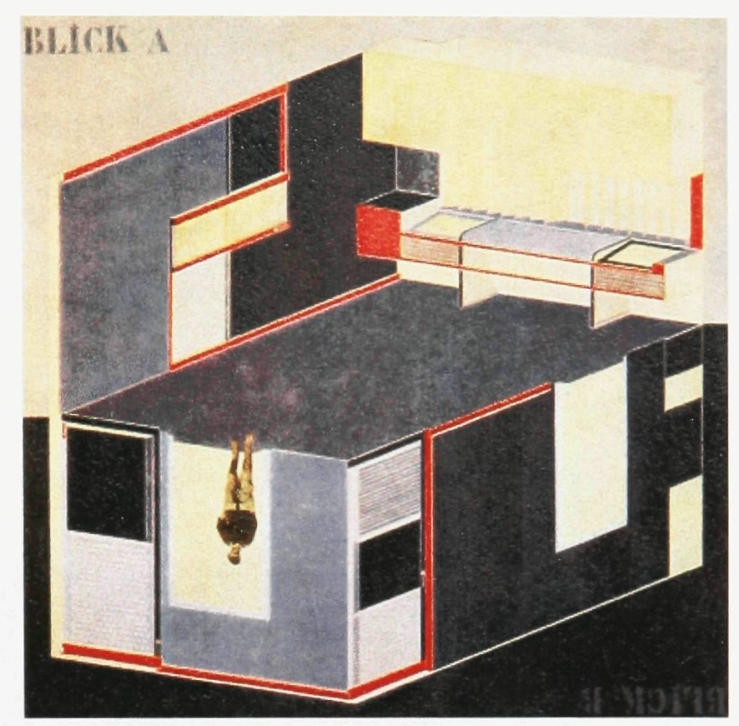

Figure 47 El Lissitzky, Design for the first Exhibition Room, International Art Exhibition, 1926, Niedersächsische Landesgalerie, Hanover.

Contingency and particularity are the prime features of Lissitzky's design for the First Exhibition Room. The paintings and sculptures on display in these exhibition/ museum spaces are no longer presented as epiphanic moments but are conceived with the viewer's participation in mind.

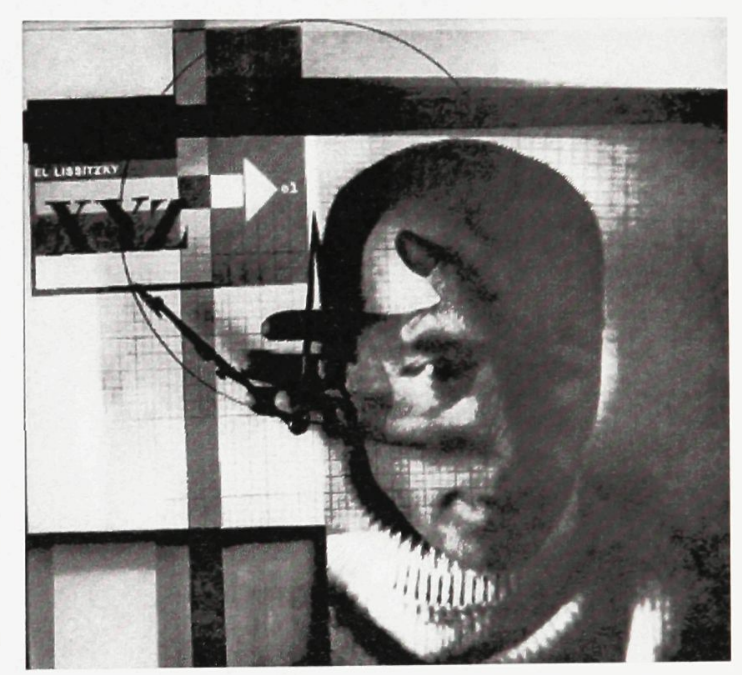

Figure 48 El Lissitzky, Self-Portrait, 1924, location unknown.

\footnotetext{
${ }^{34}$ Yve-Alain Bois and Rosalind E. Krauss, "The Use Value of 'Formless'”, Formless: a User's Guide, (New York: Zone Books, 1997) 26.
} 
conjure up a vision alternate to that of a flattened, two-dimensional image, the experience of viewing art must consider occupying the theoretical plane of the horizontal. This does not mean, however, that architecture should force people to view art on their hands and knees, rather, that architecture has the capacity to elicit the recognition of one's body (and therefore the "bodies" of others) and mortality in space-time through a viewing that requires the participation and

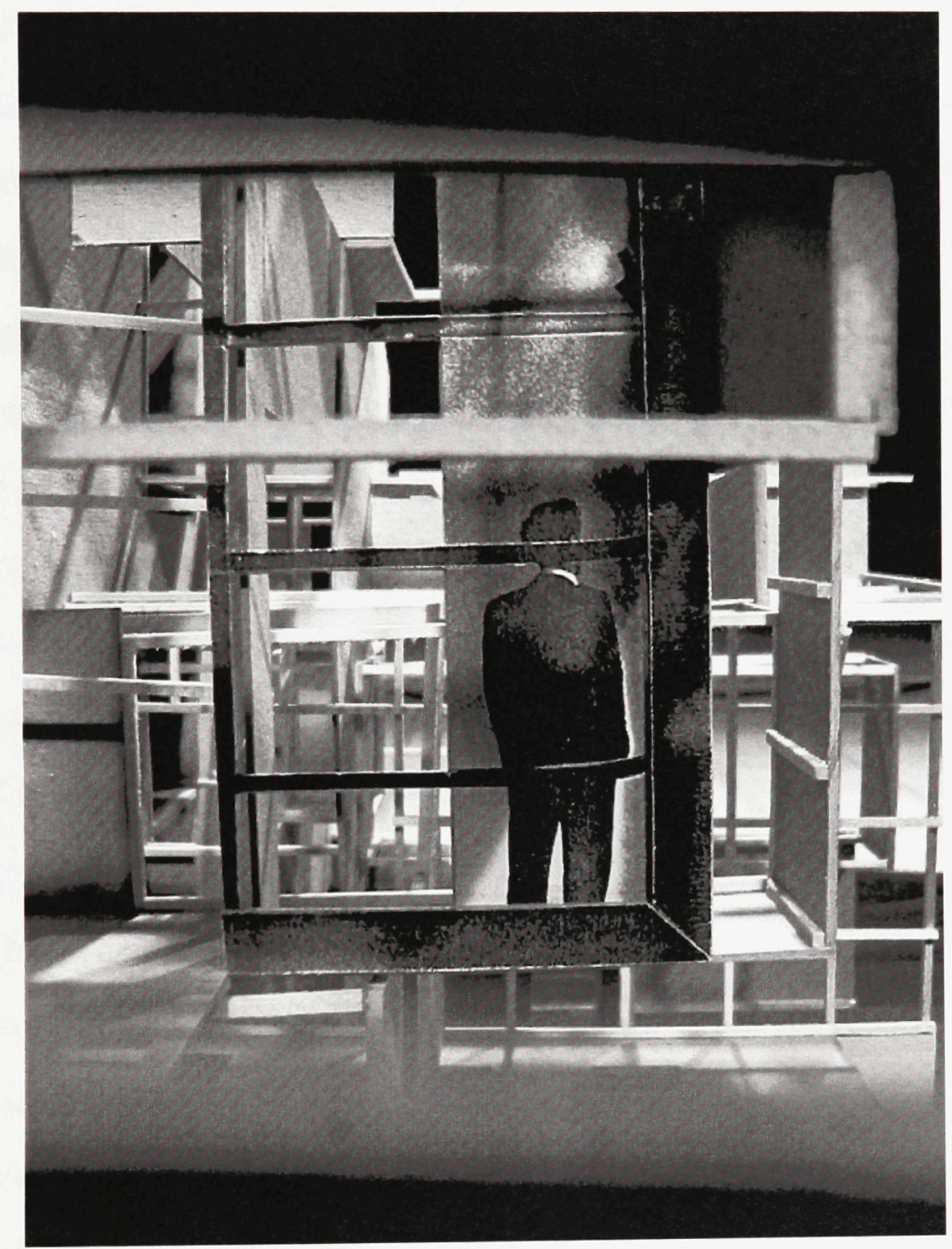

Figure 49 View of conceptual model 
involvement to see, to see-behind, to see-beyond and to be seen.

Canadian artist and filmmaker, Michael Snow acknowledges primal instincts in works of art that force viewers to navigate the fine line of seeing and being seen. The work entitled, Portrait, consists simply of an aluminum frame whose dimensions can be modified to conform to the particular site it is framing. The work is essentially two-sided - the viewer may in fact be the viewed at any given moment and vice-versa. Portrait is a frame that does not frame a specific person or event but instead frames people at various times; it frames the literal space of embodiment and the conceptual space of thought. Its simple structure heightens one's awareness and therefore ruptures the monotony of the gallery experience by reversing one's vision back onto the self. Snow's work is essentially just a frame but its existence in a gallery setting, and its contrast against the conventional exhibition of other work's, instantly calls attention to the bodily participation involved in viewing and can thus be incorporated into an architectural proposition that hopes to elicit such an experience. Juxtaposing conditions of viewing art with conditions of viewing across and through spaces facilitates a heterogeneous environment that consists of a constant fluctuation of experiences. The act of viewing art, the privilege of viewing others and the consciousness of being viewed, are conditions that can be overlapped and simultaneously experienced through the articulation of spaces. And, therefore, considerations that incorporate the various implications of viewing do not confine the creation nor the viewing of art as a solitary, epiphanic moment but instead opens the experience up as an intertwining of subjectivities. 
Since artists have always been inspired by the way museums operate and exhibit works of art, as seen in the works of Duchamp, Buren and Snow, a re-contemplation of the way art is exhibited creates the opportunity for existing works of art to project new messages while providing a new framework for the conception of future artworks to comment. While works of art that comment on the institution of the museum often use the existing infrastructure and conventions of viewing to subvert traditional notions, there exists unique works of art that force their contexts to conform to them. The use of visual allegory makes Hans Holbein's, The Ambassadors [Figures 50, 51], one of the most interpreted and examined works of art in history. The life-size, double portrait depicts an anamorphic representation of a scull, a common metaphor for mortality, as a reference to the limitations inherent in vision.

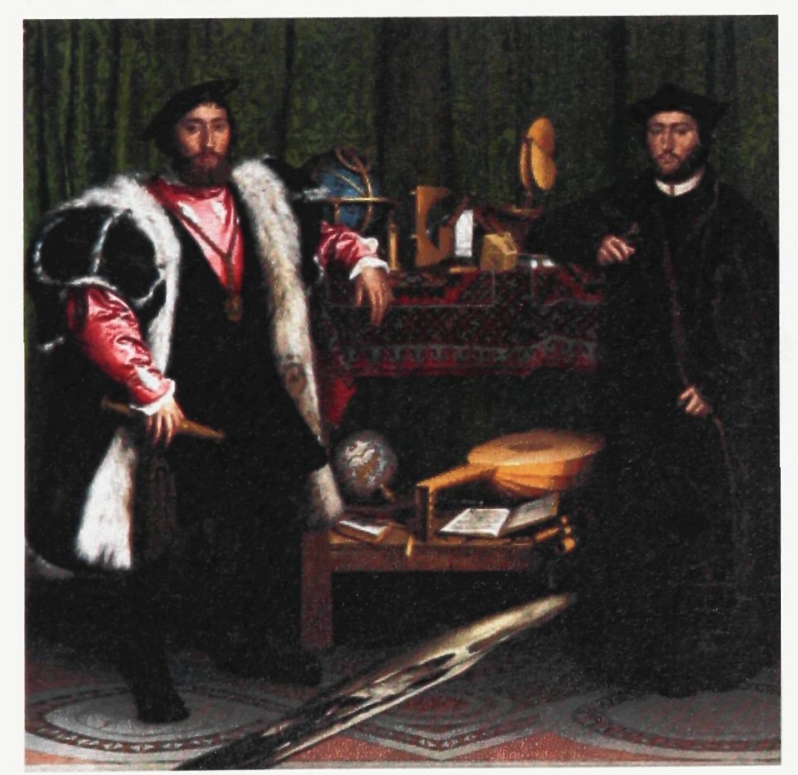

Figure $\mathbf{5 0}$ Hans Holbein, The Ambassadors, 1533, National Gallery, London.

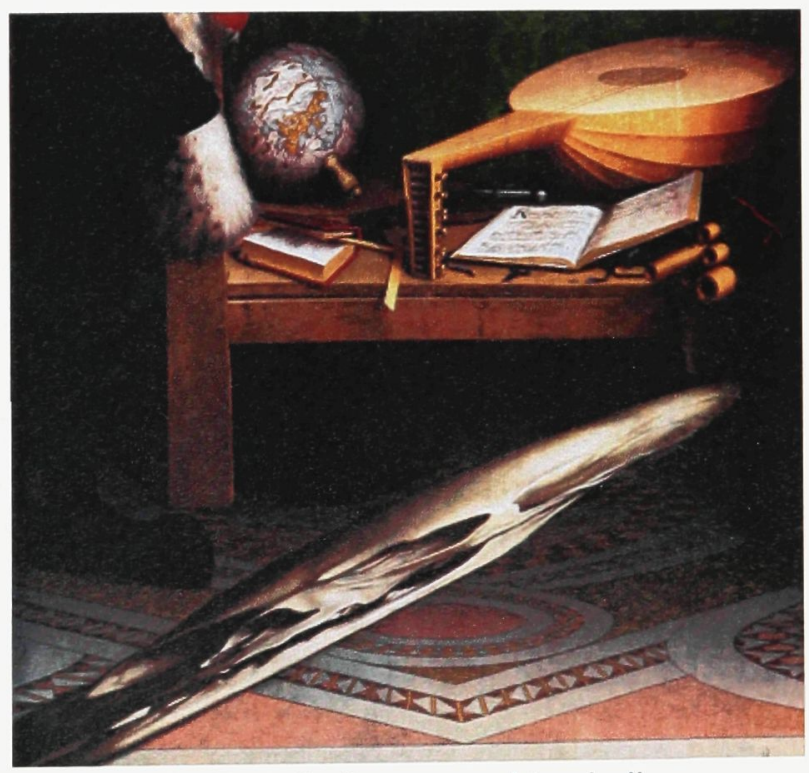

Figure 51 Detail of anamorphic skull. 
Whereas other portraitists who wished to separate the imitation of mortality from the main depiction would paint in on the back of the panel, Holbein boldly conceals his skull on the front of the portrait. The fact that its shadow falls in the opposite direction to others in the painting may serve to indicate the presence of an object from a dimension beyond the temporal. ${ }^{35}$

The use of anamorphosis in the painting suggests a presence that is neither here nor there - one that exists in between and comes in and out of our perceptual realm based on the viewer's approach and the vantage. Taking into consideration the anamorphic perspective that must be taken to "see" the skull, the display of the painting in the National Gallery in London, brings the canvas forward and lower on an extended portion of a wall, while also, dispensing with the conventional barriers allowing visitors to gain the optimum angle for viewing. Adopting an anamorphic posture may indeed grant a view of the skull "corrected", but more importantly, a reversal occurs in the distortion of the rest of the painting allowing for an alternative view of not just the skull but of the Ambassadors as well. Through the granting of the frontal view of the skull, the authority and privilege of the Ambassadors is revealed as superficial and

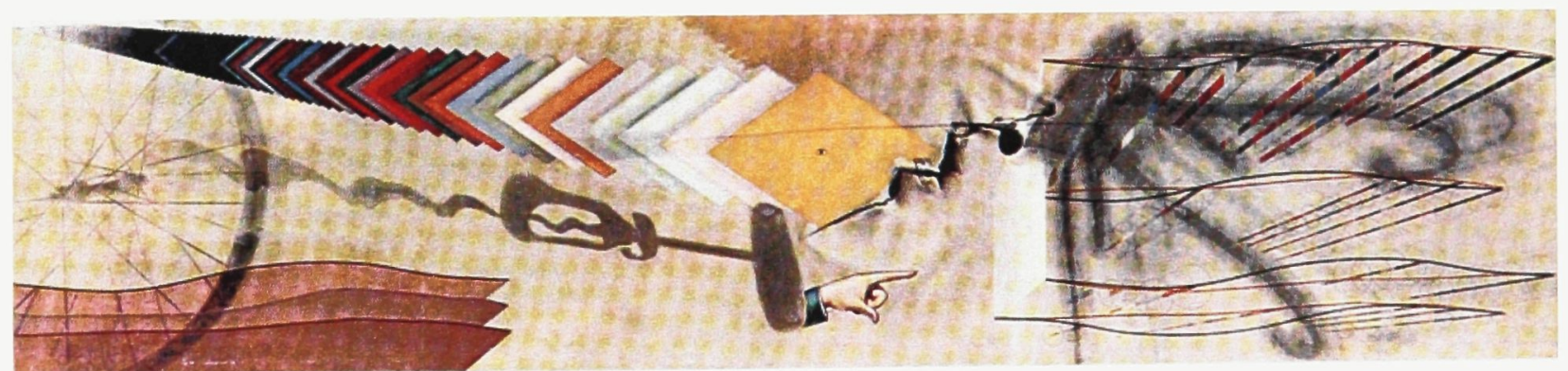

Figure 52 Marcel Duchamp, Tu'm, 1918, Yale University Art Gallery, New Haven. This anamorphic, multi-media work by Duchamp incorporates some of the artist's well known motifs.

${ }^{35}$ Susan Foister et al, Holbein's Ambassadors, London: National Gallery Publications, 1997, 48. 
skewed representations, lasting only as long as their mortality. Therefore, an architectural approach of anamorphosis can also be incorporated in the viewing of works of art that do not require to be seen from acute angles. Portraits that may be contemplated from various vantages, allows a viewer to elicit alternative interpretations of a work that cannot be gained from strictly vertical and frontal planes. An anamorphic approach such as this does not necessarily inform a literal practice of viewing but can also be regarded theoretically - as a shift in attitude that allows the possibilities of new worlds to be opened up. By allowing the freedom to move and oscillate between various points of view, the seemingly impossible is given a chance to be conceived and thus manifested. 


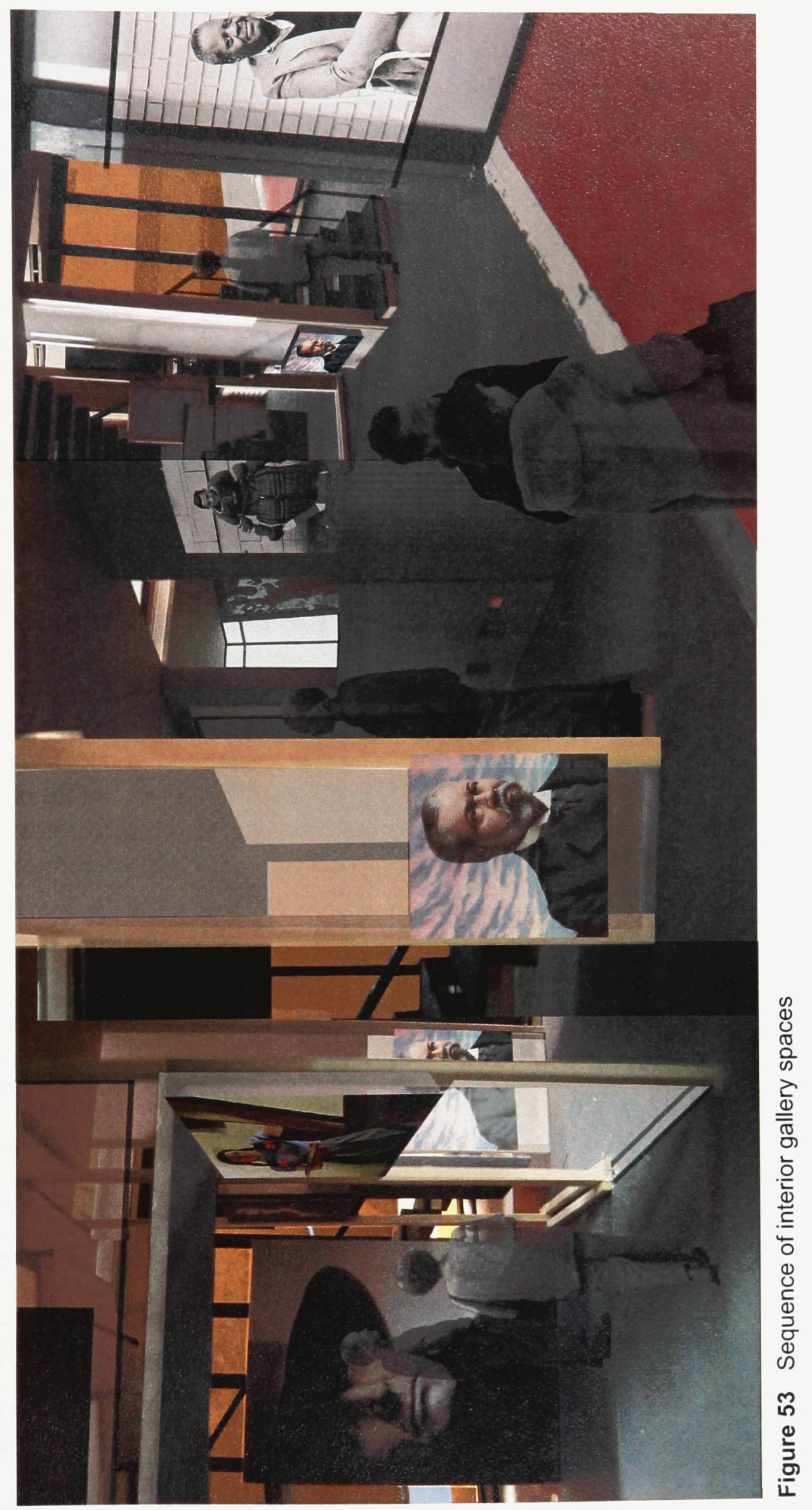




\section{Identity, Interrupted}

I am not I can be you and me. [This] means that I am not I, am within and without i. I/i can be I or i, you and me both involved. We (with capital W) sometimes include(s), other times exclude(s) me. You and I are close, we intertwine; you may stand on the other side of the hill once in a while, but you may also be me, while remaining what you are and what I am not. ${ }^{36}$

Infinite alterity is quite simply what there is. Any experience at all is the infinite deployment of infinite differences [...] But what we must recognize is that these differences hold no interest for thought, that they amount to nothing than the infinite and self-evident multiplicity of humankind [...] The Same, in effect, is not what is (i.e. the infinite multiplicity of differences) but what comes to be. ${ }^{37}$

"I am not I can be you and me." The circularity and overlapping of pronouns in this utterance is evocative of a condition of existence that travels with the ebb and flow of constantly shifting ontological states. Throughout these discussions, an argument has been made on the notion that identity is manifested through a process of identification that is always in a state of

\footnotetext{
36 Trinh T. Minh-Ha, Woman, Native, Other, (Indianapolis: Indiana U.P., 1989) 90.

${ }^{37}$ Alain Badiou, Ethics: An Essay on the Understanding of Evil, trans., Peter Hallward, (New York, Verso, 2002) 25-7.
} 
becoming, that is, a process that never rests on one fixed notion but that it is identifiable with, and in, a specific time and space. The gained understanding of this multiplicity, paradoxically, renders a clarity of vision to "universal" notions of truths and ethics. The discourse on identity politics often makes claim that existing hierarchical structures obscure and oppress marginalized groups in order to fulfill a will of hegemony. As a result of this understanding, recognition of the Other has been fundamental to contemporary theories of identity politics, seen in the proliferation of writings on gender and ethnicity. However, the difficulty with relativised notions such as this is that they are often contingent on specified definitions of what Otherness entails. Alain Badiou explicates,

The problem is that the 'respect for differences' and ethics of human rights do seem to define an identity! And that as a result, the respect for differences applies only to those differences that are reasonably consistent with this identity, as seen by the partisans of ethics, are acceptably different only when they are 'integrated', only if they seek integration. ${ }^{38}$

In this sense, politics of identity and Otherness represents the other side of the same proverbial coin; blind acceptance of differences leads to indifference and remains within accepted realms that seek to define, name, and perpetuate stereotypes. However, the inclination towards "sameness" is what an understanding of true multiplicity engenders. If, differences are palpable and self-evident, then, the desire to uncover the Same requires not only a conscious participation but also a conscience participation. The Same is the condition that is unknown, it is always beyond us, it eludes us, and therefore it is what "comes

${ }^{38}$ Badiou, 24. 
to be", in essence, what should be. As such, it requires moral reasoning and judgment to acknowledge that, what should be, should be for all. This notion is neither unified nor prescriptive but embodies a process that is inherently social, communicative and is contingent on the specificity of time and place. In this sense, an ethical stance is both peculiar and particular to the fluctuating movements and currents of differences and is manifested in spite of them.

Architecture is undoubtedly a part of this ethical process as it gives manifested form to the spaces of our interactions while possessing the ability to conger the imagination, so that yet-to-be conceived possibilities may occur. As, our behaviour and choices are informed by others and the world around us, architecture facilitates space(s)-and-time(s) for occurrences that make explicit the layered and shared nature of our existence. By offering and making the spaces of our experiences, architecture's affect on the way we interact with one another, the way we move through the city, the way we look at ourselves, the way we solve problems - essentially the way we are - cannot be overlooked. Because our contemporary cultural condition is not structured on universal systems of knowledge, architecture's role cannot be caught up in the determination of "new" matrices on which new modes of experience are to be derived. Instead, architecture does not constitute but rather evokes/invokes our realities by pulling together and separating dominant and emerging paradigms by intertwining foreground into background, object into fabric, mimesis into invention, theory into intuition. Similarly, the fluctuation of this discussion on identity has at times touched on discreet notions that inform one another - notions that also contribute to an overall way of thinking of identity that is not prescriptive yet still 
evocative of our contemporary cultural condition. The way that notions of identity in portraiture affect and are affected by philosophy, politics, psychology and architecture, is no coincidence. The reciprocity of influences signifies that these strands are so intertwined that it is impossible to identify one from the other. The apparent unity that is formed by this knot is, in fact, made up of diverse and heterogeneous elements that are in constant evolution and transformation. Whether, it is through the turning of a phrase, the re-interpretation of a function, or the anamorphic viewing of a notion, the interruption of conventional and accepted views of identity is necessary if we are to make room for an understanding that is based on neither a fixed system nor a universal structure of thought. An interruption marks neither beginning nor end, rather, an interruption marks the space of pause - a temporary break in continuity or discourse so that existing conditions can be re-interpreted and re-presented. Just as portraits have the power to capture the infinitely layered traces of a subject's life and death, moments of interruption are evoked by works of art and architecture that acknowledge the subject, as always, a subject-in-process. 
Appendix A Process Work

A.1 Book Panels
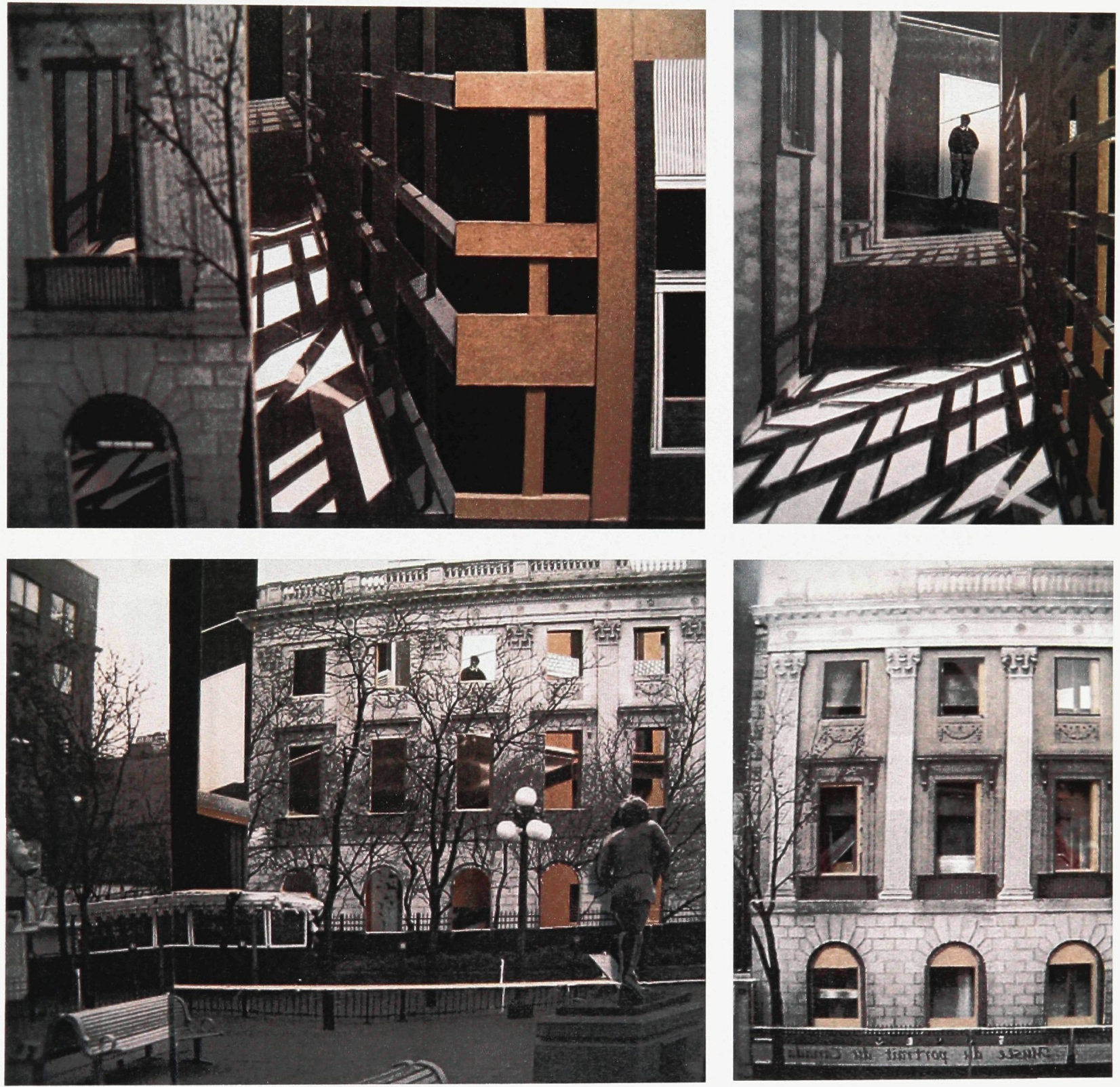
A.2 Conceptual Model
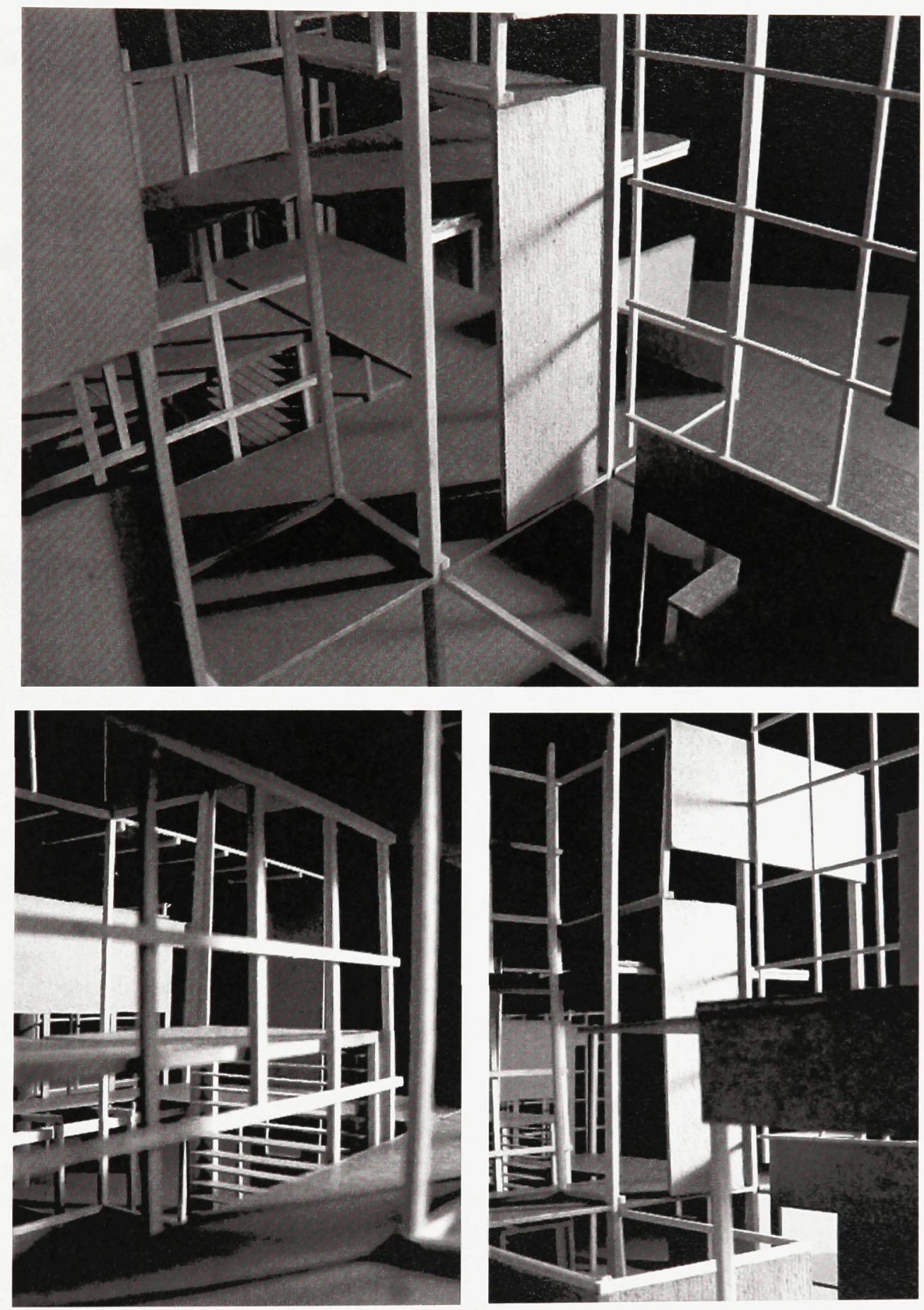


\section{Appendix A Process Work}

\section{A.3 Axonometric Drawings and Collages}
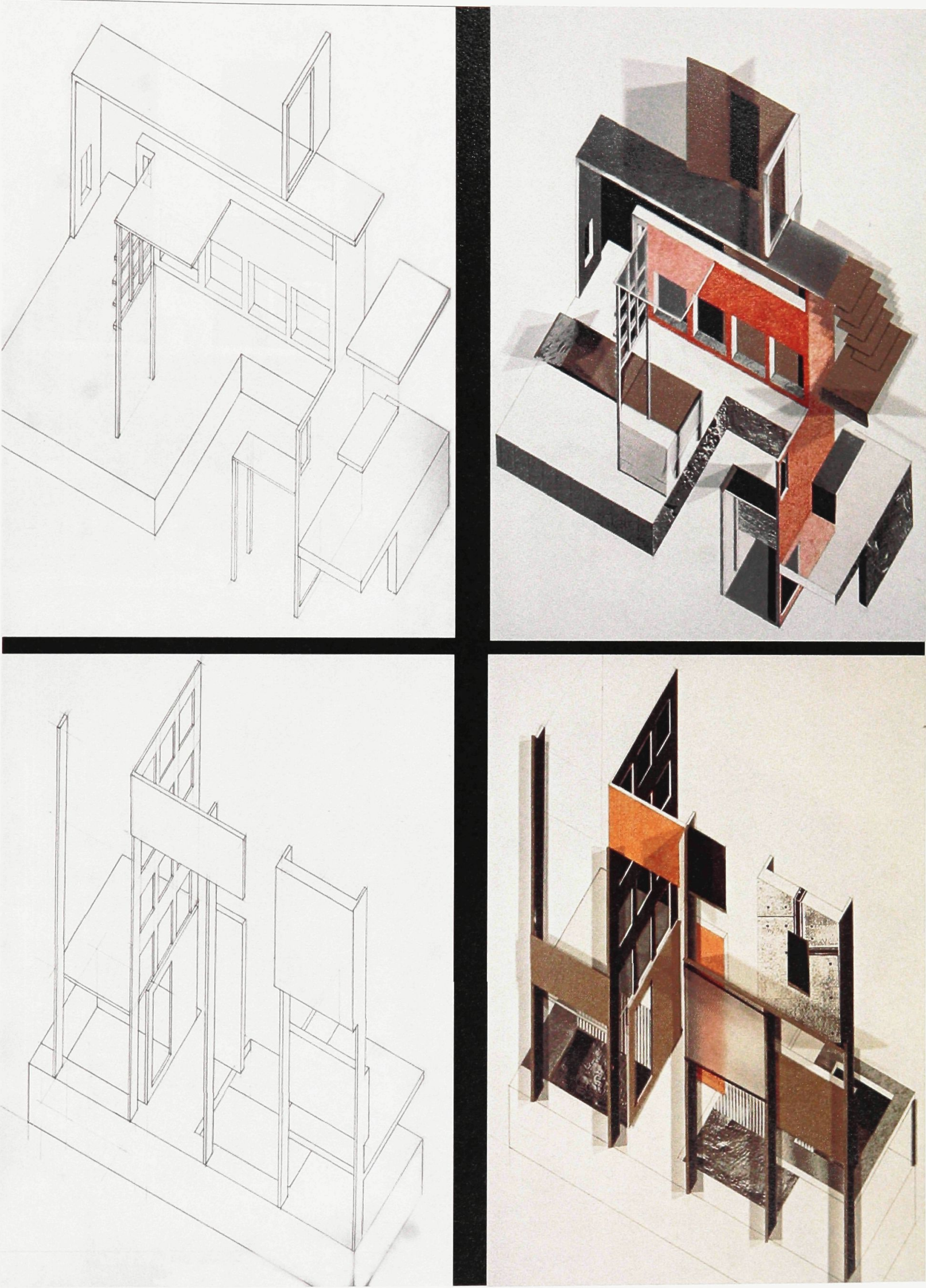
Appendix A Process Work

A.3 Axonometric Drawings and Collages

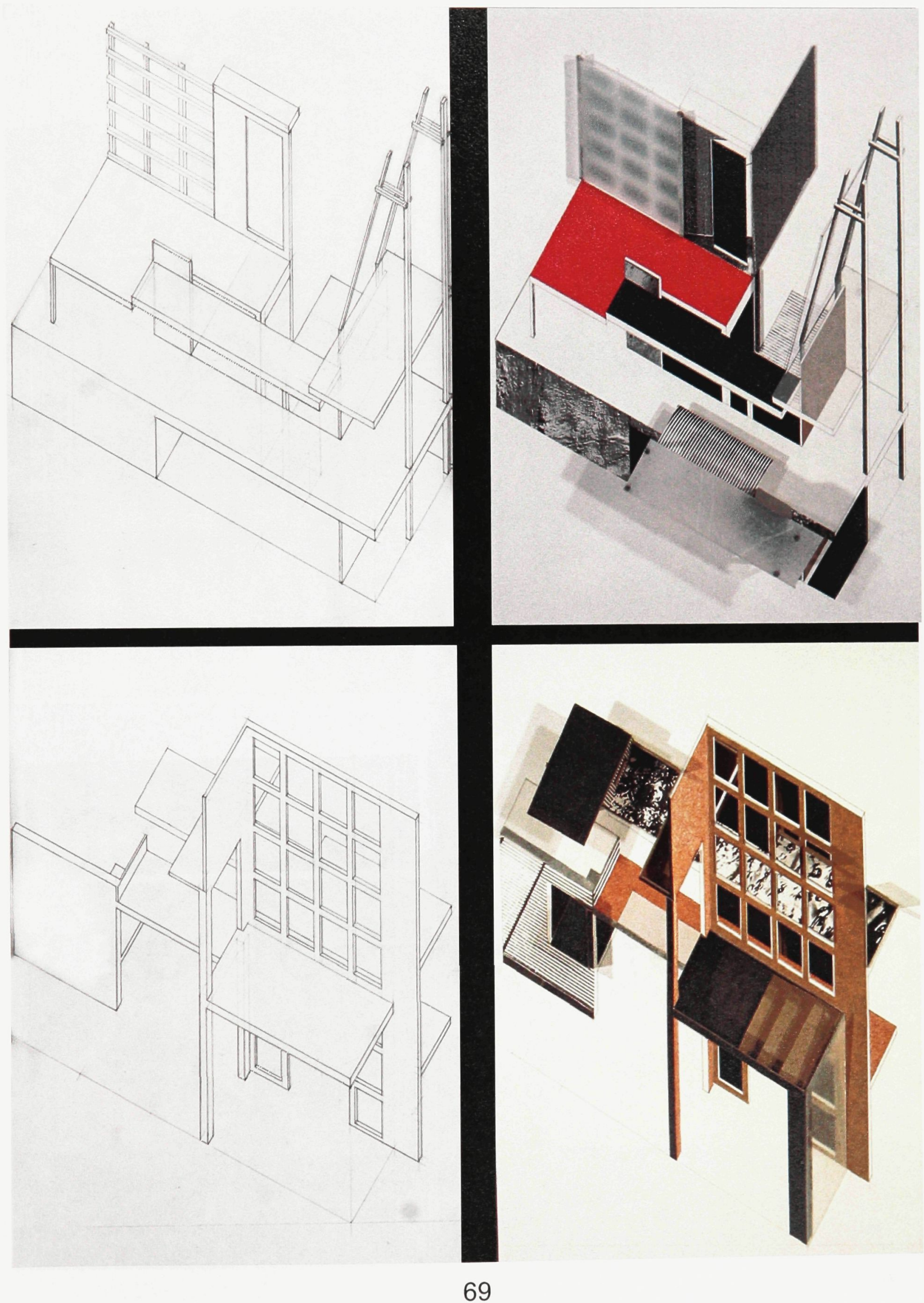


Appendix A

Process Work

A.3 Axonometric Drawings and Collages

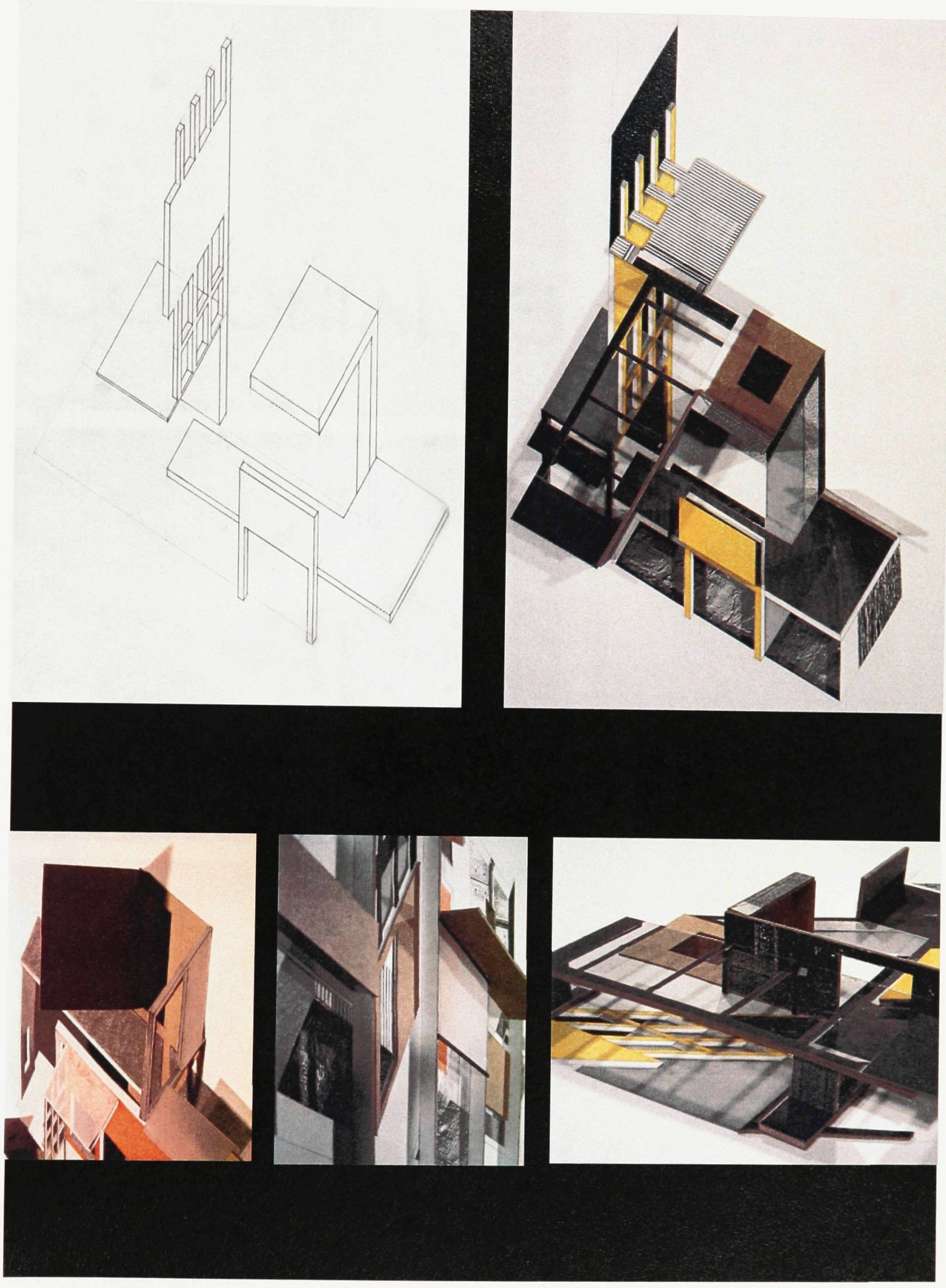




\section{Appendix B Urban Studies}

Site Massing Models
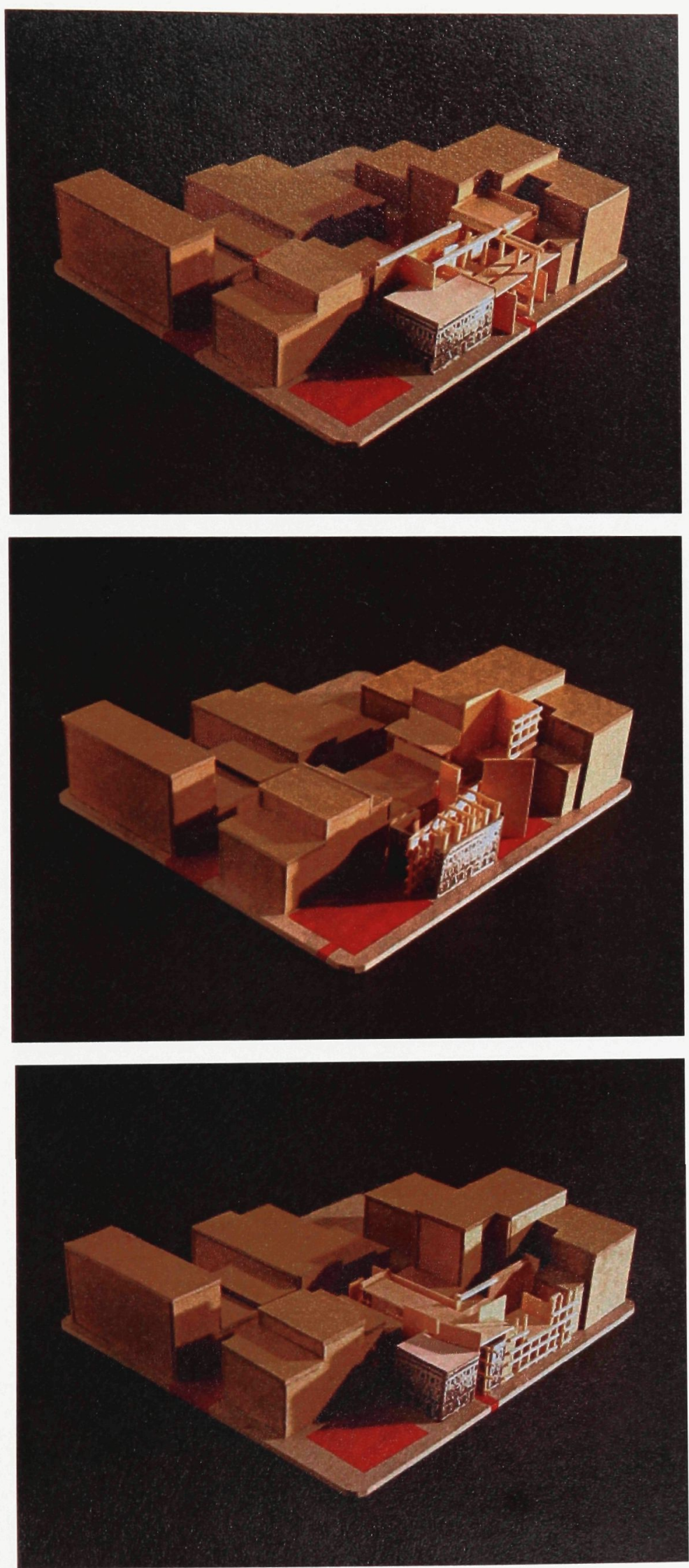


\section{Appendix B Urban Studies}

Site Massing Models
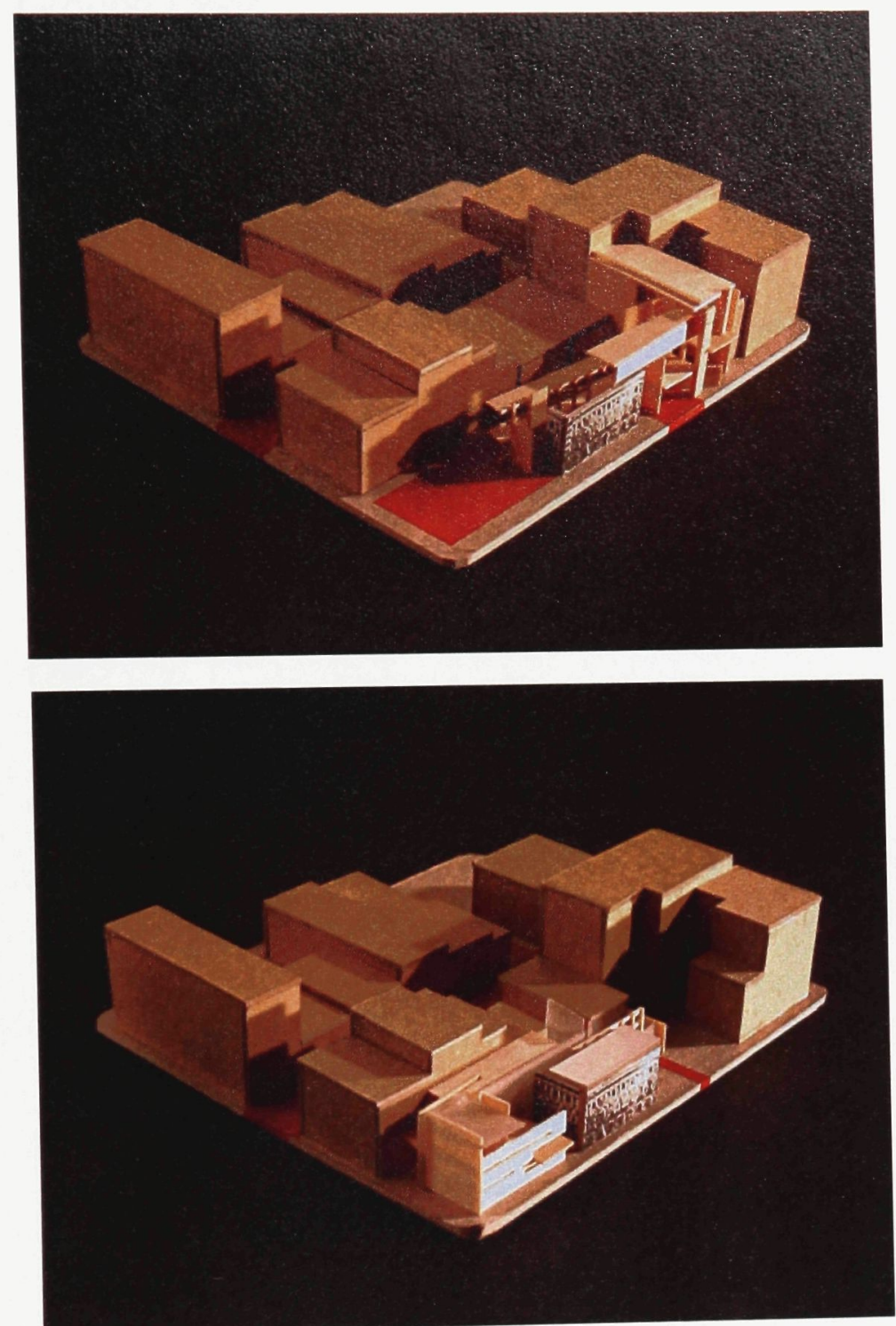


\section{Ground Floor}

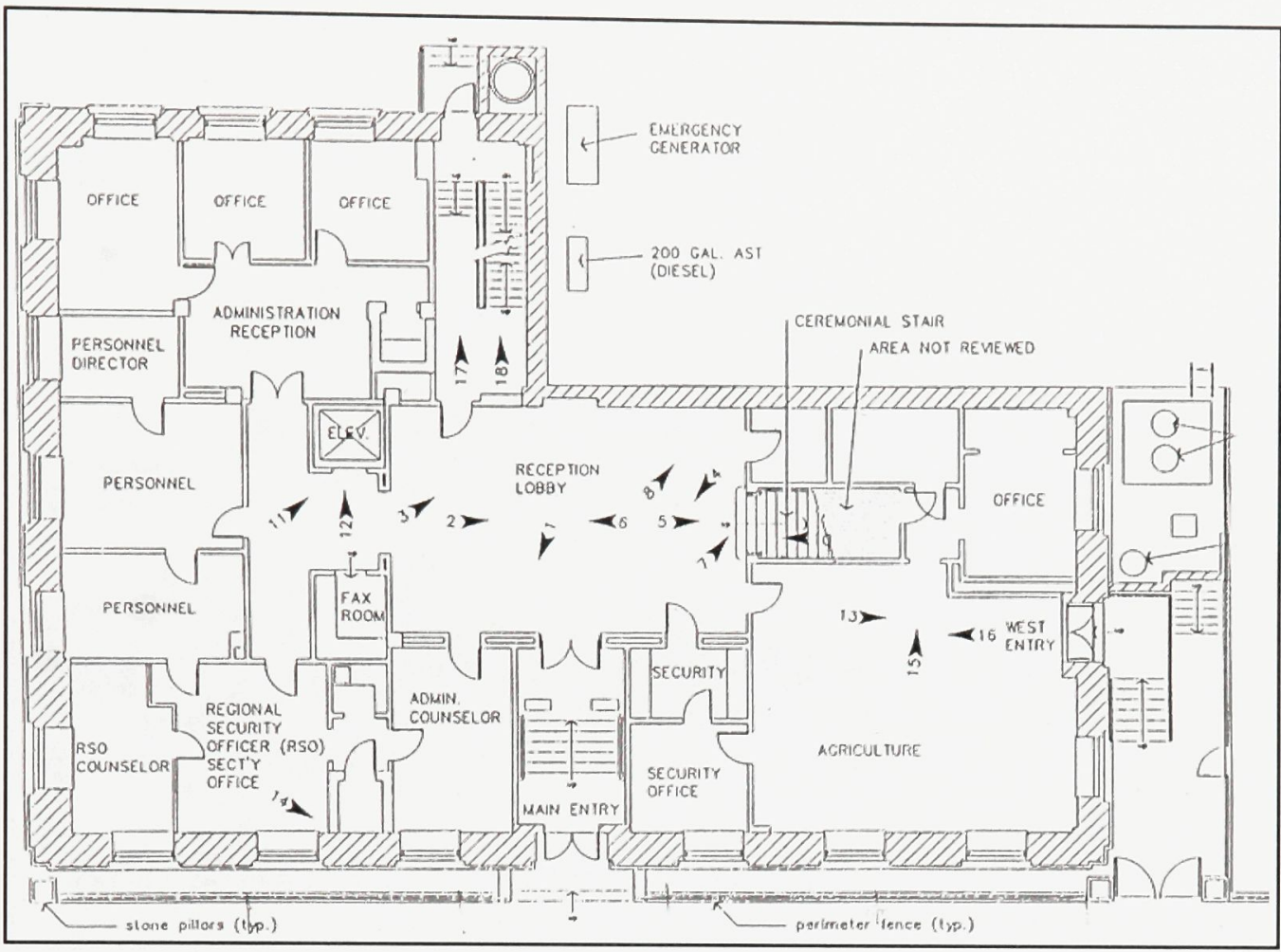

\section{Second Floor}

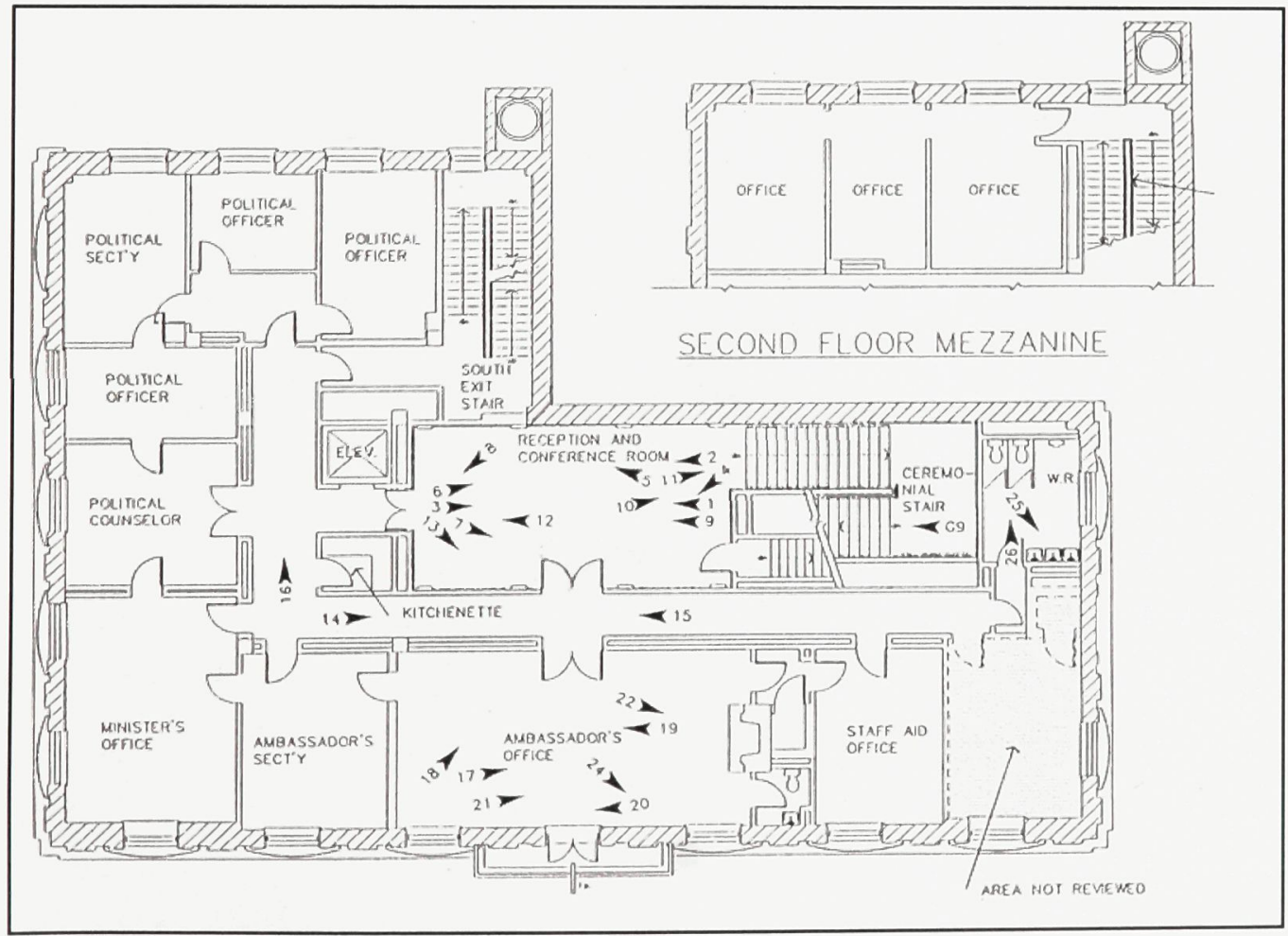


Appendix C Chancery Building Floor Plans

Third Floor

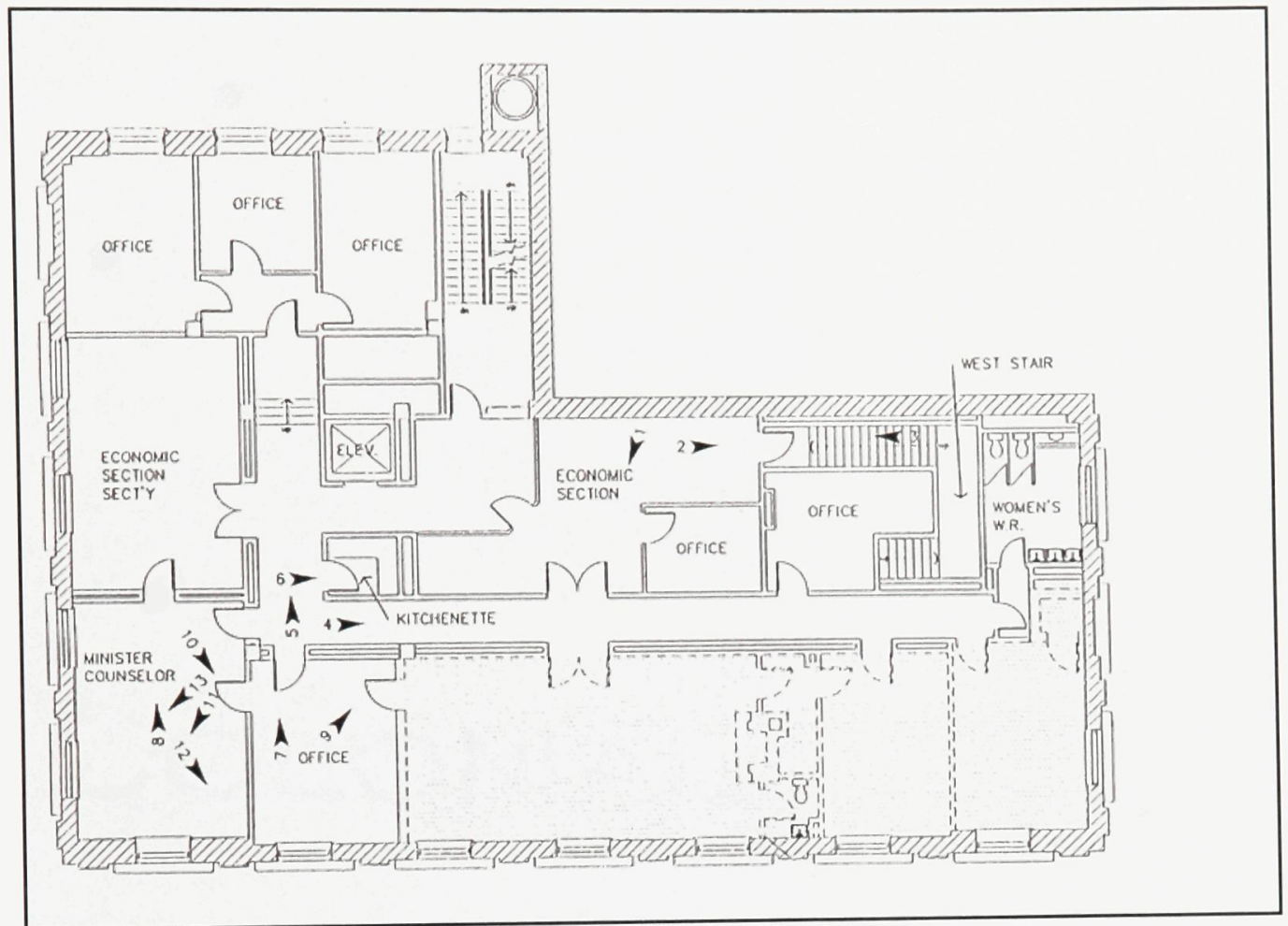



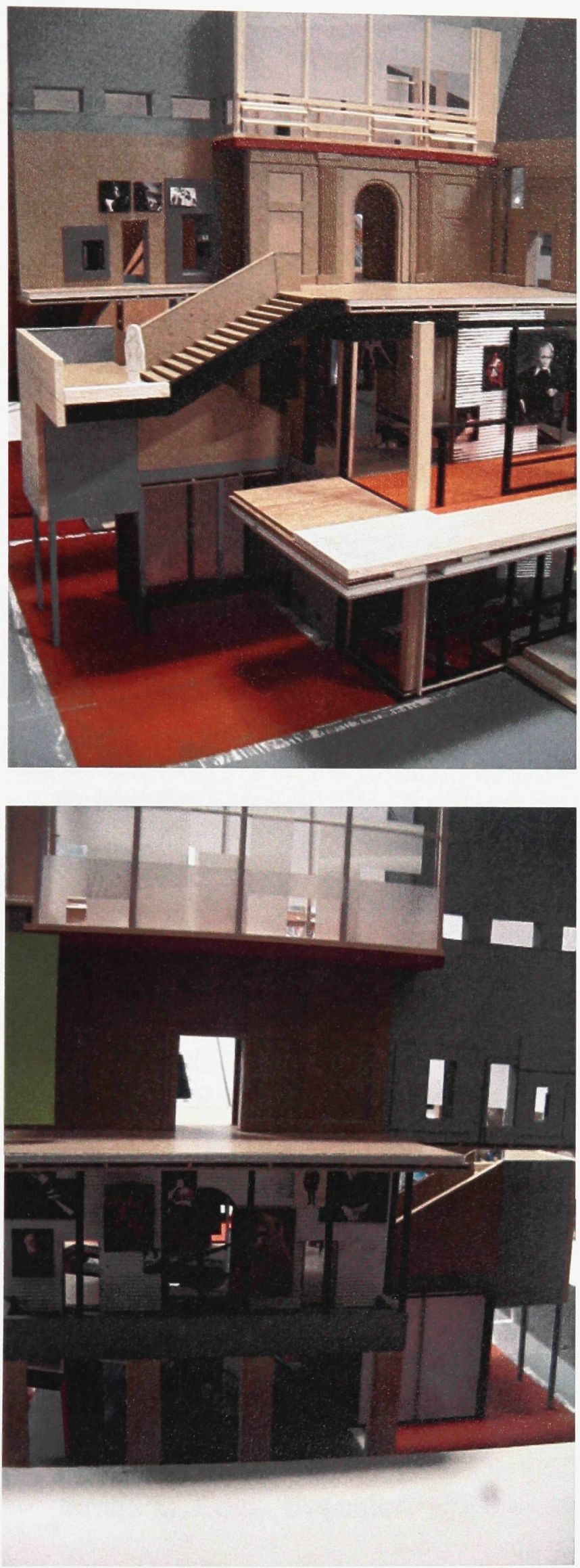


\section{Works Cited}

Alphen, Ernst Van. "The Portrait's Dispersal: Concepts of Representation and Subjectivity in Contemporary Portraiture." Portraiture: Facing the Subject. Ed. Woodall, Joanna. New York: Manchester UP, 1997. 239-256.

Badiou, Alain. Ethics : An Essay on the Understanding of Evil. Trans. Peter Hallward. New York : Verso, 2001.

Bois, Yve-Alain and Rosalind E. Krauss. Formless: a User's Guide. New York: Zone Books, 1997.

Buren, Daniel. "Function of the Museum". Eds. Bronson, AA and Peggy Gale. Museums by Artists. Toronto: Art Metropole, 1983. 57-60.

Foister, Susan et al. Holbein's Ambassadors. London: National Gallery Publications, 1997.

Foucault, Michel. The Order of Things: An Archaeology of the Human Sciences. New York: Random House, 1970.

Gadamer, Hans-George. The Relevance of the Beautiful and Other Essays. Robert Bernasconi. Ed. Nicholas Walker. Trans. Cambridge:Cambridge UP, 1977.

Levin, David Michael. "Visions of Narcissism: Intersubjectivity and the Reversals of Reflection." Merleau-Ponty Vivant. Ed. M.C. Dillon. Albany: State University of New York Press, 1991. 47-90.

Lomas, David. "Inscribing alterity: transactions of self and other in Miró selfportraits." Portraiture: Facing the Subject. Ed. Woodall, Joanna. New York: Manchester UP, 1997. 167-88.

Lyotard, Jean-François. The Postmodern Condition: A Report on Knowledge. Trans. Geoff Bennington. Minneapolis: Minnesota U.P., 1984.

Merleau-Ponty, Maurice. "Cézanne's Doubt." Trans. Hubert Dreyfus and Patricia Allen Dreyfus. Sense and Non-Sense. Evanston: Northwestern UP, 1964. 9-25.

---. "Eye and Mind." Trans. Carleton Dallery. The Primacy of Perception. Ed. James M. Edie. Evanston: Northwestern UP, 1964. 159-90. 


\section{Works Cited}

---. Sense and Non-Sense. Trans. Hubert Dreyfus and Patricia Allen Dreyfus. Evanston: Northwestern UP, 1964.

Meyer, Karl E. The Art Museum: Power, Money, Ethics. New York: William Morrow, 1979.

Nancy, Jean-Luc. "Of Being Singular Plural." Being Singular Plural. Eds. Werner Hamacher and David Wellbery.Stanford: Stanford U.P., 2000. 1-100.

National Archives of Canada with Public Works and Government Services Canada. Portrait Gallery of Canada Project Mandate. Ottawa: National Archives, 2003.

Pérez-Gómez, Alberto and Louise Pelletier. Architectural Representation and the Perspective Hinge. Cambridge, MA: MIT Press, 2000.

Price, Nicholas Stanley et al, eds. Historical and Philosophical Issues in the Conservation of Cultural Heritage. Los Angeles: The Getty Conservation Institute, 1996.

Preziosi, Donald, ed. The Art of Art History: A Critical Anthology. New York: Oxford UP, 1998.

---. "Brain of the Earth's Body." The Rhetoric of the Frame. Ed. Paul Duro. New York: Cambridge UP, 1996.

Sola-Morales, Ignasi de. Trans. Graham Thompson. Differences. Ed. Sarah Whiting. Cambridge: MIT Press, 1997.

---. "An Eclectic Panorama." Contemporary Spanish Architecture. New York: Rizzoli, 1986. 21-31.

Trinh T. Minh-Ha. Woman, Native, Other. Indianapolis: Indiana U.P., 1998.

Woodall, Joanna, ed. Portraiture: Facing the Subject. New York: Manchester UP, 1997. 


\section{Selected Bibliography}

Abbas, Ackbar. "Hyphenation: The Spatial Dimensions of Hong Kong Culture." Walter Benjamin and the Antinomies of Tradition. Ed. John McCole. Ithaca: Cornell UP, 1993. 210-24.

Alderman, Harold. "Heidegger's Critique of Science and Technology." Heidegger and Modern Philosophy. 35-50.

Alphen, Ernst Van. "The Portrait's Dispersal: Concepts of Representation and Subjectivity in Contemporary Portraiture." Portraiture: Facing the Subject. Ed. Woodall, Joanna. New York: Manchester UP, 1997. 239-256.

Badiou, Alain. Ethics : An Essay on the Understanding of Evil. Trans. Peter Hallward. New York: Verso, 2001.

Bois, Yve-Alain and Rosalind E. Krauss. Formless: a User's Guide. New York: Zone Books, 1997.

Buren, Daniel. "Function of the Museum". Eds. Bronson, AA and Peggy Gale. Museums by Artists. Toronto: Art Metropole, 1983. 57-60.

Buchloh, Benjamin H. D. "The Museum and the Monument: Daniel Buren's Les Couleurs/ Les Formes." Neo-Avantgarde and Culture Industry. Cambridge: MIT Press, 2000.

Certeau, Michel de. The Practice of Everyday Life. Trans. Steven F. Rendall. London: University of California Press, 1984.

Dillon, M.C., ed. Merleau-Ponty Vivant. Albany: State University of New York Press, 1991.

Duncan, Carol. Civilizing Rituals: Inside Public Art Museums. New York: Routledge, 1995.

Foister, Susan et al. Holbein's Ambassadors. London: National Gallery Publications, 1997.

Foster, Hal. "Against Pluralism". Recodings: Art, Spectacle, Cultural Politics. Seattle: Bay Press, 1985. 13-32. 


\section{Selected Bibliography}

Foucault, Michel. The Order of Things: An Archaeology of the Human Sciences. New York: Random House, 1970.

Gadamer, Hans-George. The Relevance of the Beautiful and Other Essays. Robert Bernasconi. Ed. Nicholas Walker. Trans. Cambridge:Cambridge U.P., 1977.

Gowing, Lawrence and Sam Hunter. Francis Bacon. New York: Thames and London, 1989.

Kellman, Tila L. Figuring Redemption: Resighting My Self in the Art of Michael Snow. Waterloo, Canada: Wilfrid Laurier Press, 2002.

Krauss, Rosalind E. The Originality of the Avant-Garde and Other Modernist Myths. Cambridge, MA: The MIT Press, 1985.

Kochhar-Lindgren, Gray. Narcissus Transformed. University Park, PA: Pennsylvania State U.P., 1993.

Kunze, Donald. "Architecture as a Site of Reception: Part 1: Cuisine, Frontality, and the Infra-Thin." Chora: Intervals in the Philosophy of Architecture 1. Eds. Alberto Pérez-Gómez and Stephen Parcell. Montréal: McGill-Queens Press, 1994.

Levin, David Michael. "Visions of Narcissism: Intersubjectivity and the Reversals of Reflection." Merleau-Ponty Vivant. Ed. M.C. Dillon. Albany: State University of New York Press, 1991. 47-90.

Lissitzky-Küppers, Sophie. El Lissitzky: Life, Letters, Texts. New York: Thames and Hudson Inc., 1980.

Lomas, David. "Inscribing alterity: transactions of self and other in Miró selfportraits." Portraiture: Facing the Subject. Ed. Woodall, Joanna. New York: Manchester UP, 1997. 167-88.

Lyotard, Jean-François. The Postmodern Condition: A Report on Knowledge. Trans. Geoff Bennington. Minneapolis: Minnesota U.P., 1984. 


\section{Selected Bibliography}

Manning, Erin. Ephemeral Territories: Representing Nation, Home and Identity in Canada. Minneapolis: U of Minnesota Press, 2003.

Merleau-Ponty, Maurice. "Cézanne's Doubt." Trans. Hubert Dreyfus and Patricia Allen Dreyfus. Sense and Non-Sense. Evanston: Northwestern UP, 1964. 9-25.

---. "Eye and Mind." Trans. Carleton Dallery. The Primacy of Perception. Ed. James M. Edie. Evanston: Northwestern UP, 1964. 159-90.

---. Sense and Non-Sense. Trans. Hubert Dreyfus and Patricia Allen Dreyfus. Evanston: Northwestern UP, 1964.

Meyer, Karl E. The Art Museum: Power, Money, Ethics. New York: William Morrow, 1979.

Mitchell, Timothy. "Orientalism and the Exhibitionary Order." The Art of Art History: A Critical Anthology. Ed. Donald Preziosi. New York: Oxford UP, 1998. 455-472.

Nancy, Jean-Luc. "Of Being Singular Plural." Being Singular Plural. Eds. Werner Hamacher and David Wellbery.Stanford: Stanford U.P., 2000. 1-100.

National Archives of Canada with Public Works and Government Services Canada. Portrait Gallery of Canada Project Mandate. Ottawa: National Archives, 2003.

Pérez-Gómez, Alberto and Louise Pelletier. Architectural Representation and the Perspective Hinge. Cambridge, MA: MIT Press, 2000.

Perez-Gomez, Alberto. "The Space of Architecture: Meaning as Presence and Representation." Questions of Perception: Phenomenology of Architecture. a+u. July 1994. 7-26.

Platzman, Steven. Cézanne: The Self-Portraits. Berkeley: Universtiy of California Press, 2001.

Prater, Andreas. Venus at Her Mirror. New York: Prestel Verlag, 2002. 


\section{Selected Bibliography}

Price, Nicholas Stanley et al, eds. Historical and Philosophical Issues in the Conservation of Cultural Heritage. Los Angeles: The Getty Conservation Institute, 1996.

Preziosi, Donald, ed. The Art of Art History: A Critical Anthology. New York: Oxford UP, 1998.

---. "Brain of the Earth's Body." The Rhetoric of the Frame. Ed. Paul Duro. New York: Cambridge UP, 1996.

Ryan, Judith and Alfred Thomas, eds. Cultures of Forgery: Making Nations, Making Selves. New York: Routledge, 2003.

Schwarz, Arturo. The Complete Works of Marcel Duchamp. New York: Delano Greenridge, 2000.

Sola-Morales, Ignasi de. Trans. Graham Thompson. Differences. Ed. Sarah Whiting. Cambridge: MIT Press, 1997.

---. "An Eclectic Panorama." Contemporary Spanish Architecture. New York: Rizzoli, 1986. 21-31.

Trinh T. Minh-ha. Woman, Native, Other. Indianapolis: Indiana U.P., 1998.

Vattimo, Gianni. "The Trace of the Trace." Religion. Eds. Jacques Derrida and Gianni Vattimo. Stanford: Stanford UP, 1996. 79-94.

---. The End of Modernity: Nihilism and Hermeneutics in Post-modern Culture. Trans. John R. Snyder. Cambridge: Polity Press, 1988.

---. The Transparent Society. Trans. David Webb. Baltimore: Johns Hopkins University Press, 1992.

West, Shearer. Portraiture. New York: Oxford University Press, 2004.

Woodall, Joanna, ed. Portraiture: Facing the Subject. New York: Manchester UP, 1997. 